\title{
A Study of Some of the World's Most Innovative Universities
}

This chapter examines in detail a study of the top twenty most innovative universities in the world according to Table 3.1. A study of one university of each country, whose name was not included among the top twenty universities, is also added. The first-ranked university in each country which none of its universities were ranked among the top twenty is selected, and its details described the same way as that of the top twenty universities. The ranking of the added universities is: $31,35,44,55,57,62$, and 63 . This study is shown below.
Stanford University is located in the heart of California's Silicon Valley. It was founded in 1891 by California senator and railway magnate Leland Stanford as a memorial of his deceased son, with the promise that "the children of California shall be our children", said the senator. Stanford University, a private research university takes first place on Reuters' list of the World's Most Innovative Universities for the third consecutive year, holding fast to its ranking by consistently producing new patents and papers that influence researchers around the globe [30].

\subsection{Stanford University_USA}

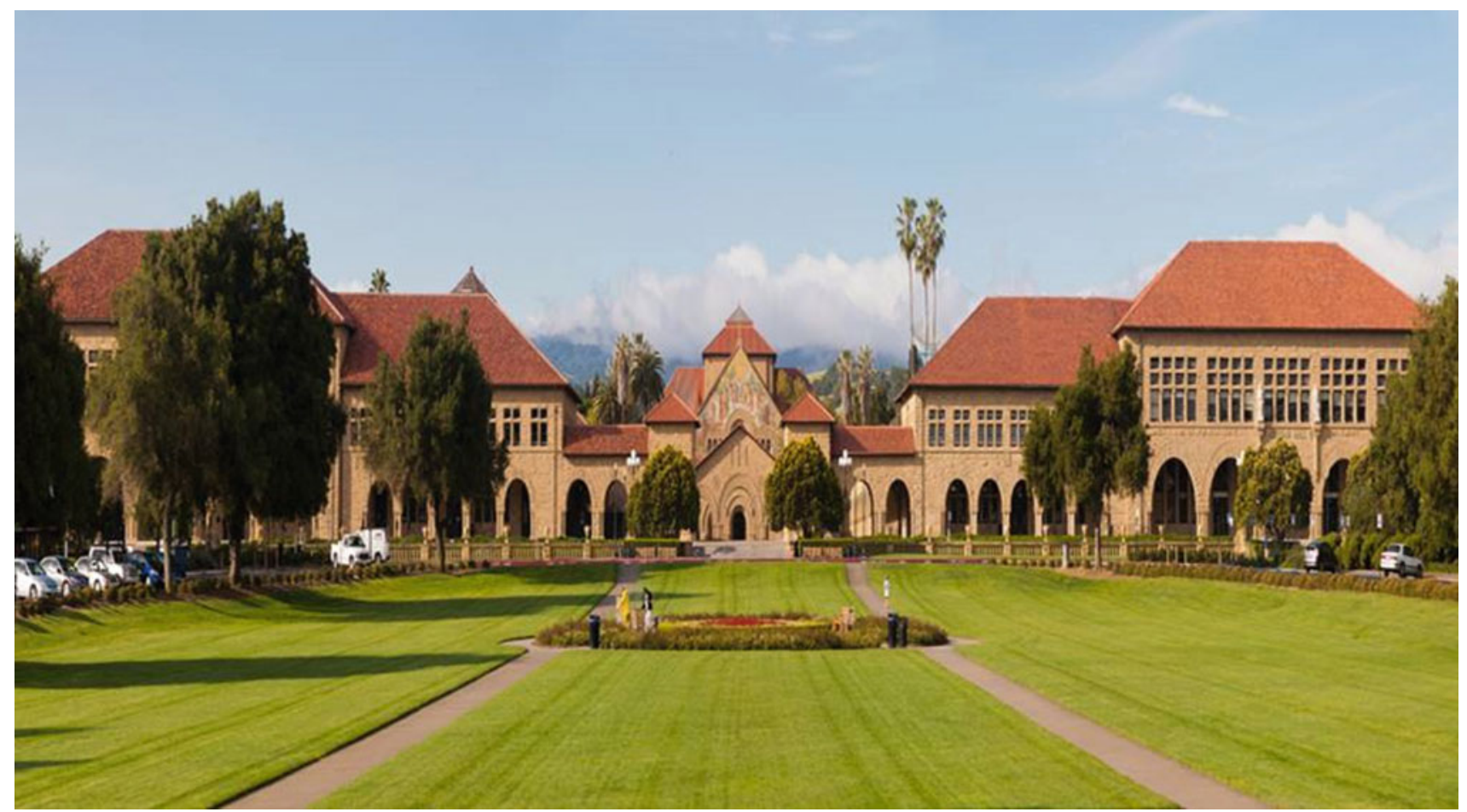


In July 2017, the university opened the Stanford Center for Definitive and Curative Medicine, a new research center focused on the development of stem cell and gene therapies to treat millions of people with genetic diseases worldwide. Also, the university recently opened the Stanford Laboratory for Cell and Gene Medicine, a $\$ 35$ million, 23,000- $\mathrm{ft}^{2}$ manufacturing facility for making stem-cell-based therapies for use in human patients.

In the 2016/2017 fiscal year, Stanford announced a total research budget of $\$ 1.6$ billion. There are more than 6000 externally sponsored projects throughout the university. The federal government sponsors approximately $81 \%$ of these projects, including National Accelerator Laboratory (SLAC), while the rest of the research budget comes from other funding sources.

SLAC National Accelerator Laboratory is actually a U.S. Department of Energy laboratory, but is operated by Stanford University. It has a variety of programs, including programs in the atomic, physics, biology, and medicine fields.

Recent researches in the university tackle the development of a drug delivery device that monitors drug levels in the body real time and delivers proper dosages to the patient. Stanford researchers have also created a vine-like, flexible "growing" robot that operates in the narrowest places, and a new camera that allows robots to capture $4 \mathrm{D}$ images in a $140^{\circ}$ field of vision. This 4D image allows viewers to refocus the image after it is captured, allowing processing the image after being taken.

Stanford University has played a key role in the development of the network-connected world. In the early 1970s, Stanford professor Vint Cerf co-designed the TCP/IP protocol that became the basic standard means of communication in the Internet. In 1991, physicists at the Stanford Linear Accelerator Center deployed the first World Wide Web server outside of Europe.

The Stanford faculty and alumni have founded major tech companies including Google, Hewlett-Packard (HP), and Cisco Systems. A 2012 study by the university estimated that companies formed by Stanford entrepreneurs generate so much revenue that if they were of an independent nation, it would rank among the ten largest economies in the world. Table 6.1 displays some key statistical figures of Stanford University that illustrate the quality of research and innovation [30-32].

Figure 6.1 shows the patents submitted by Stanford University in various fields, while Fig. 6.2 shows the percentage of accepted patents. Figure 6.3 shows the university's ranking per each of the ten innovation indicators [33].

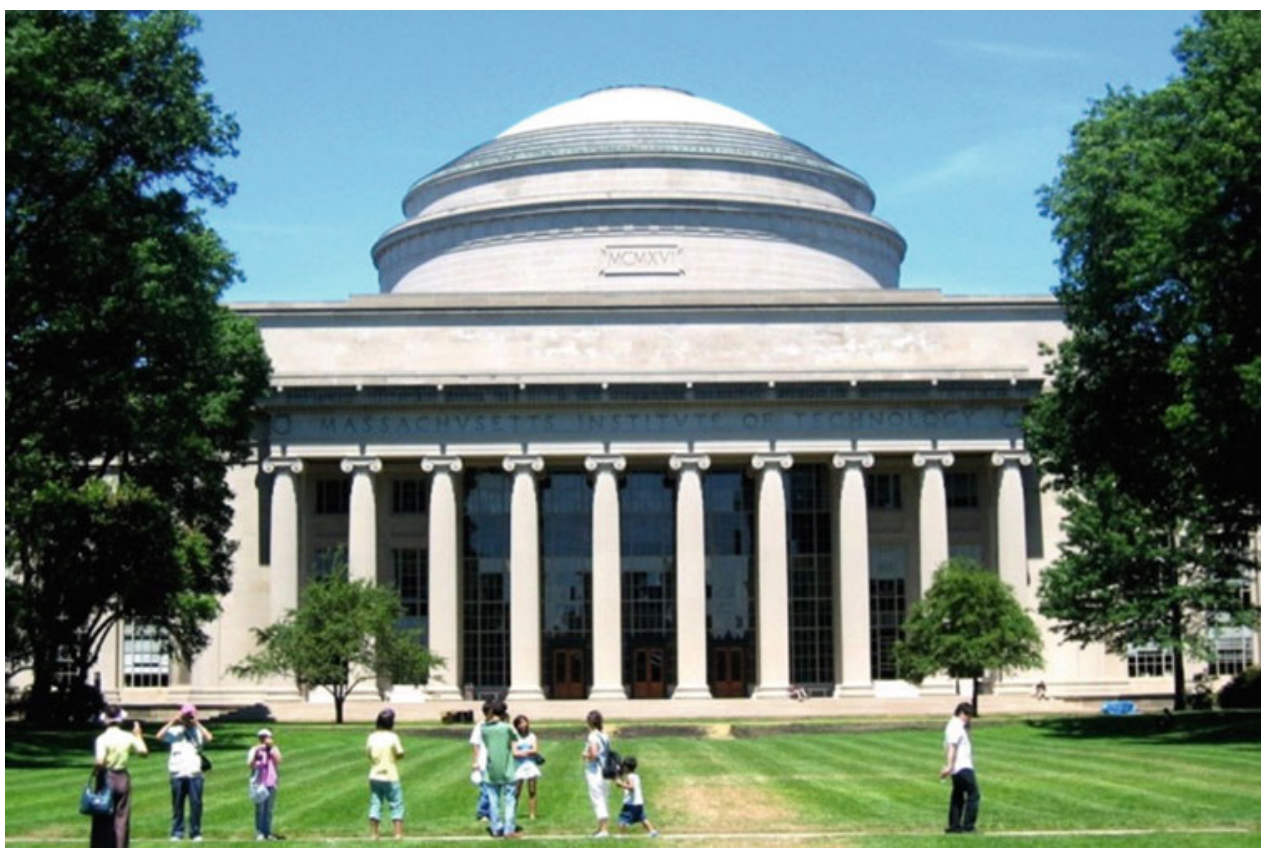


Table 6.1 Some key statistical figures of Stanford University

Fig. 6.1 Patents submitted by Stanford University

\begin{tabular}{l|l}
\hline Number of Nobel laureates among professors and graduates & 81 \\
\hline Number of professors or graduates who are Turing Prize winners & 27 \\
\hline Number of professors or graduates who are Fields Medal winners & 7 \\
\hline Endowments in 2017 & $\$ 22.8$ billion \\
\hline Campus area & $33.1 \mathrm{~km}^{2}$ \\
\hline Number of applicants for admission to the university (2016) & 43,997 \\
\hline Number of students admitted to the university (2016) & 2118 (5\% of applicants) \\
\hline Number of undergraduate students (2016) & 7032 (43\% of total students) \\
\hline Number of postgraduate students (2016) & 9304 (57\% of total students) \\
\hline Teaching staff & 2153 \\
\hline Members of the academic council & 4082 \\
\hline Student-to-academic staff ratio & $1: 4$ \\
\hline Number of administrative staff & 12,148
\end{tabular}

\section{Stanford University, USA}

\section{TOTAL PATENTS FILED}

(691)

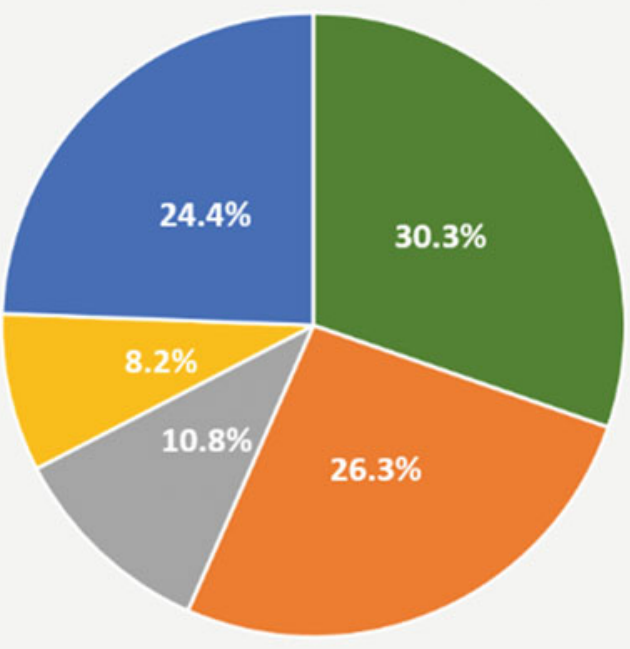

- Pharmaceuticals \& Biotech

Agriculture, Forestry \& Food

- Medical Devices \& Healthcare

Chemicals

ather 
Fig. 6.2 Percentage of accepted patents of Stanford University

\section{Stanford University, USA}

\section{PATENTS GRANTED}

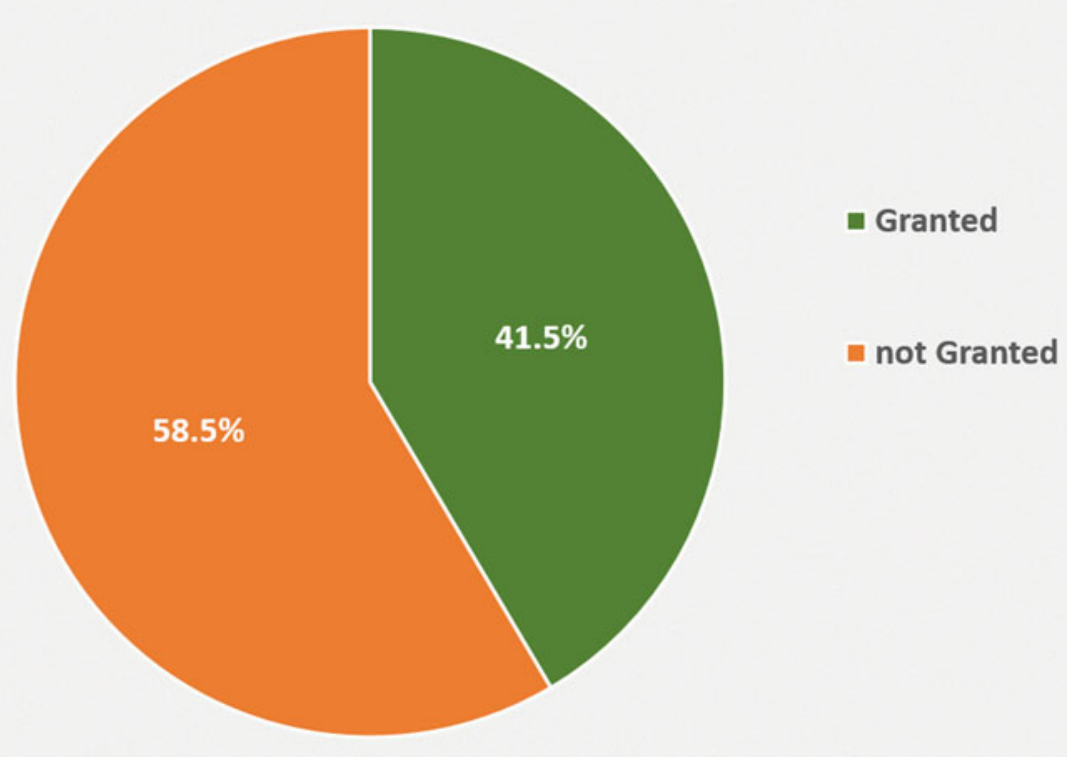

Fig. 6.3 Stanford University's ranking per each of the ten innovation indicators [33]

\begin{tabular}{|l|l|}
\hline $\begin{array}{l}\text { Stanford University } \\
\text { Indicator }\end{array}$ & Rank \\
\hline Patent Volume & 14 \\
\hline Patent Success & 117 \\
\hline Global Patents & 47 \\
\hline Patent to patent Citations & 82 \\
\hline Patent to patent Citation Impact & 73 \\
\hline Percent Patents Cited & 2 \\
\hline Patent to Article Citation Impact & 10 \\
\hline $\begin{array}{l}\text { Industry Article to Article Citation } \\
\text { Impact }\end{array}$ & 14 \\
\hline $\begin{array}{l}\text { Percent Industry Collaborative } \\
\text { Articles }\end{array}$ & 23 \\
\hline $\begin{array}{l}\text { Total Web of Science Core } \\
\text { Collection Papers }\end{array}$
\end{tabular}




\subsection{Massachusetts Institute of Technology (MIT)—USA}

Massachusetts Institute of Technology (MIT), a private technological research university, is the second most innovative university in the world for the third consecutive year [34]. It was founded in 1861 with the mission of "enhancing the advancement, development and practical application of science." MIT research has fueled some of the most important innovations of the past century, including the development of digital computers and the completion of the
Human Genome Project. Throughout its 155-year history, 89 of its professors and alumni were Nobel Prize laureates. Corporations founded by MIT's staff and alumni include: Bose, Dropbox, and iRobot. A 2014 study conducted by the university revealed that about 30,000 of these companies employed 4.6 million people and produced annual revenue of approximately $\$ 1.9$ trillion.

In the fiscal year 2016, MIT research expenditures exceeded $\$ 728$ million, $19 \%$ of which came from industry sponsors, including Ford, Intel, Shell, and Samsung. Approximately 700 companies work with MIT faculty and
Table 6.2 Some key statistical figures of Massachusetts Institute of Technology
Fig. 6.4 Patents submitted by Massachusetts Institute of Technology

\begin{tabular}{l|l}
\hline Number of Nobel laureates among professors and alumni & 89 \\
\hline Number of professors or graduates who are Turing Prize winners & 15 \\
\hline Number of Fields Medalists among professors or alumni & 6 \\
\hline Number of National Medal of Science winners & 58 \\
\hline Number of National Medal of Technology and Innovation winners & 29 \\
\hline Number of MIT alumni astronauts & 34 \\
\hline Endowments in 2017 & $\$ 14.8$ billion \\
\hline Campus area & 68 ha \\
\hline Number of applicants for admission to the university (2016) & 20,247 \\
\hline Number of students admitted to the university (2016) & $1452(7.2 \%$ of applicants) \\
\hline Number of undergraduate students (2017) & $4547(39.7 \%$ of total students) \\
\hline Number of Postgraduate Students (2017) & $6919(60.3 \%$ of total students) \\
\hline Number of international postgraduate students (2017) & $2868(41.5 \%$ of total students) \\
\hline Teaching staff & 1047 \\
\hline Members of the academic council & 5893 \\
\hline Student-to-academic staff ratio & $1: 4$ \\
\hline Total number of university staff & 12,607 \\
\hline
\end{tabular}

\section{The Massachusetts Institute of Technology (MIT), USA}

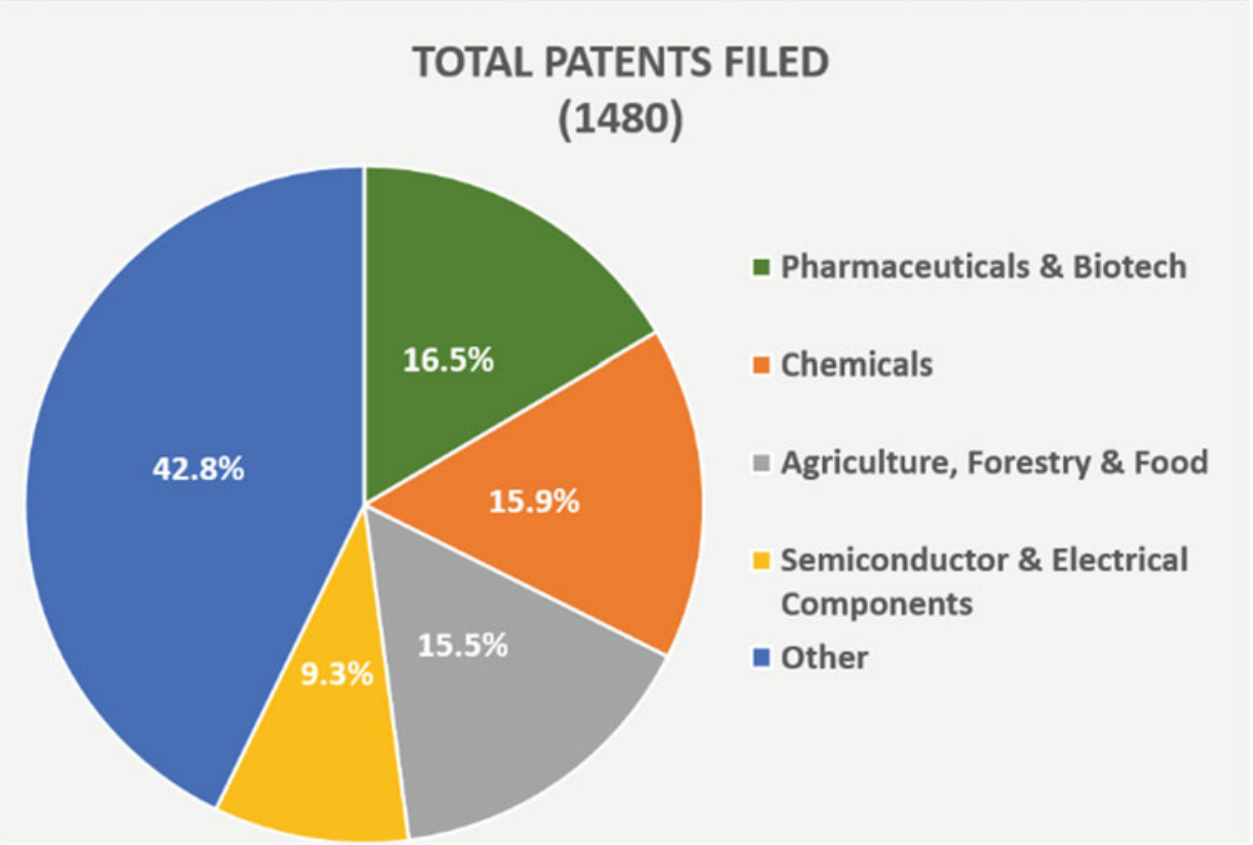




\section{The Massachusetts Institute of Technology (MIT), USA}

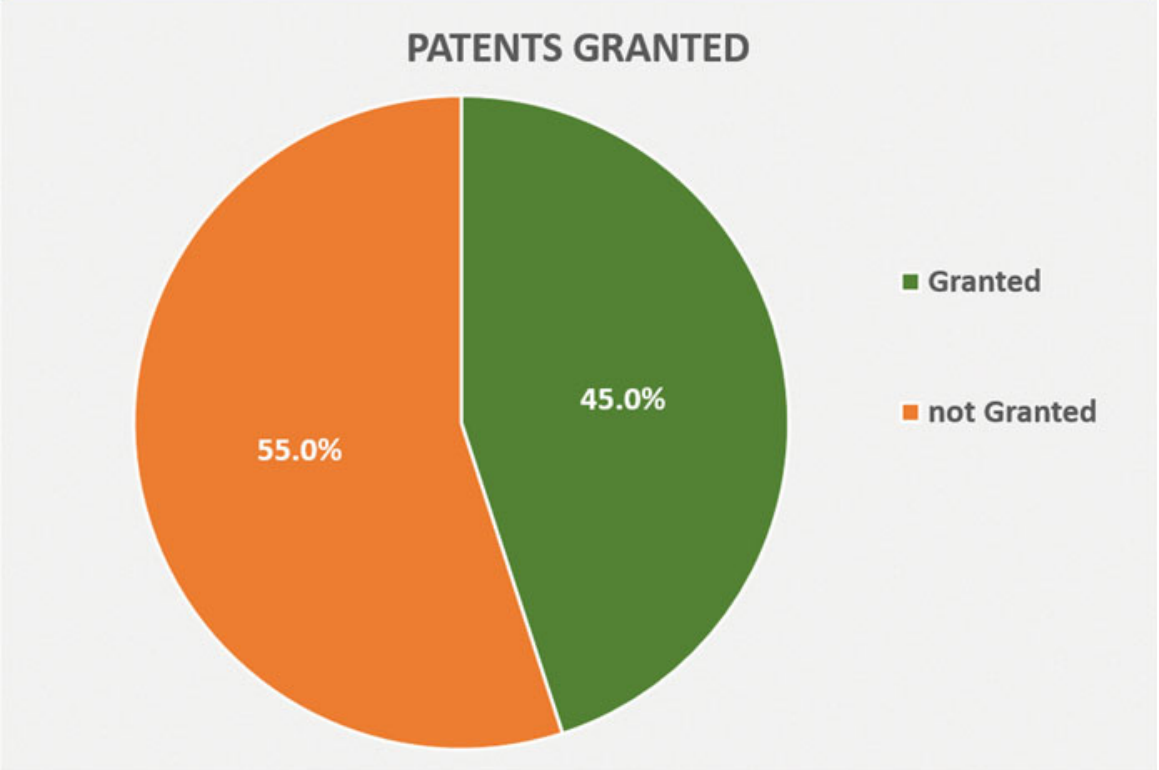

Fig. 6.5 Percentage of accepted patents of Massachusetts Institute of Technology

students through various programs such as the MIT Energy Initiative and the Industrial Liaison Program.

In 2011, the university launched an open-source platform that allows people across the globe to enroll in free online classes taught by MIT professors covering a wide variety of topics [35-36].

In 2017, MIT revamped its Sports Technology Group, which became MIT 3-Sigma Sports, a program connecting students and faculty with alumni and industry partners who work together to improve athletic performance using engineering to enhance endurance, speed, accuracy and agility in sports. Sports-focused innovations coming from this project are now in use by divers groups, International Cricket Council and CBS TV network, which uses the Emmy-award winning Swing Vision system in golf footage.

Table 6.2 displays some key statistical figures that illustrate the quality of research and innovation [34, 37-39]

Figure 6.4 shows the patents submitted by Massachusetts Institute of Technology in various fields, while Fig. 6.5 shows the percentage of accepted patents.

\subsection{Harvard University-USA}

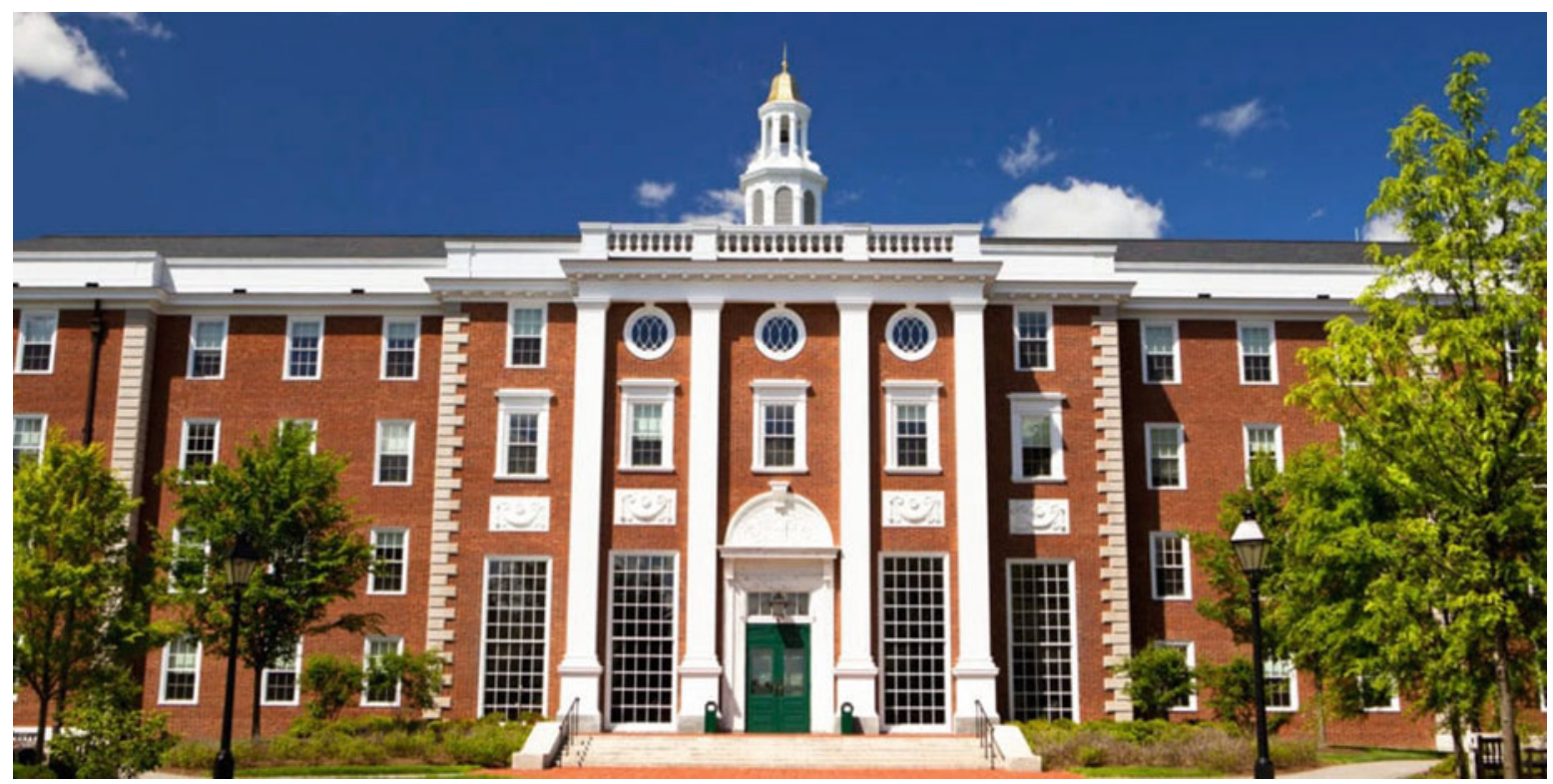


Harvard University, a private university, is ranked third among the World's Most Innovative Universities for the third consecutive year [40]. Established in 1636, Harvard University is the oldest institution of higher education in the USA. It has presented 157 Nobel laureates, 32 heads of state, and 48 Pulitzer Prize winners. With more than $\$ 37$ billion, Harvard has the largest endowment in the world. More than one million students from 195 countries around the world have enrolled in the university's free online programs [41].

In the 2014/2015 fiscal year, Harvard had approximately $\$ 800$ million budget for sponsored research. Nearly $\$ 50$ million of which came from corporate sponsors. That budget currently exceeds $\$ 900$ million.
In 2016, Harvard researchers developing quantum computing technology built a radio receiver the size of two atoms, and in 2017, researchers at the university's Wyss Institute for Biologically Inspired Engineering created a biological hard drive using gene-editing technology to alter cells in order to allow them to reserve and recall bits of DNA-encoded information. This approach could lead to new data storage formats, or could be engineered into memory devices able to record a cell's molecular activity during development or under exposure to pathogens. Researchers at the Wyss Institute also developed a tethered exosuit that can increase a runner's performance by reducing the metabolic cost of running. There are medical applications of this technology for the treatment of stroke victims and other patients who have reduced mobility.
Table 6.3 Some key statistical figures for Harvard University
Fig. 6.6 Patents submitted by Harvard University

\begin{tabular}{l|l}
\hline Number of Nobel laureates among professors and alumni & 157 \\
\hline Number of Turing Award winners among professors and alumni & 14 \\
\hline Number of Fields Medalists among professors and alumni & 18 \\
\hline Number of Pulitzer Prize winners among professors and alumni & 48 \\
\hline Endowments in 2017 & $\$ 37$ billion \\
\hline Campus area & 85 ha \\
\hline Number of applicants for admission to the university (2021) & 39,506 \\
\hline Number of students admitted to the university (2021) & 2037 (5.2\% of applicants) \\
\hline Number of undergraduate students & 6700 (31.6\% of total students) \\
\hline Number of postgraduate students & $14,500(68.4 \%$ of total students) \\
\hline Teaching staff & 2400 \\
\hline Members of the academic council & 4388 \\
\hline Total number of university staff & 16,000 \\
\hline
\end{tabular}

\section{Harvard University , USA}

(977)

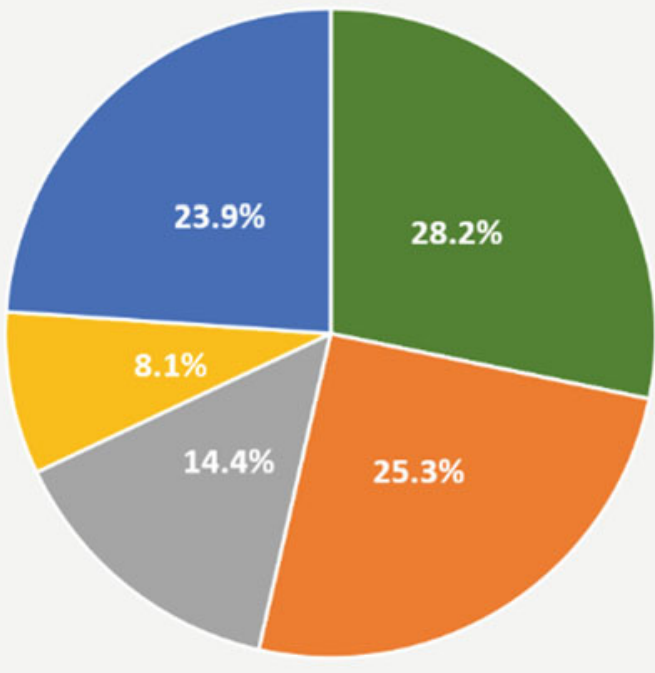

- Pharmaceuticals \& Biotech

- Agriculture, Forestry \& Food

- Chemicals

Medical Devices \& Healthcare

- Other 
Fig. 6.7 Percentage of accepted patents for Harvard University

\section{Harvard University, USA}

\section{PATENTS GRANTED}

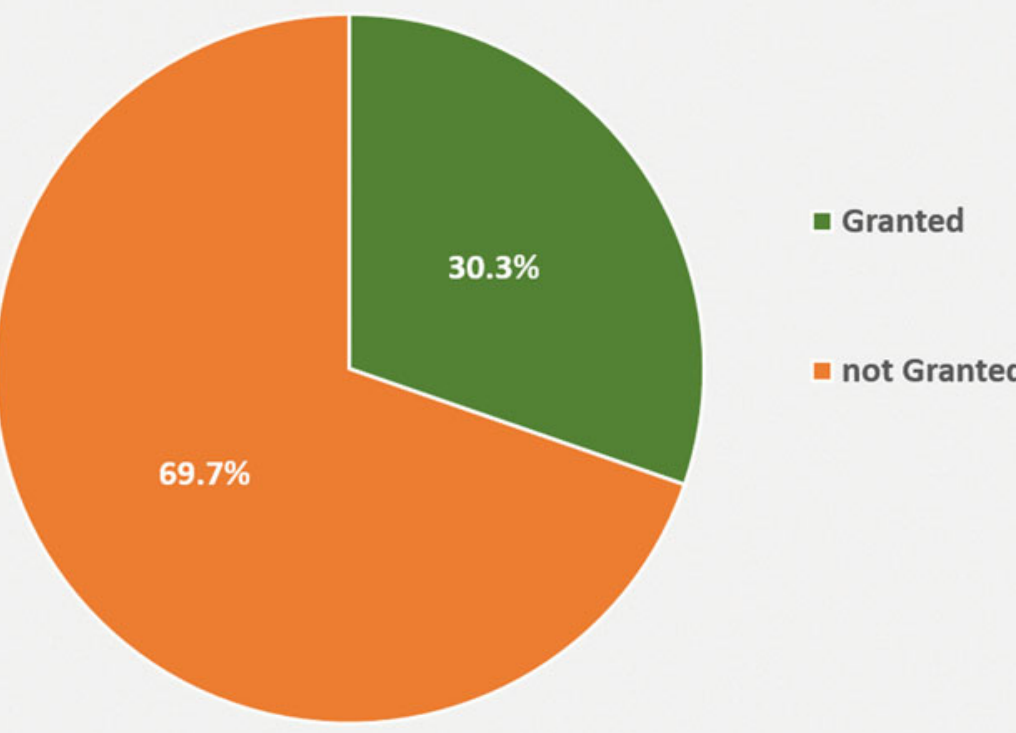

Table 6.3 displays some key statistical figures that illustrate the quality of research and innovation [40, 42-44].

Figure 6.6 displays the patents submitted by Harvard University in various fields, while Fig. 6.7 shows the percentage of accepted patents.

\subsection{University of Pennsylvania-USA}

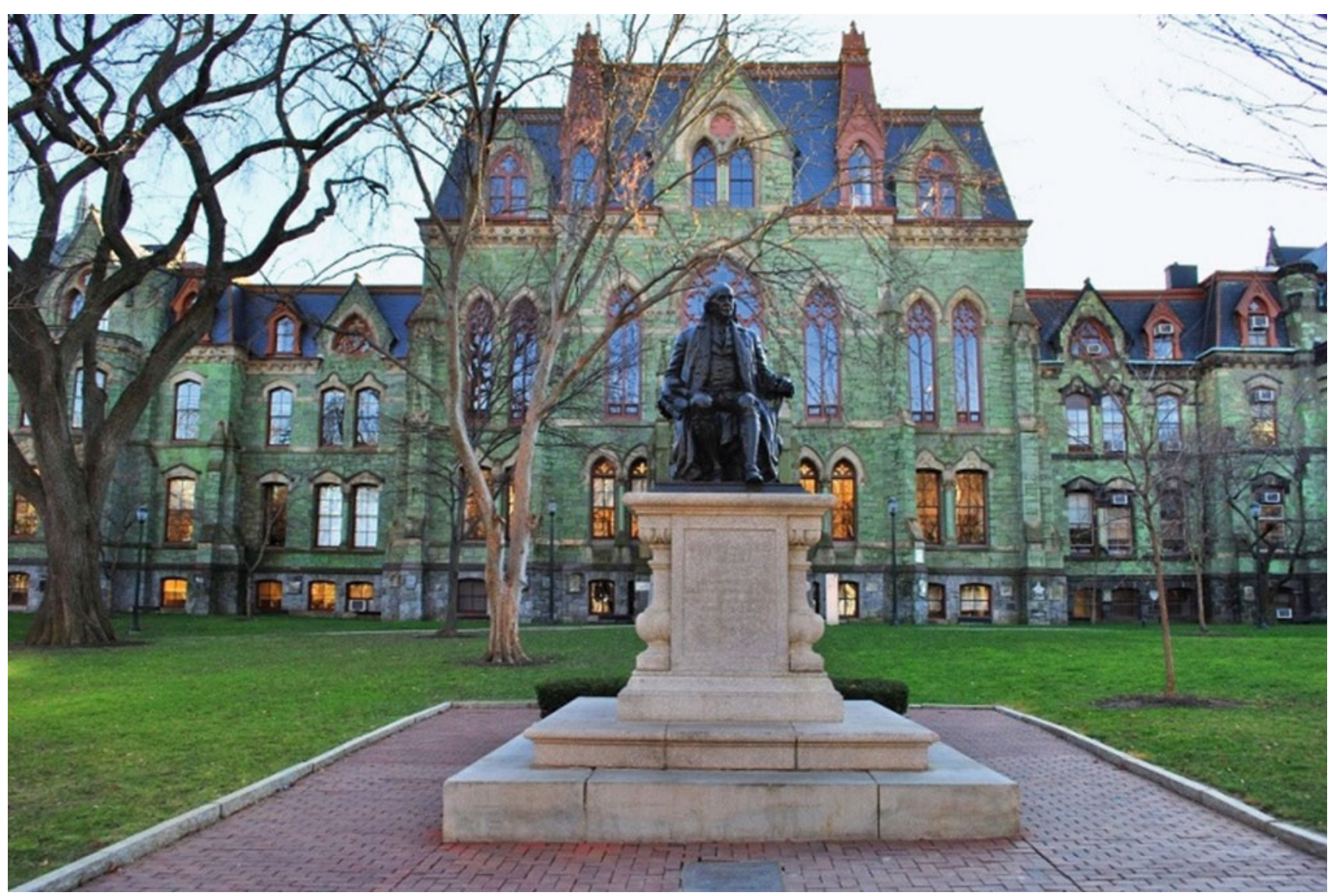


The University of Pennsylvania, a private university, managed to be listed in Reuters' ranking of the World's Most Innovative Universities thanks to its researchers [45]. It was established in 1740 and has been home to 4 Nobel Prize laureates and 4 National Medal of Science winners in the past two decades alone. The university comprises 137 research centers and institutes.

In 2016, the scientific research budget amounted to more than $\$ 1$ billion in grants for sponsored projects. Also, in 2013, the University of Pennsylvania's business incubators and Penn Center for Innovation founded 22 start-ups that gained more than $\$ 50$ million in revenue.

In 2017, the scientific research budget amounted to $\$ 928$ million. Its scientists concluded tests on a new single-dose Zika vaccine and identified a targeted gene responsible for allowing host cells to defeat the Ebola virus. Researchers in
Penn's Department of Biology identified a target gene that regulates the creation of hair-like root structures in plants which increase surface area, causing greater absorption of water and other resources from the soil. Engineered crop plants with this feature became most likely to resist drought conditions.

The university's school of medicine receives significant support from the National Institute of Health NIH in America, \$10 million of which is dedicated to the establishment of the Physical Sciences Oncology Center at Penn, which will focus on the early detection and treatment of liver cancer.

Table 6.4 displays some key statistical figures that illustrate the quality of research and innovation [45-47].

Figure 6.8 shows the patents submitted by the University of Pennsylvania in various fields, while Fig. 6.9 shows the percentage of accepted patents.
Table 6.4 Some key statistical figures for the University of Pennsylvania

Fig. 6.8 Patents submitted by the University of Pennsylvania

\begin{tabular}{l|l}
\hline Number of Nobel laureates among professors and alumni & 30 \\
\hline Endowments in 2017 & $\$ 12.2$ billion \\
\hline University budget in 2017 & $\$ 8.78$ billion \\
\hline Total campus area & $4.39 \mathrm{~km}^{2}$ \\
\hline Number of applicants for university (2017) & 40,413 \\
\hline Number of students admitted to university (2017) & $3757(9.3 \%$ of applicants) \\
\hline Number of undergraduate students & 10,496 (48.8\% of total students) \\
\hline Number of postgraduate students & $11,013(51.2 \%$ of total students) \\
\hline Teaching staff & 4300 \\
\hline Members of the academic council & 5242 \\
\hline Total number of university staff & 16,000 \\
\hline
\end{tabular}

\section{University of Pennsylvania, USA}

TOTAL PATENTS FILED

(557)

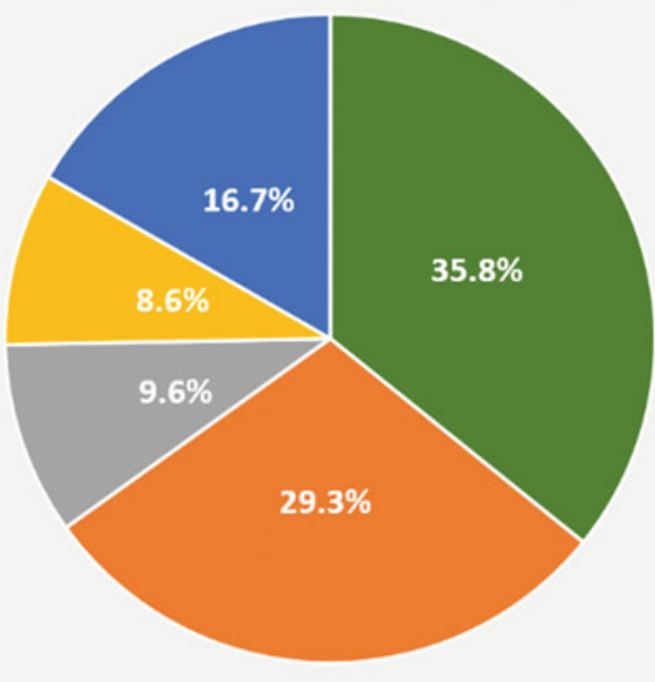

Pharmaceuticals \&

Biotech

Agriculture, Forestry \& Food

Medical Devices \&

Healthcare

Chemicals

Other 
Fig. 6.9 Percentage of accepted patents of the University of Pennsylvania

\section{University of Pennsylvania, USA}

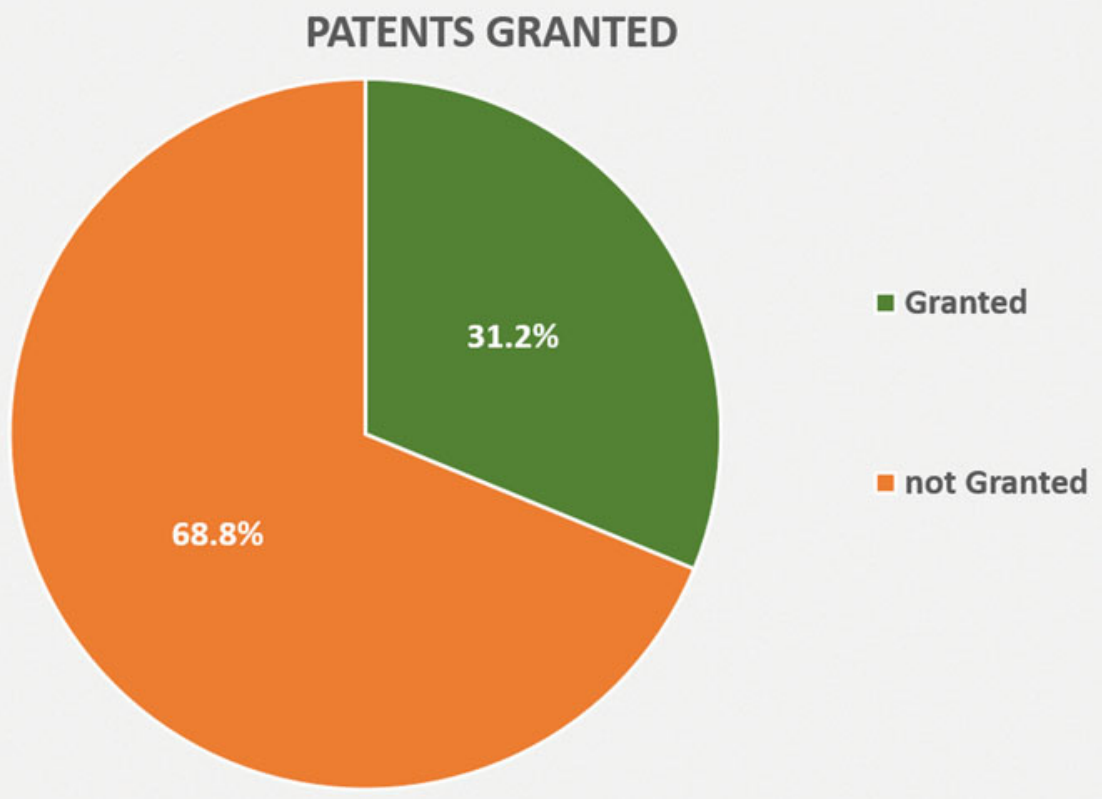

\subsection{University of Washington-USA}

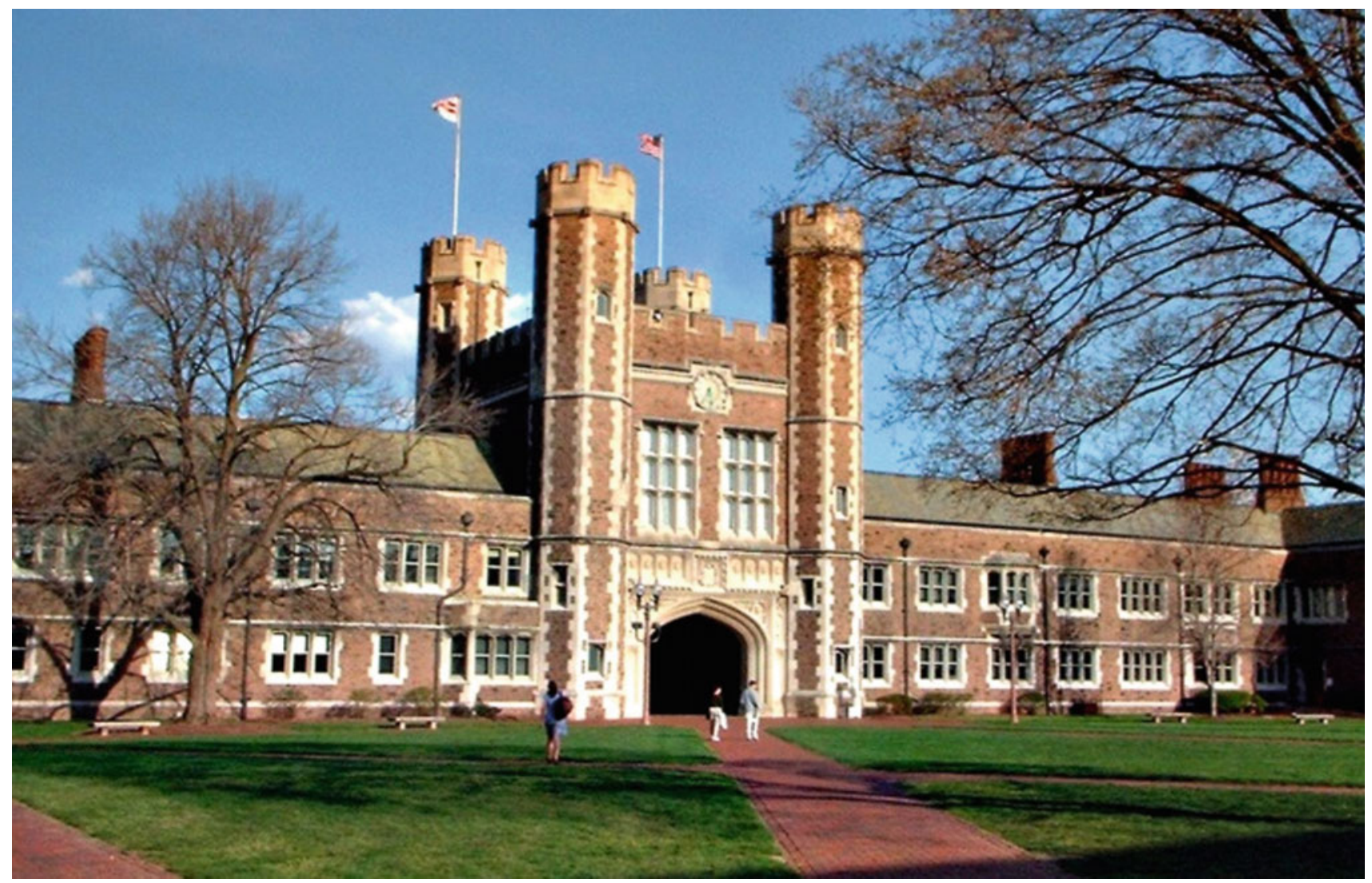


Despite coming fifth in ranking, the University of Washington (UW) is ranked first among public universities on the list. It was established in 1861 and has three campuses in Seattle, Tacoma, and Bothell.

In the 2016 fiscal year, the research budget amounted to $\$ 995$ million, which is $72 \%$ of the university's annual budget. That same year 21 new start-ups were launched making a total of 126 start-ups over the past ten years.

Materials engineering researchers at UW recently developed a fast and affordable way to create super capacitors that can store and discharge energy faster than conventional batteries. These supercapacitors use a low-density carbon material called aerogel, and there are applications for using them in a wide range of devices from electric cars to high-powered lasers. Moreover, researchers at the university have discovered that adding polydopamine (a chemical substance extracted from mussels) to various medical examinations increases examination accuracy a thousand times which could lead to better tests for HIV, Zika virus, and proteins related to cancerous tumors.

Table 6.5 displays some key statistical figures that illustrate the quality of research and innovation [48-49].

Figure 6.10 shows the patents submitted by the University of Washington in various fields, while Fig. 6.11 shows the percentage of accepted patents.
Table 6.5 Some key statistical figures for the University of Washington

Fig. 6.10 Patents submitted by the University of Washington

\begin{tabular}{l|l}
\hline Number of Nobel laureates among professors and alumni & 7 \\
\hline Number of Fields Medalists among professors or alumni & 1 \\
\hline Number of National Medal of Science winners & 7 \\
\hline Number of Pulitzer Prize winners & 2 \\
\hline Endowments in 2017 & $\$ 3361$ billion \\
\hline Campus area & $2.8 \mathrm{~km}^{2}$ \\
\hline Number of undergraduate students (2017) & $31,843(67.5 \%$ of total students) \\
\hline Number of postgraduate students (2017) & $14,843(32.5 \%$ of total students) \\
\hline Members of the academic council & 5803 \\
\hline Number of the university's administrative staff & 16,174 \\
\hline
\end{tabular}

\section{University of Washington, USA}

TOTAL PATENTS FILED

(536)

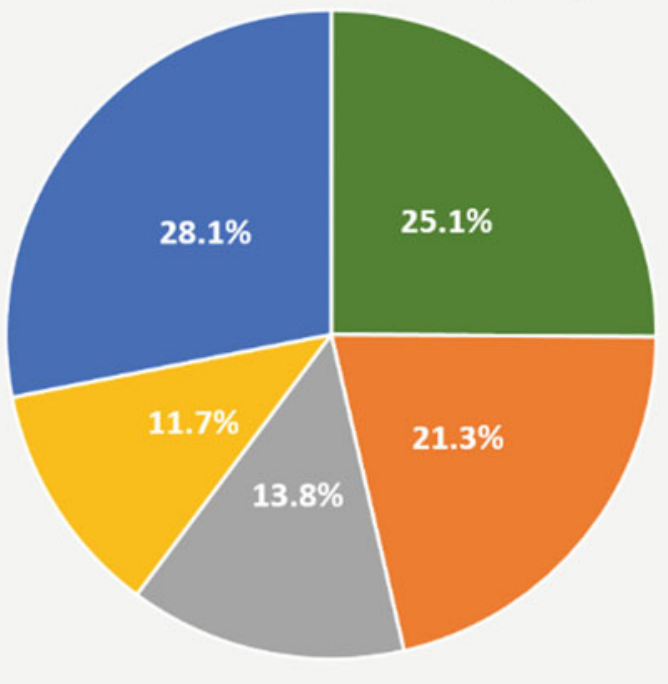

- Pharmaceuticals \& Biotech

- Agriculture, Forestry \& Food

- Medical Devices \& Healthcare

Chemicals 
Fig. 6.11 Percentage of accepted patents of the University of Washington

\section{University of Washington, USA}

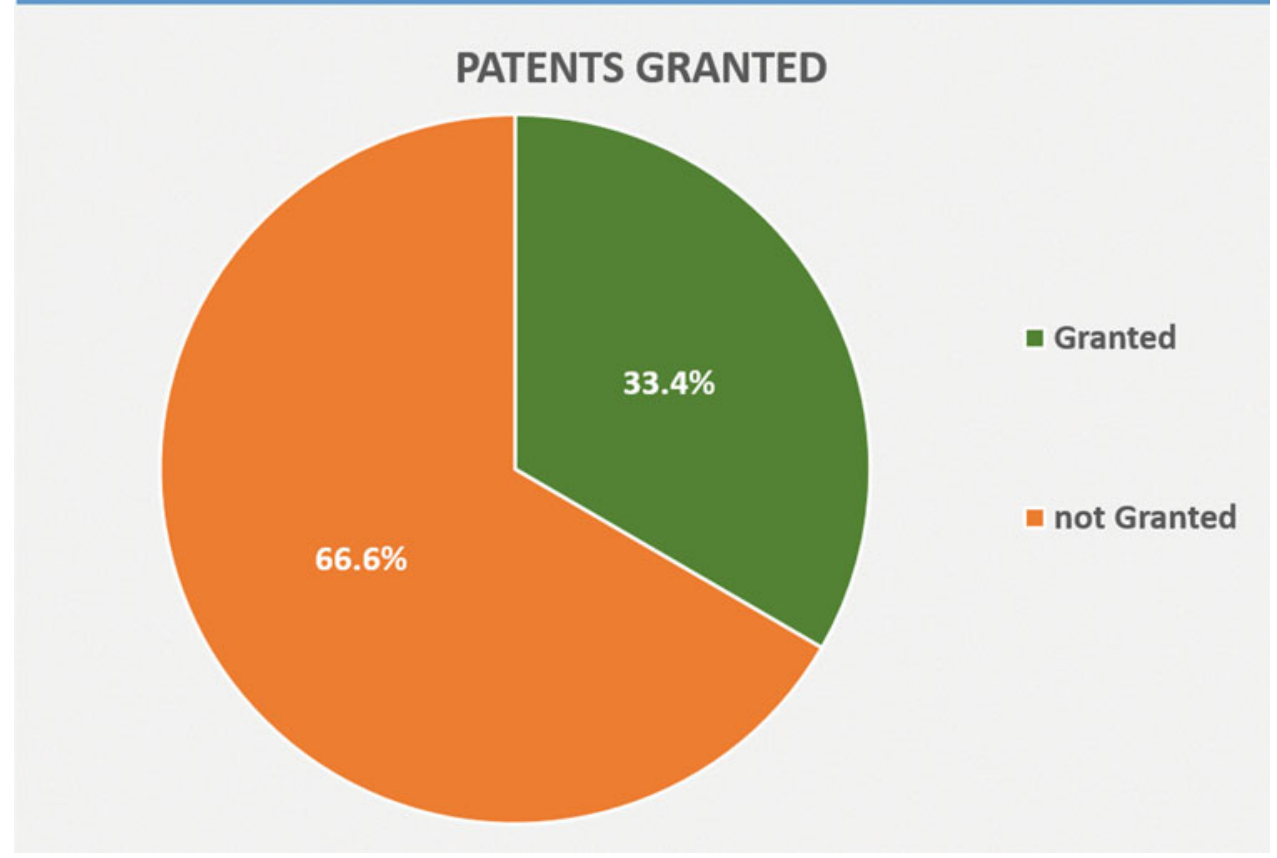

\subsection{University of Texas System-USA}

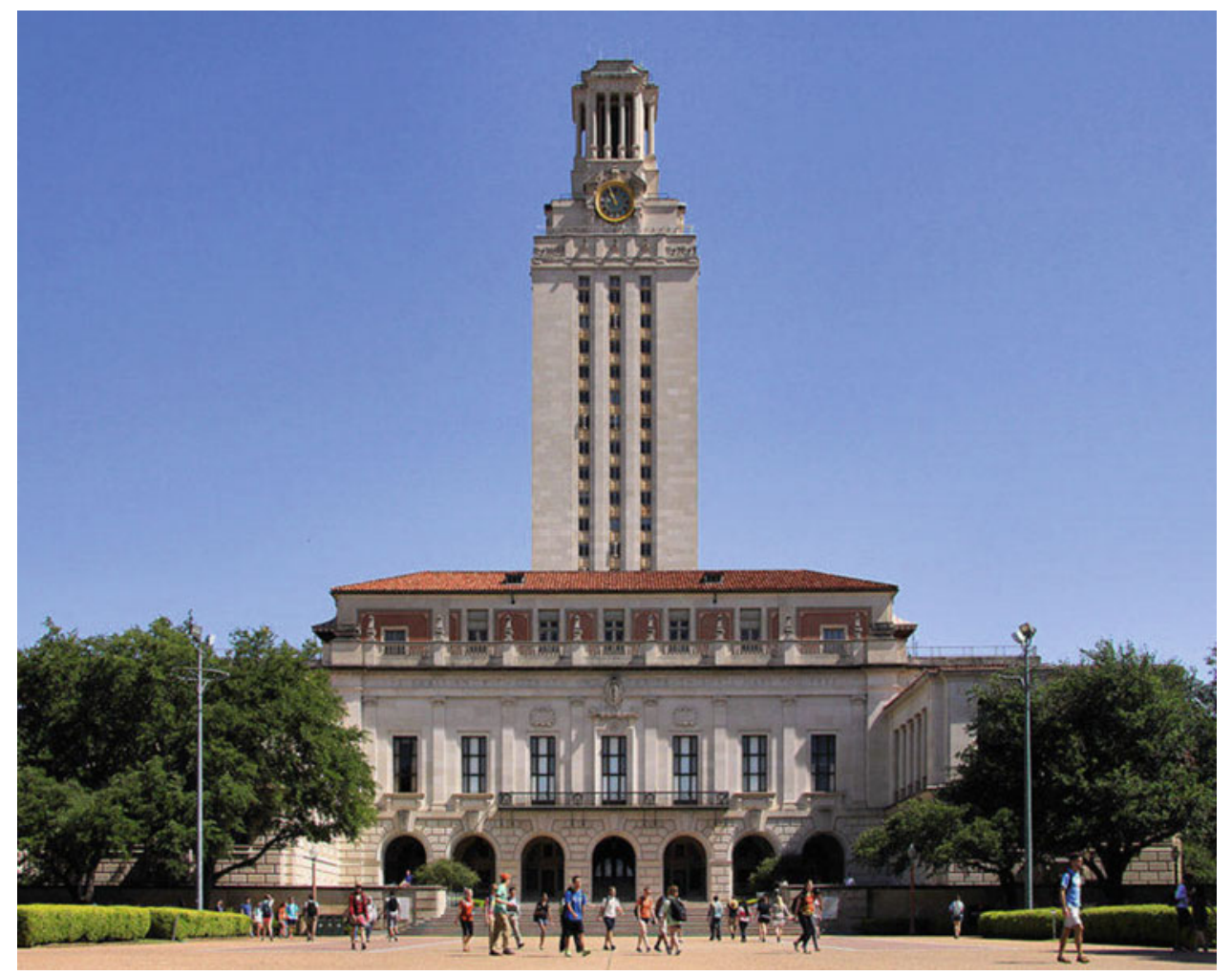


The eight public universities and six health institutions in the University of Texas (UT) System serve more than 221 thousand students each year, confer more than one-third of the state's undergraduate degrees, and educate two-thirds of the state's healthcare professionals annually. The system's faculty include 8 Nobel laureates. Its headquarters is in Austin, and the flagship campus there is the largest in the system.

This system receives almost $70 \%$ of all research funds dedicated to public institutions in Texas, and its annual research expenditures exceed $\$ 2.7$ billion, of which $\$ 641$ million is from private sector sources. Over the past five years, researchers from 14 institutions thereof have produced more than 120 thousand scientific papers.
In 2017, the University of Texas at Arlington announced the establishment of the Conrad Greer Lab, which will develop new methods of compressing natural gas into diesel and jet fuel. In the same year, the UT Austin campus built Stampede2, the most powerful supercomputer at any US university. As for the UT at Dallas campus, researchers invented a non-invasive biomonitor for diabetics, which uses the glucose levels in sweat to track blood-sugar levels.

Table 6.6 displays some key statistical figures that illustrate the quality of research and innovation [50-51].

Figure 6.12 shows the patents submitted by the University of Texas System in various fields, while Fig. 6.13 shows the percentage of accepted patents.
Table 6.6 Some key statistical figures of the University of Texas System

Fig. 6.12 Patents submitted by the University of Texas System

\begin{tabular}{|l|l|}
\hline Endowments in 2017 & $\$ 24$ billion \\
\hline Number of undergraduate students (2017) & $167,028(75.4 \%$ of total students) \\
\hline Number of postgraduate students (2017) & 54,309 (24.6\% of total students) \\
\hline Members of the academic council & 17,158 \\
\hline Number of administrative staff & 62,982 \\
\hline
\end{tabular}

\section{University of Texas System, USA}

TOTAL PATENTS FILED

(1023)

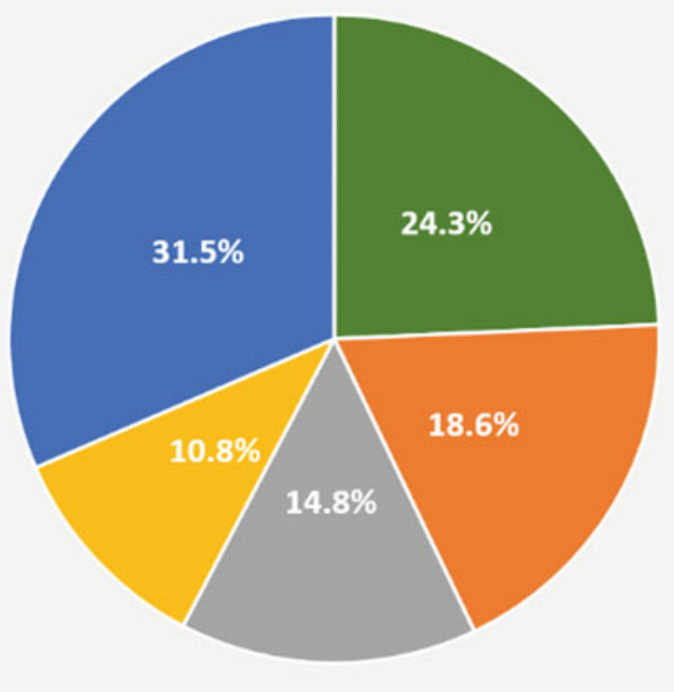

- Pharmaceuticals \& Biotech

- Agriculture, Forestry \& Food

Chemicals

- Medical Devices \& Healthcare

- Other 
Fig. 6.13 Percentage of accepted patents for the University of Texas System

\section{University of Texas System, USA}

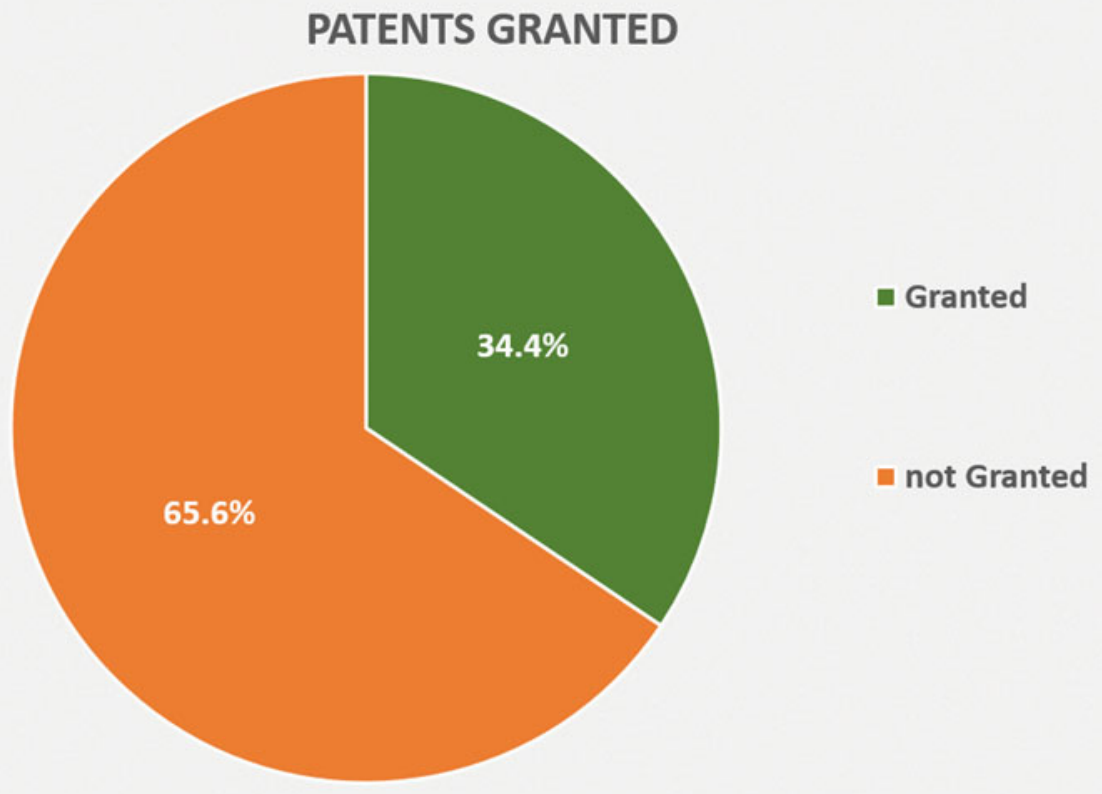

\subsection{KU Leuven-Belgium}

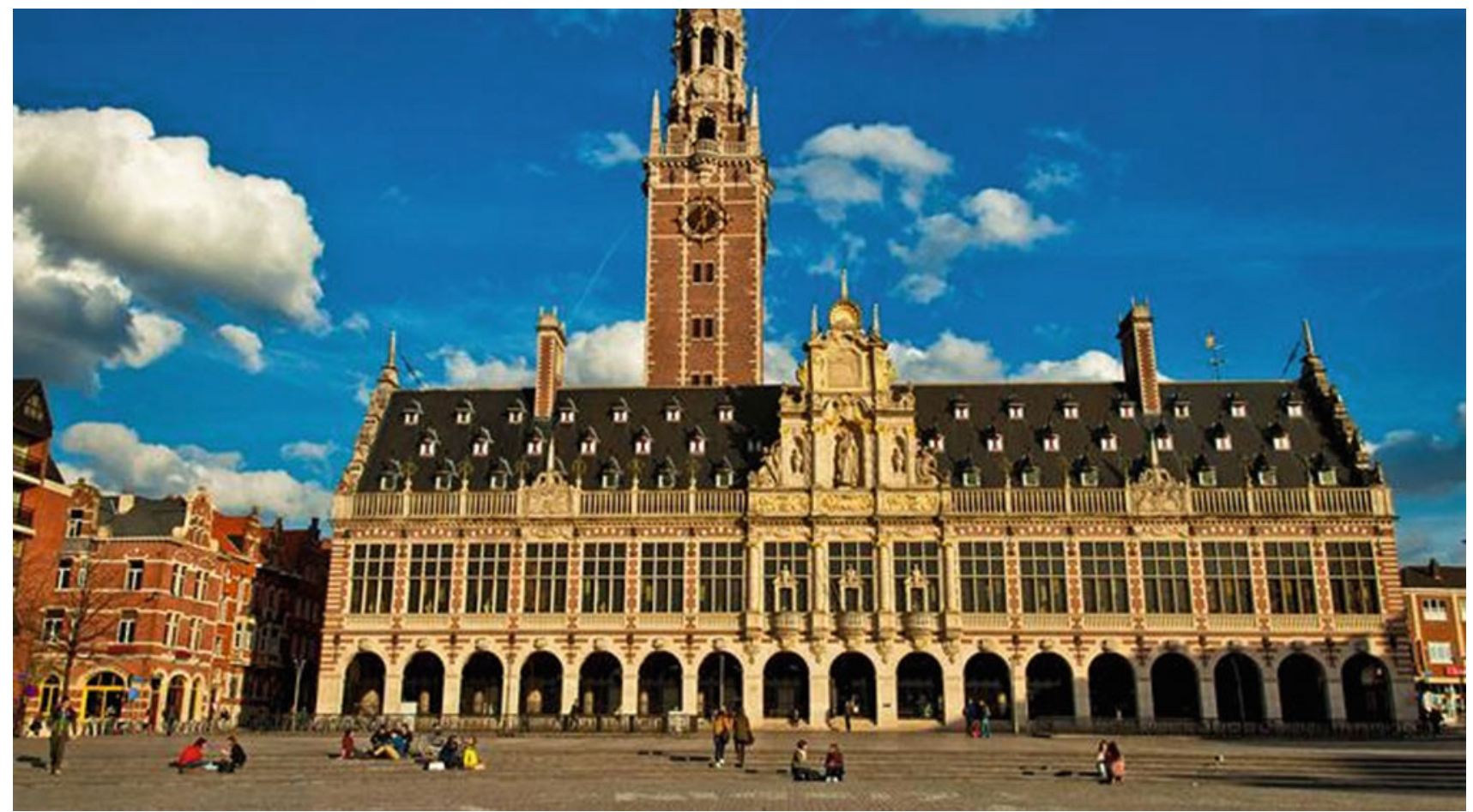


Founded in 1425 by Pope Martin V, KU Leuven is the oldest Catholic university, but it is not limited to theology. Part of KU's modern mission is to conduct comprehensive and advanced scientific research. A Dutch-speaking school based in Belgium's Flanders region, it is open to students of all faiths, operates independently from the Church and maintains one of the largest research and development organizations in the world [51].

KU Leuven Research and Development (LRD), established in 1972, was one of the first tech transfer offices in Europe, and has helped the university spin off more than one company across a range of industries. In 2012, Siemens acquired KU spinoff LMS International, a leading provider of mechatronic simulation software, in a deal worth approximately $€ 680$ million.

In the fiscal year 2015, the university's total research expenditure exceeded $€ 454$ million. The school's patent portfolio includes 586 patents.
In 2016, KU Leuven announced a new partnership with Ford Motor Company to study the durability of auto parts created using a " $3 \mathrm{D}$ printing" manufacturing process. And in the eye surgery department, eye surgeons at University Hospital Leuven recently performed the first robotic surgery on a patient with retinal vein occlusion. Using a needle about $0.03 \mathrm{~mm}$ diameter, the robot injected a drug into the patient's retinal vein (which is about the diameter of a human hair. Both the robot and needle were developed by KU Leuven.

Table 6.7 displays some key statistical figures that illustrate the quality of research and innovation [52-53].

Figure 6.14 shows the patents submitted by KU Leuven in various fields, while Fig. 6.15 shows the percentage of accepted patents.
Table 6.7 Some key statistical figures for KU Leuven

Fig. 6.14 Patents submitted by KU Leuven

\begin{tabular}{l|l} 
Endowments in 2017 & $€ 950$ million \\
\hline Number of students & 56,351 \\
\hline Number of doctoral students & $4272(7.6 \%$ of total students) \\
\hline Members of the academic council & 1107 \\
\hline Total number of university staff & 11,534 \\
\hline
\end{tabular}

\section{KU Leuven, Belgium}

TOTAL PATENTS FILED (300)

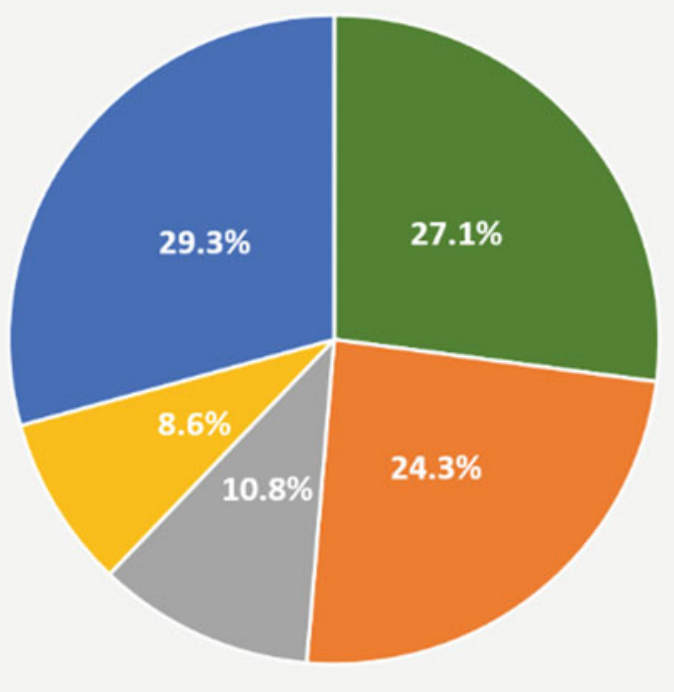

- Pharmaceuticals \& Biotech

- Agriculture, Forestry \& Food

- Chemicals

- Medical Devices \& Healthcare

a Other 
Fig. 6.15 Percentage of accepted patents of KU Leuven

\section{KU Leuven, Belgium}

\section{PATENTS GRANTED}

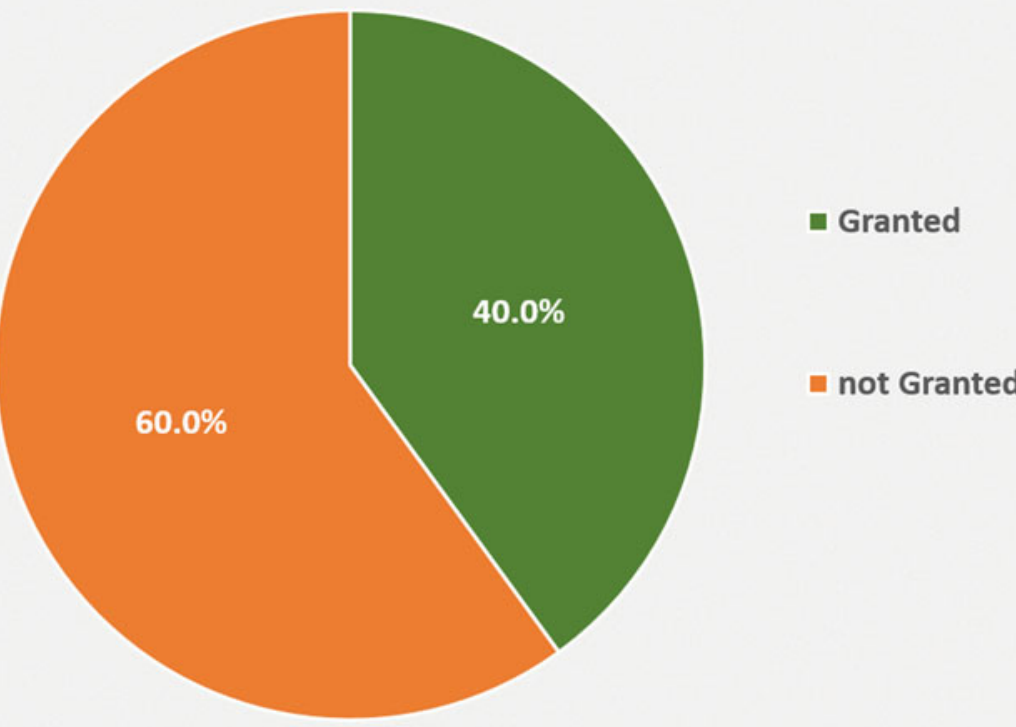

\subsection{Imperial College London-United Kingdom}

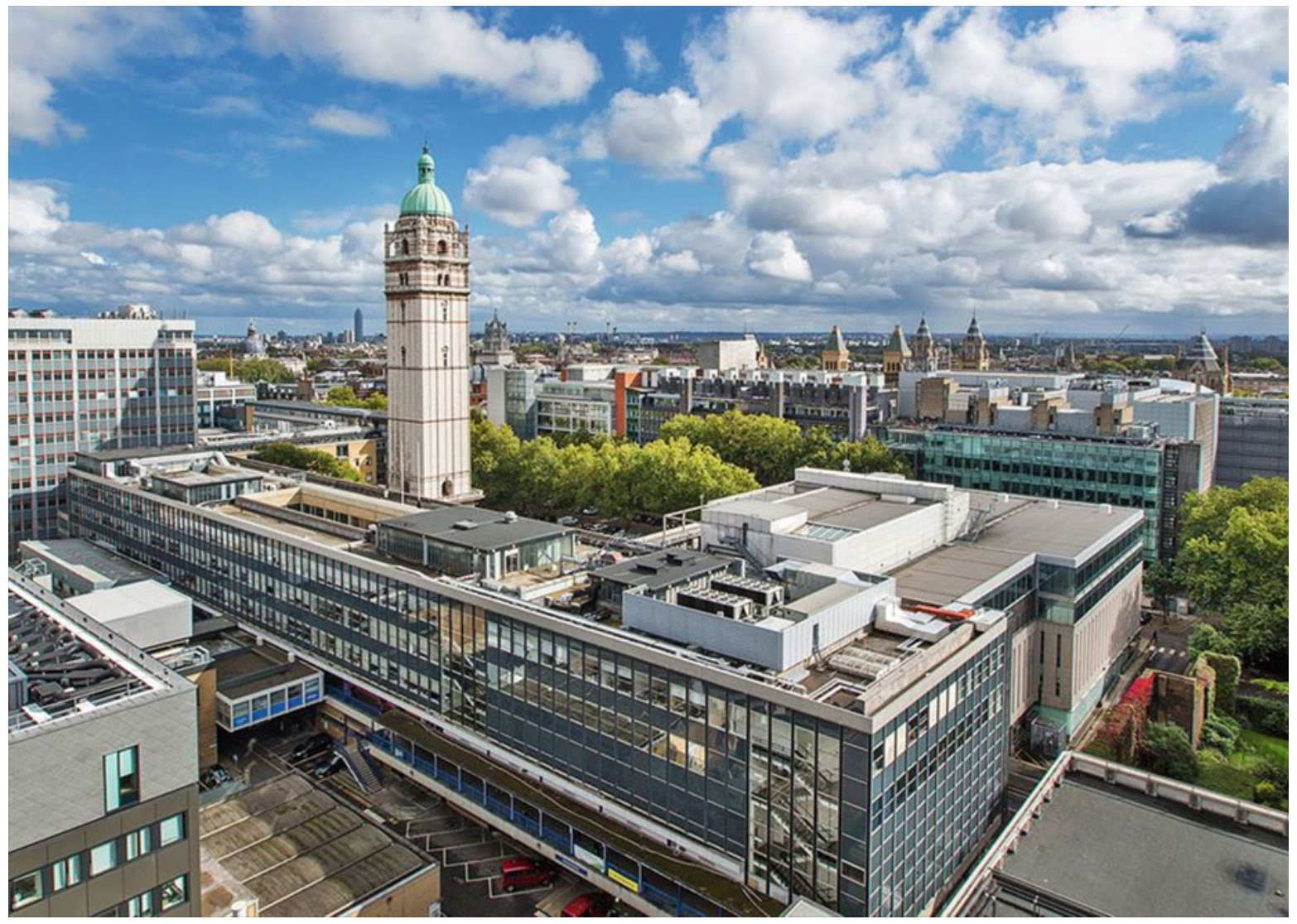


Imperial College London is a research university, founded in 1907 as a part of the University of London, and became fully independent in July 2007. It now focuses on four main disciplines: science, engineering, medicine and business. Throughout its history, Imperial College researchers have been responsible for innovations including the discovery of penicillin and the development of fiber optics. The university serves about 17,000 students from more than 125 countries and awards 6700 degrees annually. The university's 2015 annual research grant budget was about $£ 436$ million. This is in addition to the university's expenditures of research and equipment from its own budget, which amounted to £991 billion in 2017 [54].

Recent most important research at Imperial College London includes the development of nanoparticles that drive chemical reactions including artificial photosynthesis, which could be used in building more efficient solar panels. Imperial College scientists have also demonstrated a method for transferring power wirelessly to drones while hovering.

In 2016, the university opened a new innovation center called the I-Hub, which provides laboratories and office spaces to help entrepreneurs and start-ups commercialize new research. Imperial College's corporate partners include Shell and Qatar Petroleum, which fund the Carbon Storage Research Centre. Scientists there are investigating cleaner methods for the production and use of oil and gas.

Technology Company NEC is working with the university to make water systems more energy efficient and eco-friendly. Imperial College London is home to the Parkinson's UK Brain Bank, which supports more than 100 research projects and has more than 6000 registered potential tissue donors.

The 14 Nobel Prize laureates of Imperial College researchers and scientists enhance its excellence in innovation. Additionally, three young Imperial College mathematicians won the Fields Medal for mathematics, which is awarded to young mathematicians under the age of 40.

Table 6.8 displays some key statistical figures that illustrate the quality of research and innovation [54-57].

Figure 6.16 shows the patents submitted by Imperial College London in various fields, while Fig. 6.17 shows the percentage of accepted patents.
Table 6.8 Some key statistical figures of Imperial College London

\begin{tabular}{l|l}
\hline Number of Nobel laureates among professors and graduates & 14 \\
\hline Number of professors or graduates who are Fields Medal winners & 3 \\
\hline Endowments (2017) & $£ 141.7$ million \\
\hline University budget (2016/2017) & $£ 983$ million (\$1.35 billion) \\
\hline Annual grants value for research since 2013 until 2017 & $£ 330-460$ million \\
\hline Number of students & 17,485 \\
\hline Number of undergraduate students & 9503 (55\% of total students) \\
\hline Number of postgraduate students (2016) & 7982 (45\% of total students) \\
\hline Acceptance rate of students & $14.3 \%$ \\
\hline Number of degrees awarded annually & 6700 \\
\hline Members of the academic council & 3765 \\
\hline Number of administrative staff & 3940 \\
\hline
\end{tabular}


Fig. 6.16 Patents submitted by Imperial College London

Fig. 6.17 Percentage of accepted patents of Imperial College London

\section{Imperial College London, United Kingdom}

TOTAL PATENTS FILED

(297)

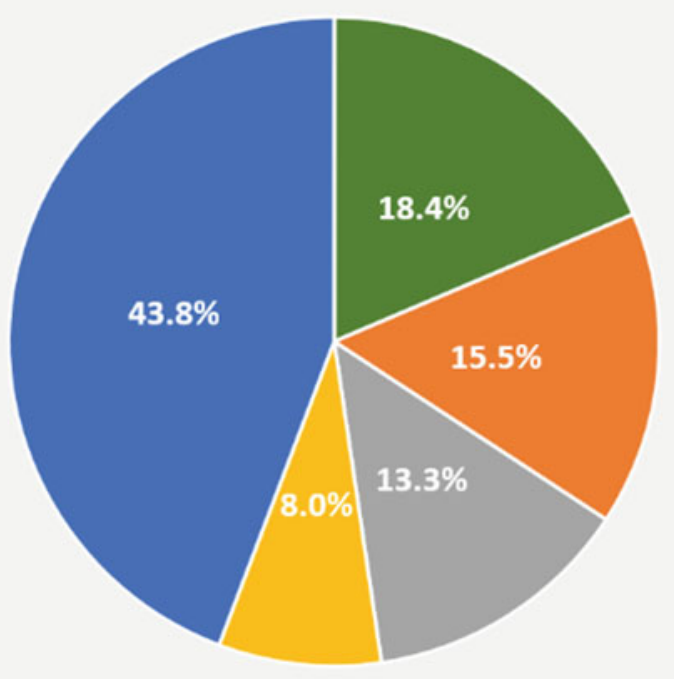

- Pharmaceuticals \& Biotech

n Agriculture, Forestry \& Food

- Chemicals

n Computer Software \& Internet

a other

\section{Imperial College London, United Kingdom}

\section{PATENTS GRANTED}

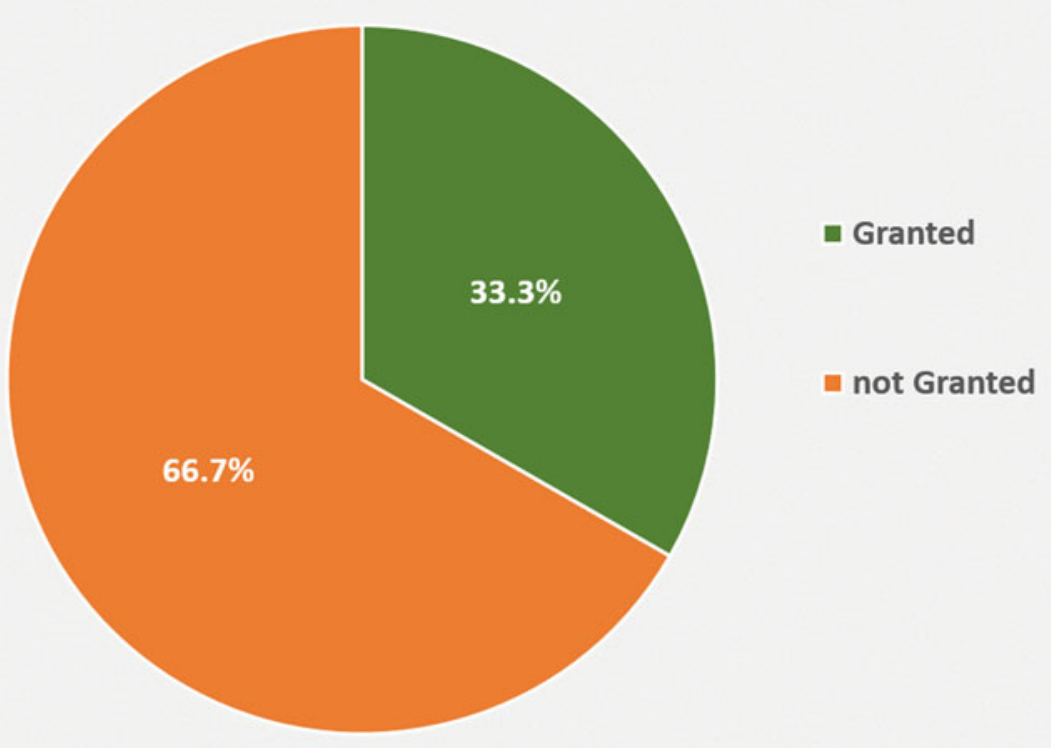




\subsection{University of North Carolina Chapel Hill -USA}

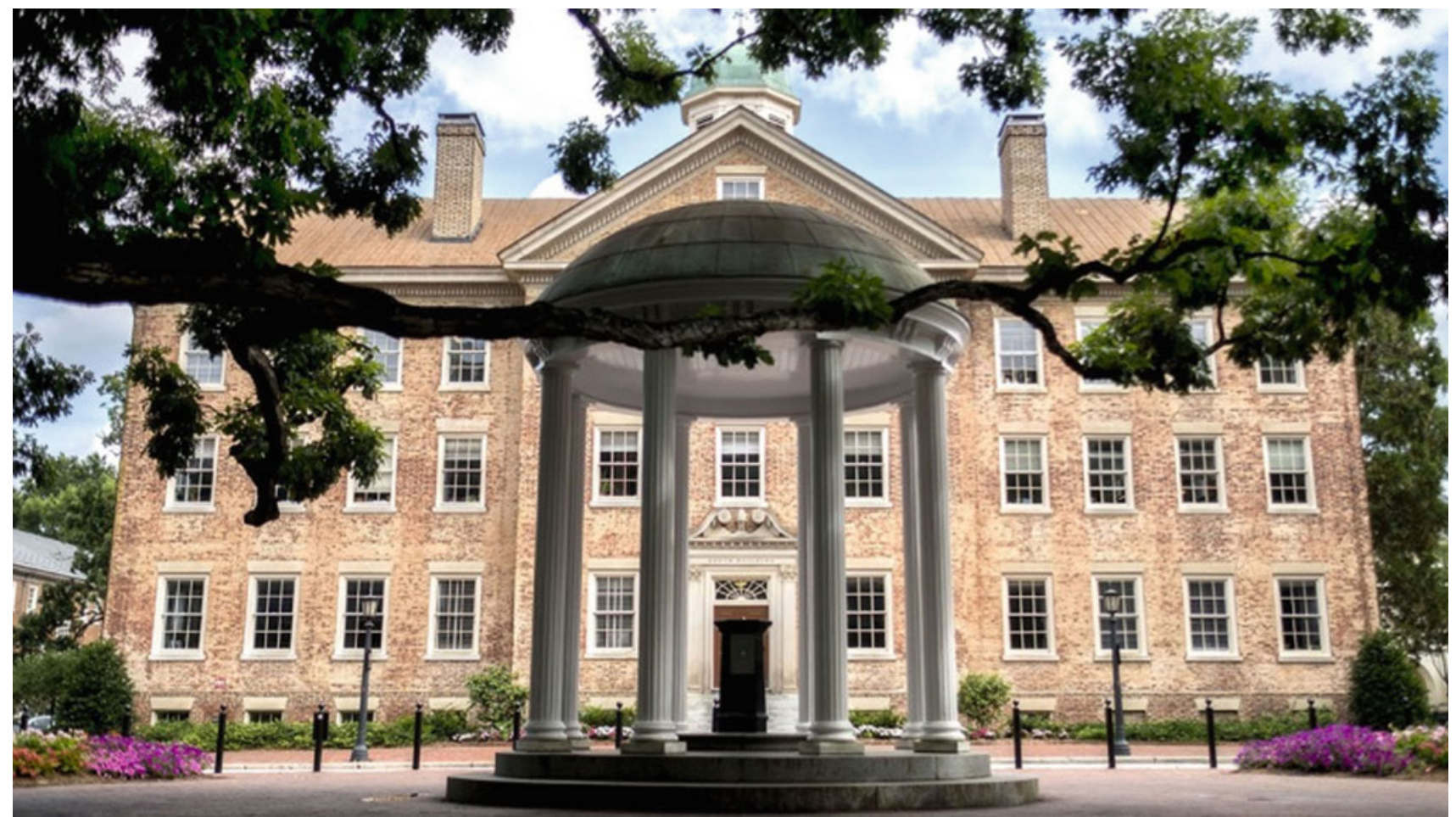

Table 6.9 Some key statistical figures of the University of North Carolina Chapel Hill

\begin{tabular}{l|l}
\hline Number of Nobel laureates among professors and graduates & 2 \\
\hline Campus area & 729 acres $\left(3 \mathrm{~km}^{2}\right)$ \\
\hline Number of students (2017) & 29,877 \\
\hline Number of undergraduate students (2017) & 18,715 \\
\hline Number of postgraduate students (2017) & 11,132 \\
\hline Teaching staff & 3887 \\
\hline Number of administrative staff (2015) & 8287
\end{tabular}

The University of North Carolina, a public research university in Chapel Hill, North Carolina, was founded on December, 1789. It is the flagship of the 17 universities of the University System of North Carolina. The university first began enrolling students in 1795, which makes it one of three schools to claim the title of the oldest public university in the USA. In 2015, US News and World Report ranked university of North Carolina fifth among the best US public colleges and universities.

In the past two decades, the university's research project expenditures have doubled, to the point that it gained reputation as a top national research university. The university's research expenditures exceeded $\$ 1$ billion dollars during that period. Therefore, UNC-Chapel Hill is ranked sixth among research universities for federal funding devoted to development and research.

In 2016, the university conducted 767 research projects that directly tackled health, education and welfare of North Carolina citizens. The fact that it incorporated more than 3000 undergraduates who produced original research lays emphasis on its excellence in research.

Table 6.9 displays some key statistical figures that illustrate the quality of research and innovation [58-59].

Figure 6.18 shows the patents submitted by UNC-Chapel Hill in various fields, while Fig. 6.19 shows the percentage of accepted patents. 
Fig. 6.18 Patents submitted by UNC-Chapel Hill

Fig. 6.19 Percentage of accepted patents for UNC-Chapel Hill

\section{University of North Carolina Chapel Hill, USA}

TOTAL PATENTS FILED

(368)

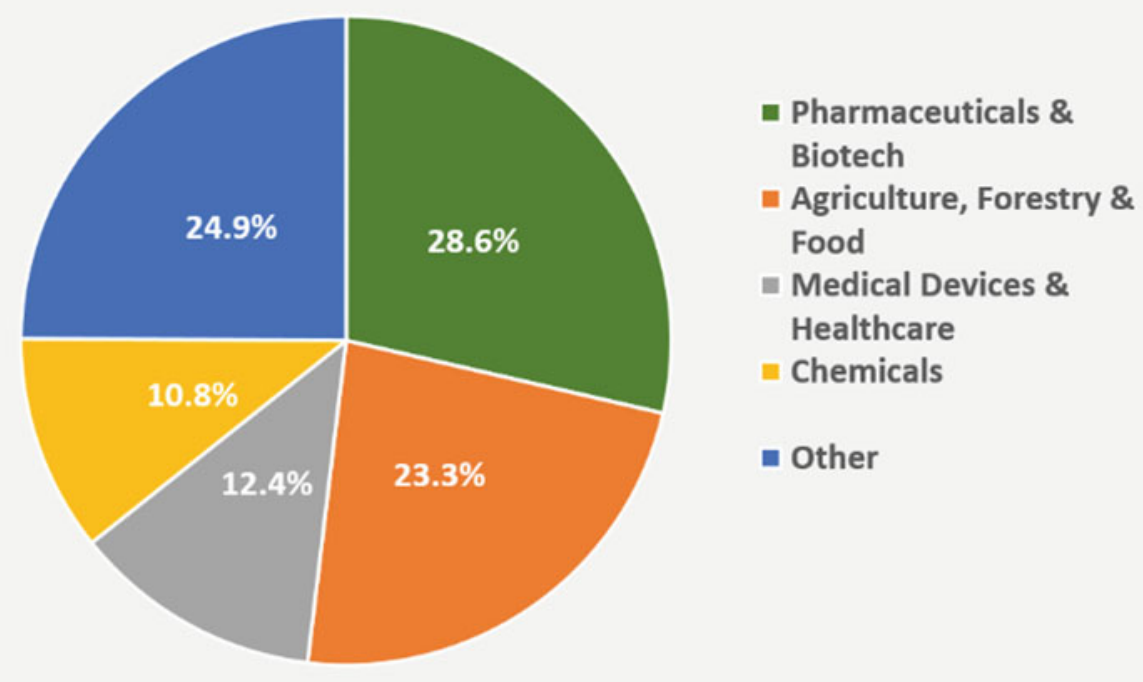

\section{University of North Carolina Chapel Hill, USA}

\section{PATENTS GRANTED}

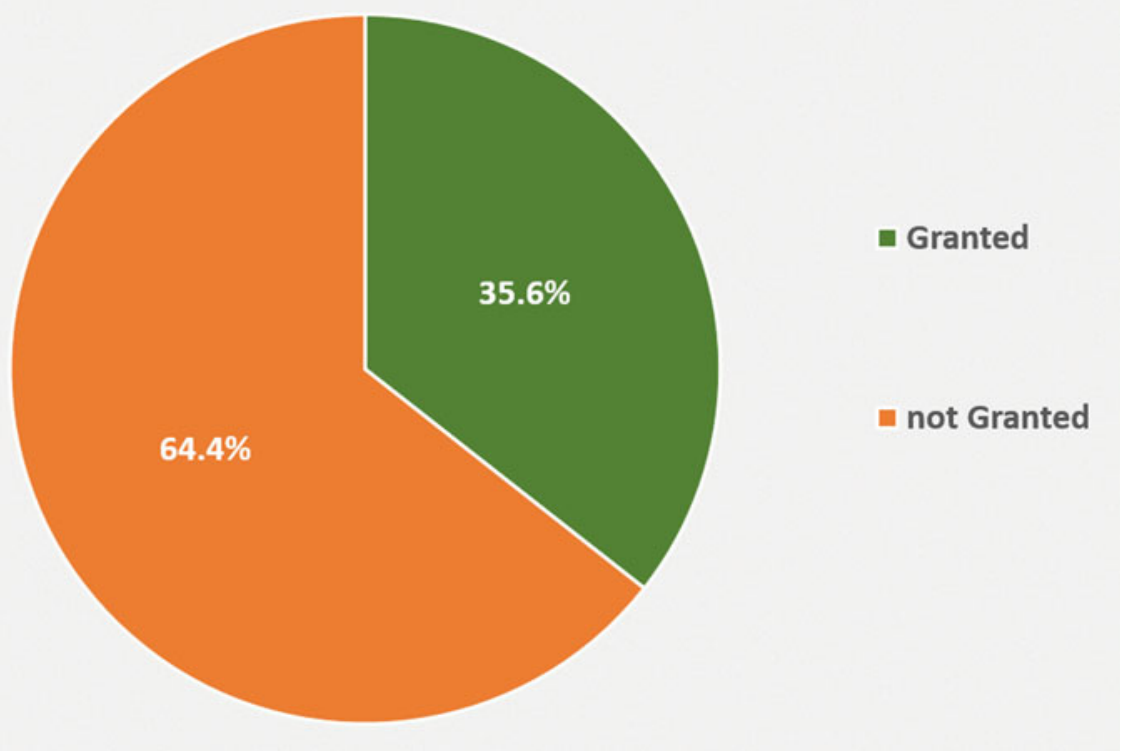




\subsection{Vanderbilt University-USA}

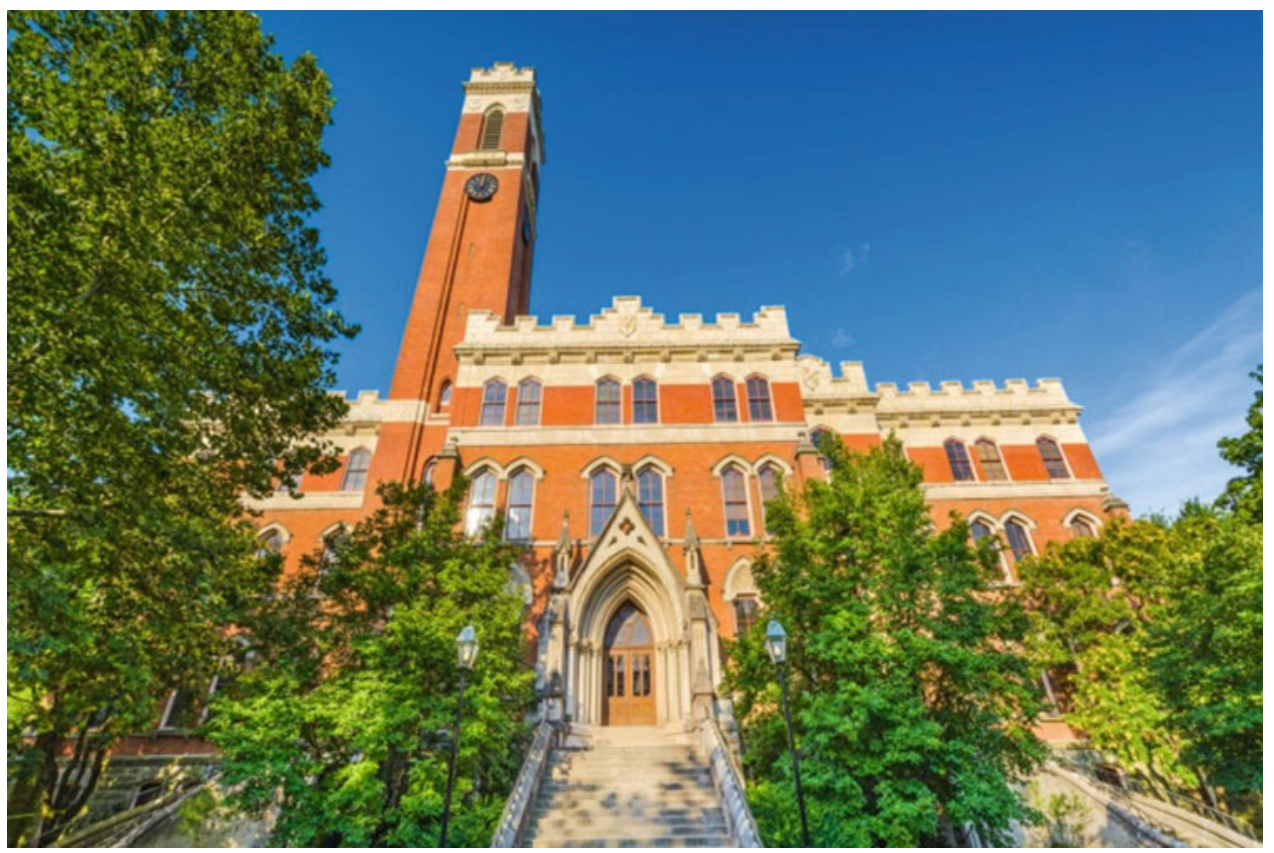

Table 6.10 Some key statistical figures for Vanderbilt University

\begin{tabular}{|l|l|}
\hline Number of Nobel laureates among professors and alumni & 3 \\
\hline Number of Fields Medalists among professors or alumni & 2 \\
\hline Endowments in 2017 & $\$ 4.1$ billion \\
\hline Campus area & $1.3 \mathrm{~km}^{2}$ \\
\hline Number of undergraduate students (2017) & $6885(54.7 \%$ of total students) \\
\hline Number of postgraduate students (2017) & 5707 (45.3\% of total students) \\
\hline Number of teaching staff members & 1519 \\
\hline Members of the academic council & 4102 \\
\hline
\end{tabular}

Vanderbilt University was ranked in the tozp ten for the first time in 2017, climbing from No. 20 in 2016 as its patent citations by other researchers around the globe increased.

Vanderbilt University was founded in 1873 with a \$1 million gift Mr. Cornelius Vanderbilt. Up to this day, it is a private institution that includes 10 schools and approximately 120 centers and institutes of various disciplines.

In the fiscal year 2016, the university's total research expenditures were approximately \$235 million, and it sponsored research and project awards totaled \$214 million. That same year the Center of Technology Transfer and Commercialization reported $\$ 6.5$ million in revenue from licensing.

Recently, a team of Vanderbilt University researchers developed "smart underwear" that employs a series of straps to remedy back pain. Vanderbilt researchers have also developed circuit boards embedded with "cotton candy" tangles of silver nanowire that dissolve when cooled. The circuit boards are designed for use in devices of temporary function, including medical devices implantable for a temporary end and can be gotten rid of when not needed by cooling human body. Vanderbilt-developed products that have recently entered the market including lower limb exoskeleton that enables people with spinal cord injuries to stand and walk. Also a line of energy-saving pneumatic directional control valves for use in factory work.

Table 6.10 displays some key statistical figures that illustrate the quality of research and innovation [60-61].

Figure 6.20 shows the patents submitted by Vanderbilt University in various fields, while Fig. 6.21 shows the percentage of accepted patents. 
Fig. 6.20 Patents accepted by Vanderbilt University

\section{Vanderbilt University, USA}

\section{TOTAL PATENTS FILED}

(231)

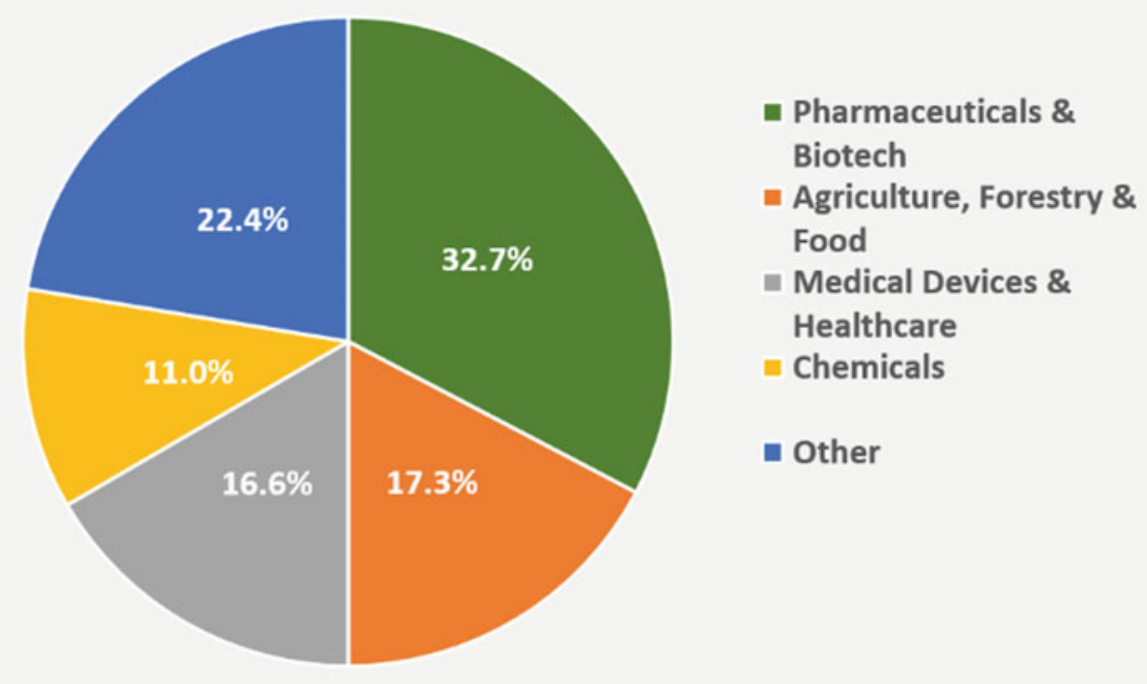

Fig. 6.21 Percentage of accepted patents of Vanderbilt University

\section{Vanderbilt University, USA}

\section{PATENTS GRANTED}

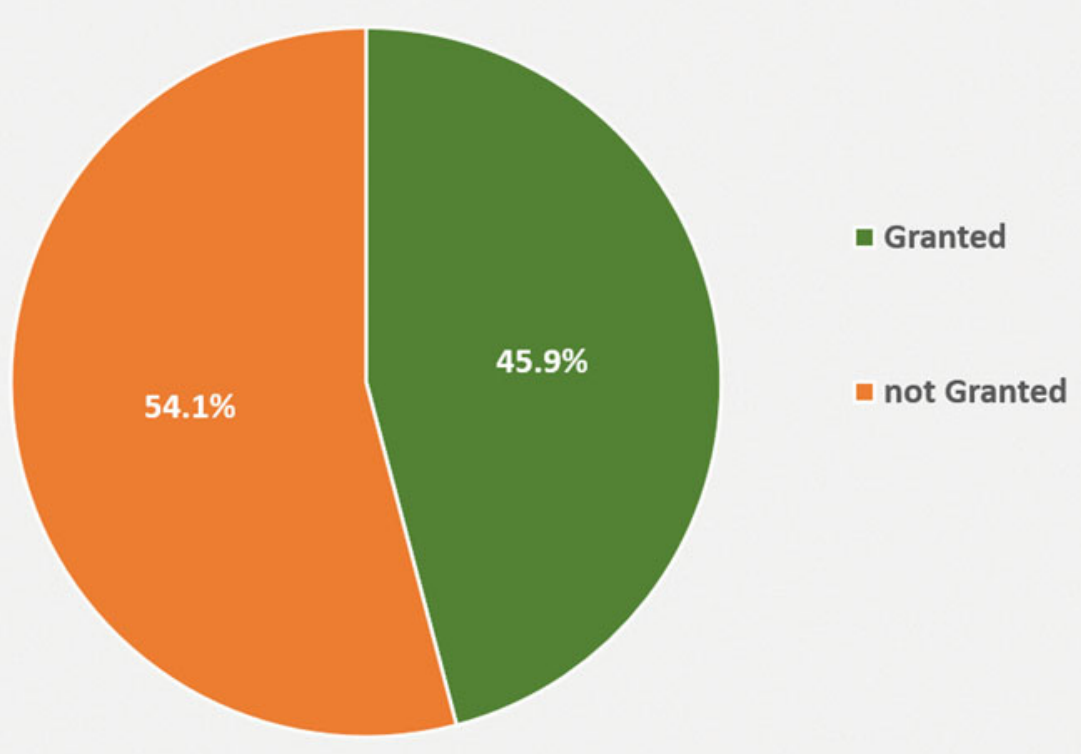




\subsection{Korea Advanced Institute of Science and Technology (KAIST)—South Korea}

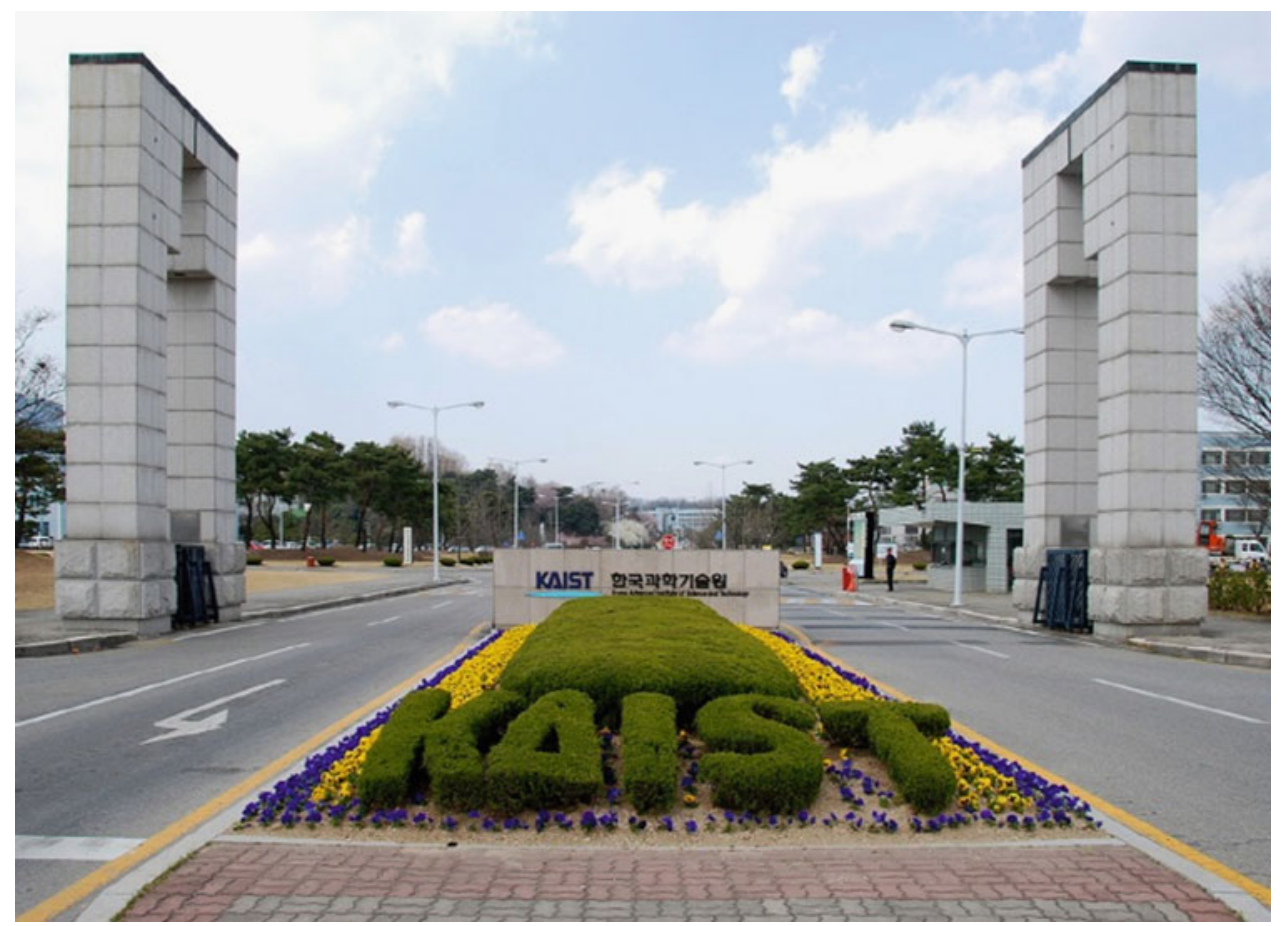

Table 6.11 Some key statistical figures of KAIST University

\begin{tabular}{l|l}
\hline Number of undergraduate students & $4047(39.5 \%$ of total students $)$ \\
\hline Number of postgraduate students & $6202(60.5 \%$ of total students $)$ \\
\hline Number of doctoral students & $2311(37.3 \%$ of postgraduate students $)$ \\
\hline Number of joint academic programs students & 1137 \\
\hline Teaching Staff & 1140 \\
\hline
\end{tabular}

The full name of this university was Korea Advanced Institute of Science and Technology, but starting from 2008, only the abbreviation (KAIST) has been used [62].

KAIST is one of the oldest Korean research universities specializing in sciences and engineering. It operates in three cities; Daejeon, Seoul, and Busan. The university was established in 1971 by the Korean government on the model of US engineering faculties. At the beginning, it was funded with a loan worth millions of dollars by the United States Agency for International Development. Most curricula are delivered there in English, and the university still maintains strong relations with American academic institutions. The university supports joint academic programs, allowing students to get degrees from it as well as its partners such as Carnegie Mellon University and Georgia Institute of Technology.

The university provides students with a special entrepreneurship program called "Start-up KAIST," which helps to develop business initiatives and to provide financial support for new business. Yi So-yeon, the first Korean to fly in space, has graduated from such program.
In 2015, the cooperation between a university team and Rainbow, a company that emerged from (Humanoid Robot Research Center), a university research center, contributed to the university's being awarded by the US Department of Defense in a man-like adaptable robotics competition.

The university researchers have recently developed the "parasitic" robot system that controls the movement of the host animal. The robot is mounted on the carapace of the turtle and uses lights and food to encourage the animal to move in the required direction.

Among other pieces of research was the development of shock absorbing touch sensors that can be used as a robotic membrane. The mobile applications of this technique help to report traffic violations, such as breaking traffic signals or taking a banned turn.

Table 6.11 shows some key statistical figures of high-quality research and innovations [63].

Figure 6.22 shows patent applications submitted by KAIST in different fields, while Fig. 6.23 shows the percentage of accepted patent applications. 
Fig. 6.22 Patent applications submitted by KAIST University

Fig. 6.23 Percentage of accepted patent applications submitted by KAIST University

\section{Korea Advanced Institute of Science \& Technology (KAIST), South Korea}

\section{TOTAL PATENTS FILED}

(1000)

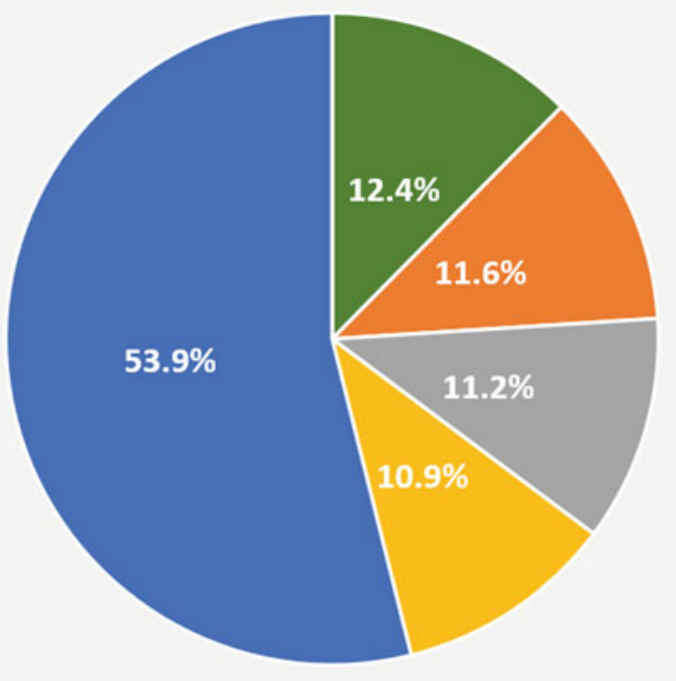

- Chemicals

- Agriculture, Forestry \& Food

- Pharmaceuticals \& Biotech

- Telecommunications

- Other

\section{PATENTS GRANTED}

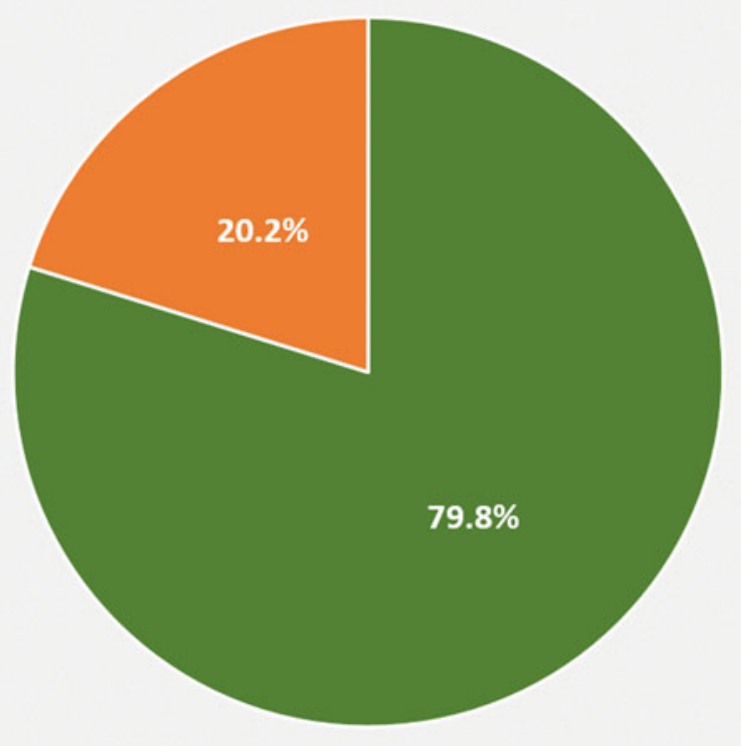

- Granted

not Granted 


\subsection{Swiss Federal Institute of Technology in Lausanne (EPFL)—Switzerland}

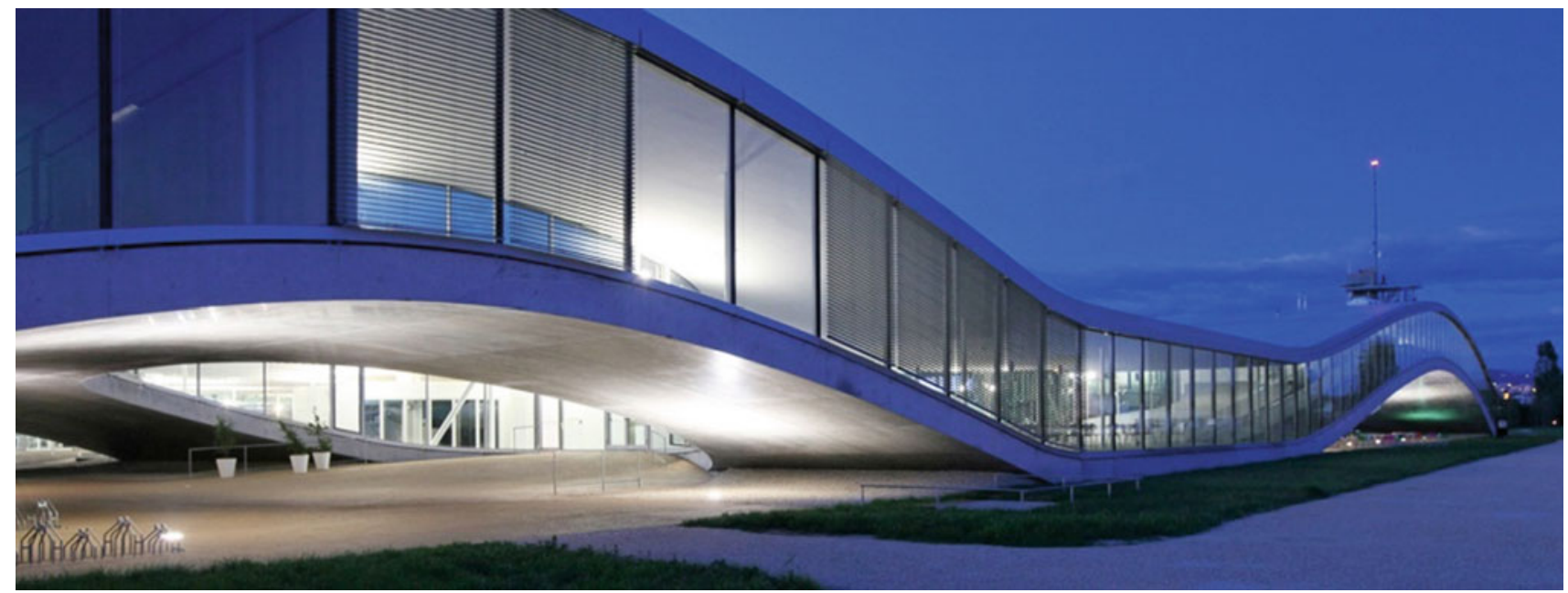

Table 6.12 Some key statistical figures of Swiss Federal Institute of Technology in Lausanne

\begin{tabular}{l|l}
\hline University budget (2017) & 950 million francs (950 million U.S. dollars) \\
\hline Number of students (2016) & 10,343 \\
\hline Number of undergraduates (2016) & 5418 (52\% of total students) \\
\hline Number of postgraduate students (2016) & 4925 (48\% of total students) \\
\hline Number of teaching staff members & 874 \\
\hline Number of participating professors & $(27 \%$ of the total) \\
\hline Number of assistant professors & $(14 \%$ of the total) \\
\hline Members of the academic council (2016) & 3971 \\
\hline Number of administrative staff & 1195 \\
\hline Number of start-ups & 115
\end{tabular}

This institute is located alongside Lake Geneva and at the foot of the Alps. It is one of two Swiss federal institutes of technology, including more than 350 laboratories and research centers in the main campus. The institute also includes a massive computer used by several research groups. Among the projects carried out, there is the human mind simulation project, called Blue Brain Project. This project aims to provide neuroscientists with a better understanding of neurological diseases. The student-academic staff ratio is about 10:1, and the budget allocated for the institute is up to 950 million Swiss francs [64].

The institute has an innovation park, where laboratories, offices, and researchers from more than 150 companies and start-ups such as Nestlé, Siemens, and others are hosted. The start-ups associated with the innovation park have raised their budget to around 400 million Swiss francs in 2016, with an increase of $50 \%$ of 2014 total budget. Companies listed in 2016 include Mindmaze, a healthcare company, that develops virtual reality rehabilitation programs, with a budget of more than 100 million Swiss francs, i.e., the largest single amount reached by an unlisted company on campus. Another start-up, AC Immune, which develops a vaccine against Alzheimer's, has raised its budget to 42.7 million Swiss francs.

The institute has the Vice President Innovation (VPI) agency, which mainly links between the institute and business world, and encourages entrepreneurship and building start-ups. Industry helps develop partnerships with the Institute and fosters innovation and research. In 2017, the Institute initiated 15 start-ups, in addition to 115 companies in the Innovation Park. Such start-ups have raised their budgets to 112 million Swiss francs.

Table 6.12 displays some key statistical figures that illustrate the quality of research and innovation [64-66].

Figure 6.24 shows patent applications submitted by the Swiss Federal Institute of Technology in Lausanne in different fields, while Fig. 6.25 shows the percentage of accepted patent applications. 
Fig. 6.24 Patents applications submitted by Swiss Federal Institute of Technology in Lausanne

Fig. 6.25 Percentage of accepted patent applications of Swiss Federal Institute of Technology in Lausanne
12. EPFL - Swiss Federal Institute of Technology Lausanne, Switzerland

\section{TOTAL PATENTS FILED}

(213)

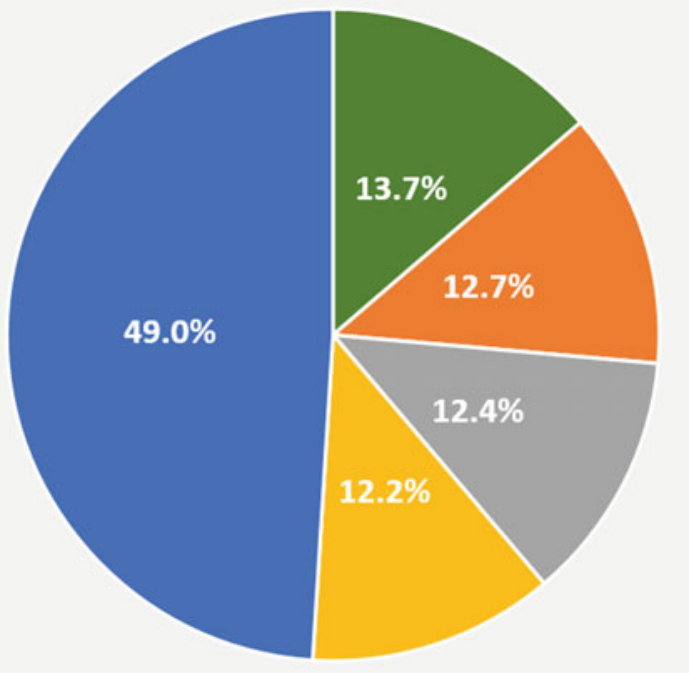

- Medical Devices \& Healthcare

- Pharmaceuticals \& Biotech

n Chemicals

= Semiconductor \& Electrical Components

- Other

\section{EPFL - Swiss Federal Institute of Technology Lausanne, Switzerland}

\section{PATENTS GRANTED}

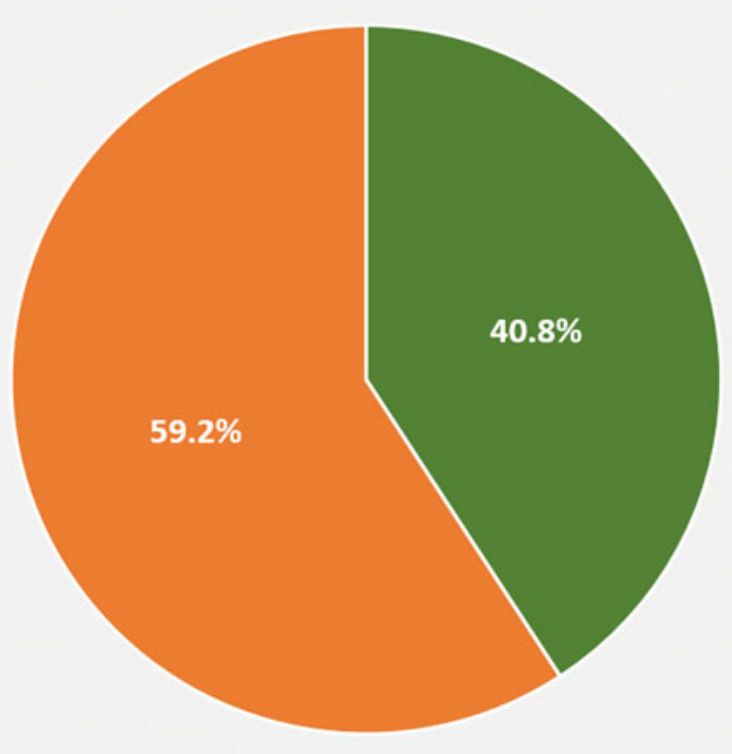

- Granted

not Granted 


\subsection{Pohang University of Science and Technology-South Korea}

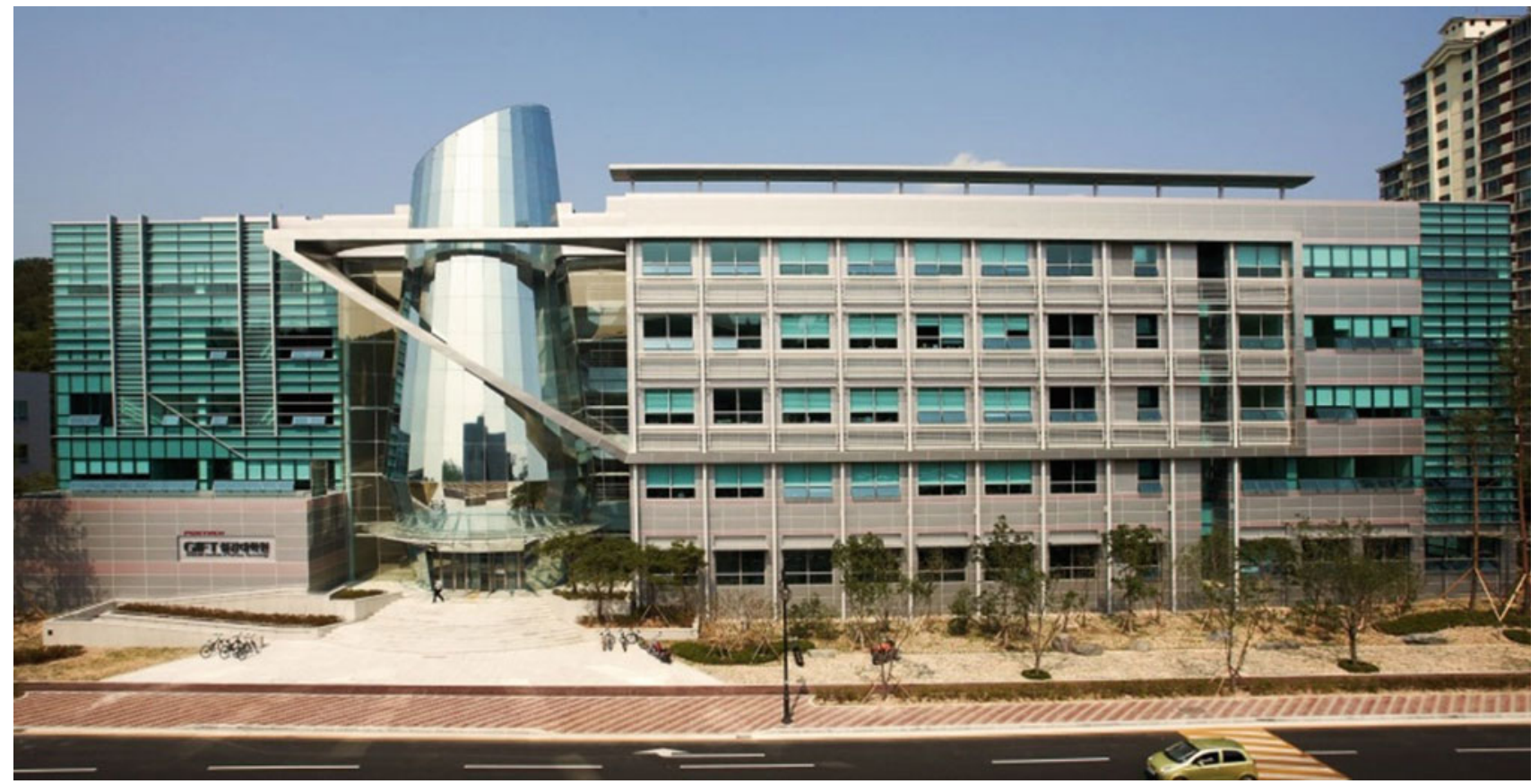

Table 6.13 Some key statistical figures of Pohang University of

\begin{tabular}{l|l}
\hline The amount of scholarships and research contract (2016) & $\$ 155$ million \\
\hline $\begin{array}{l}\text { The presented patents (2016) } \\
\text { The registered patents (2016) }\end{array}$ & 479 \\
\hline $\begin{array}{l}\text { Number of undergraduates (2016) } \\
\text { Number of postgraduate students (2016) }\end{array}$ & 372 \\
\hline $\begin{array}{l}\text { Number of teaching staff members } \\
\text { Members of the academic council }\end{array}$ & 21449 (40\% of total students) \\
\hline
\end{tabular}
Science and Technology (POSTECH)

Pohang University of Science and Technology (POSTECH) was established in 1986 as a private research university closely related to the industry. Its 400 -acre campus is just a few minutes away from the South Korean steel-making company headquarters POSCO). Its revenues from the scholarships and research contracts exceeded $\$ 155$ million in fiscal year (FY) 2016, accounted for $46 \%$ of the overall budget of the university. It is a high percentage leading to excellence in research and inventions.

The number of students in Pohang University is 3588, the number of teaching staff members is 303 (student-teacher ratio is 10:1), and the university has four departments of science and seven departments of engineering, i.e., only 11 scientific departments. The university has 72 research units, including an institute for $\mathrm{CO}_{2}$ reduction, a robotics lab and a machine learning center. The university also has a radiation accelerator laboratory, the only one in South Korea [67].

In 2016, the university developed X-Ray Free-Electron Laser (XFEL) instrument, an instrument that will allow scientists to observe the material at the nanoscale level and track the movements at ten trillionths of a second. This instrument is the third one of its kind in the world. Modern innovations include the development of an economical and environment friendly way of creating waterproof surfaces, namely through coating surfaces with salt granules (particles) being commercially available.

Important facts leading to distinctiveness in innovation include the fact that postgraduate students reached (2139) in $2016 \mathrm{G}$, exceeding the number of undergraduate students of (1449) and accounting for $60 \%$ of the total number of students. With respect to researchers, their number reached 630 researchers, i.e., double the number of teaching staff members of 303 .

Table 6.13 displays some key statistical figures that illustrate the quality of research and innovation [67-68].

Figure 6.26 shows the patent applications submitted by POSTECH in different fields, while Fig. 6.27 shows the percentage of accepted patent applications. 
Fig. 6.26 Patent applications submitted by Pohang University of Science and Technology (POSTECH)

\section{Pohang University of Science \& Technology (POSTECH), South Korea}

\section{TOTAL PATENTS FILED}

(372)

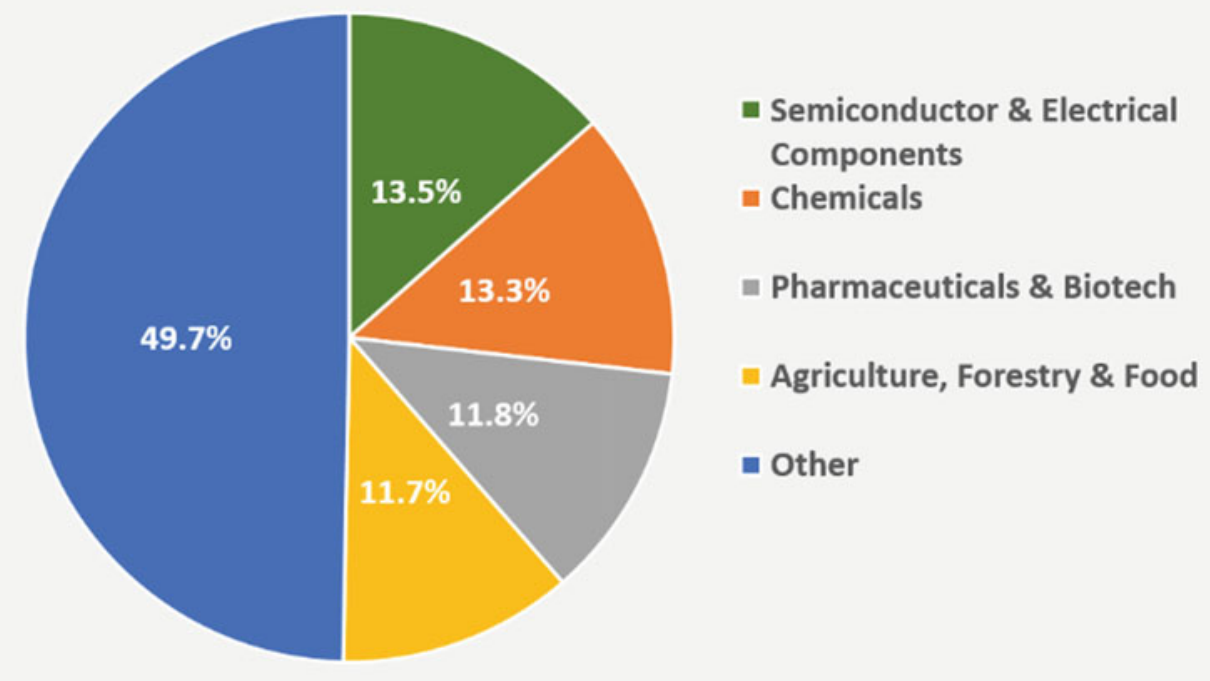

Fig. 6.27 Percentage of accepted patent applications of Pohang University of Science and Technology (POSTECH)
13. Pohang University of Science \& Technology (POSTECH), South Korea

\section{PATENTS GRANTED}

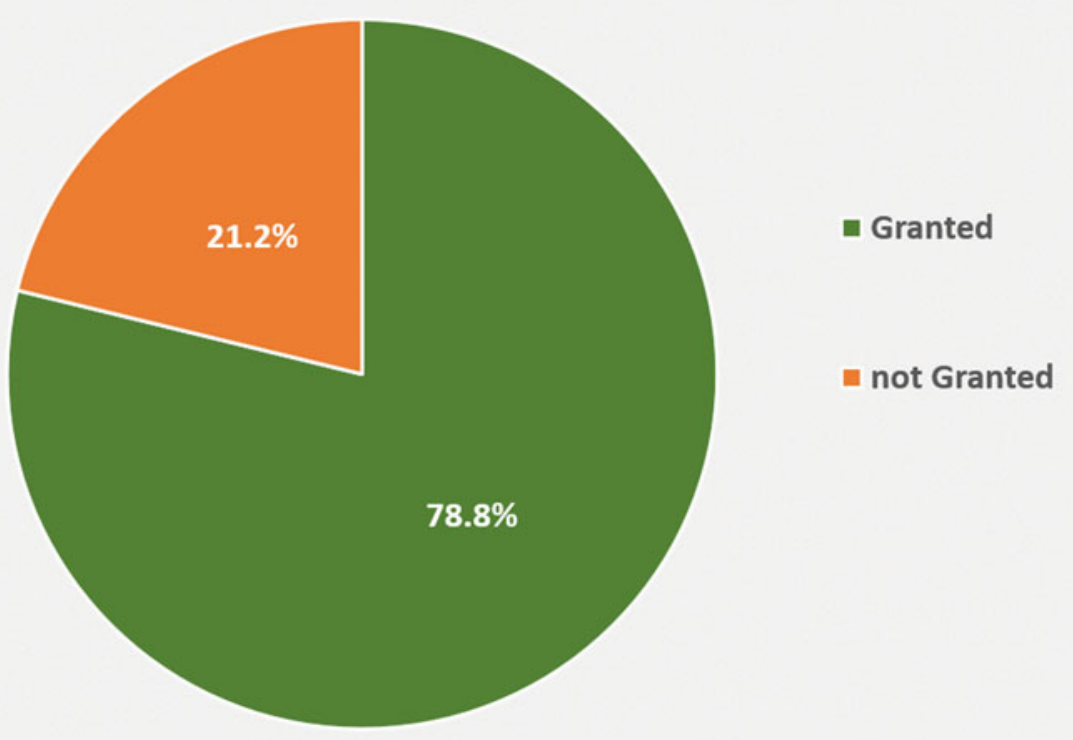




\subsection{University of California System-USA}

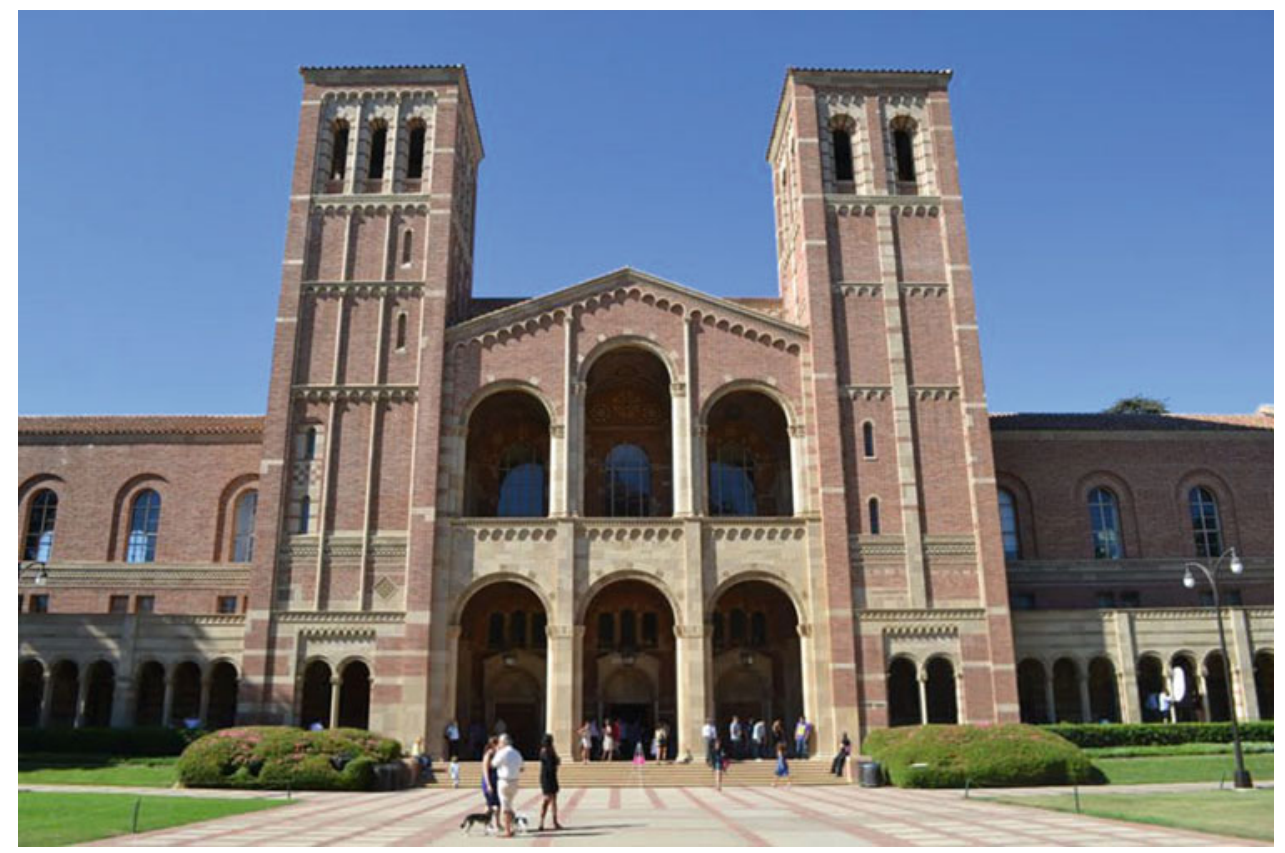

In 1869, University of California, a state public university located in California, started with only 10 teaching staff members and 38 students. Today, it includes 10 campuses (located in Berkeley, Davis, Irvine, Los Angeles, Merced, Riverside, San Diego, San Francisco, Santa Barbara, and Santa Cruz) and serves more than 273,000 students, including 56,432 postgraduate students. The university employs more than 22,000 teaching staff members, with a total of $1,700,000$ graduates who live and work around the world. The university system operates five medical centers, and since 1943, it has been involved in managing three national laboratories (Lawrence Berkeley, Lawrence Livermore, and Los Alamos) for the US Department of Energy [69].

University of California is ranked the first in terms of the total number of patent applications submitted in 2015. The ten affiliated universities produce five new inventions on average per day. The university has received more than $\$ 4.97$ million to fund research conducted this year.

Recently, California researchers in Los Angeles have discovered a new way to activate stem cells in hair follicles to help hair grow. This discovery can lead to new medications that promote hair growth for people with alopecia or hair loss.

In July 2015, Defense Advanced Research Projects Agency (DARPA) provided \$21.6 million to scientist in California Berkeley to develop a "brain modem" that can directly stimulate thousands of neurons using expected light. This research could lead to devices that replace damaged eye by concentrating light and directly addressing the visible cerebral cortex.

Additionally, the university has more than 160 academic specializations, 600 postgraduate programs, 61 Nobel laureates, and 20,000 courses. This has contributed with $\$ 46.3$ billion to California's economy. Until February 2011, 1029 start-ups have been established and 12,450 patents have been activated. The operating of 2017/2018 is approximately $\$ 34.5$ billion.

Table 6.14 displays some key statistical figures that illustrate the quality of research and innovation [69-71].

Figure 6.28 shows the patent applications submitted by the University of California System in different fields, while Fig. 6.29 shows the percentage of accepted patent applications.
Table 6.14 Some key statistical figures of University of California System

\begin{tabular}{l|l}
\hline Number of Nobel laureates among professors and graduates & 61 \\
\hline Number MacArthur Genius' Grant Winners among professors and graduates & 90 \\
\hline Number of National Medal among professors and graduates & 67 \\
\hline Number of university campuses & 10 \\
\hline Contractual Research Scholarships of Federal Government (2017) & $\$ 6500$ billion \\
\hline University budget (2017/2018) & $\$ 34.5$ billion \\
\hline Returns of university activities & $\$ 46.3$ billion \\
\hline Number of patents (2017) & 1803 \\
\hline Number of undergraduates (2016) & 216,568 \\
\hline & (continued)
\end{tabular}


Table 6.14 (continued)

\begin{tabular}{l|l}
\hline Number of postgraduate students (2016) & 56,432 \\
\hline Teaching staff & 22,700 \\
\hline Members of the academic council & 45,700 \\
\hline Number of administrative staff & 54,900
\end{tabular}

Fig. 6.28 Patent applications submitted by University of California System

\section{University of California System, USA}

TOTAL PATENTS FILED

(2533)

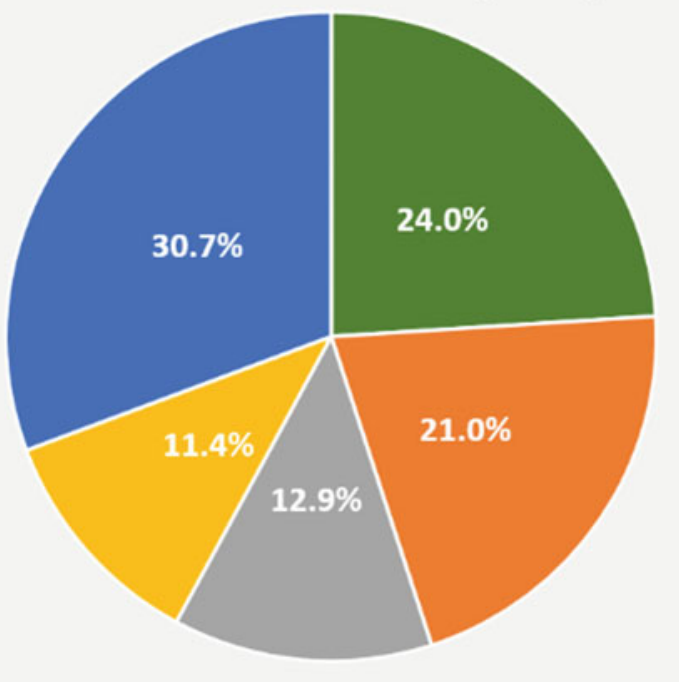

- Pharmaceuticals \& Biotech

- Agriculture, Forestry \& Food

Chemicals

- Medical Devices \& Healthcare

a Other
Fig. 6.29 Percentage of accepted patent applications submitted by University of California System

\section{University of California System, USA}

\section{PATENTS GRANTED}

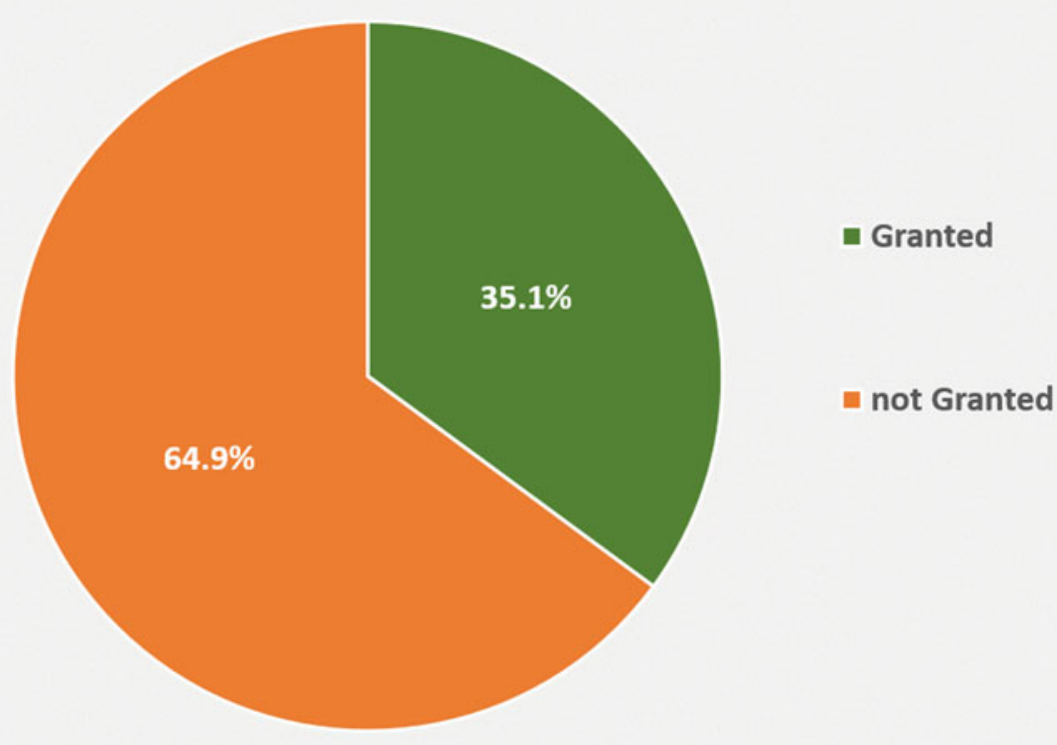




\subsection{University of Southern California_USA}

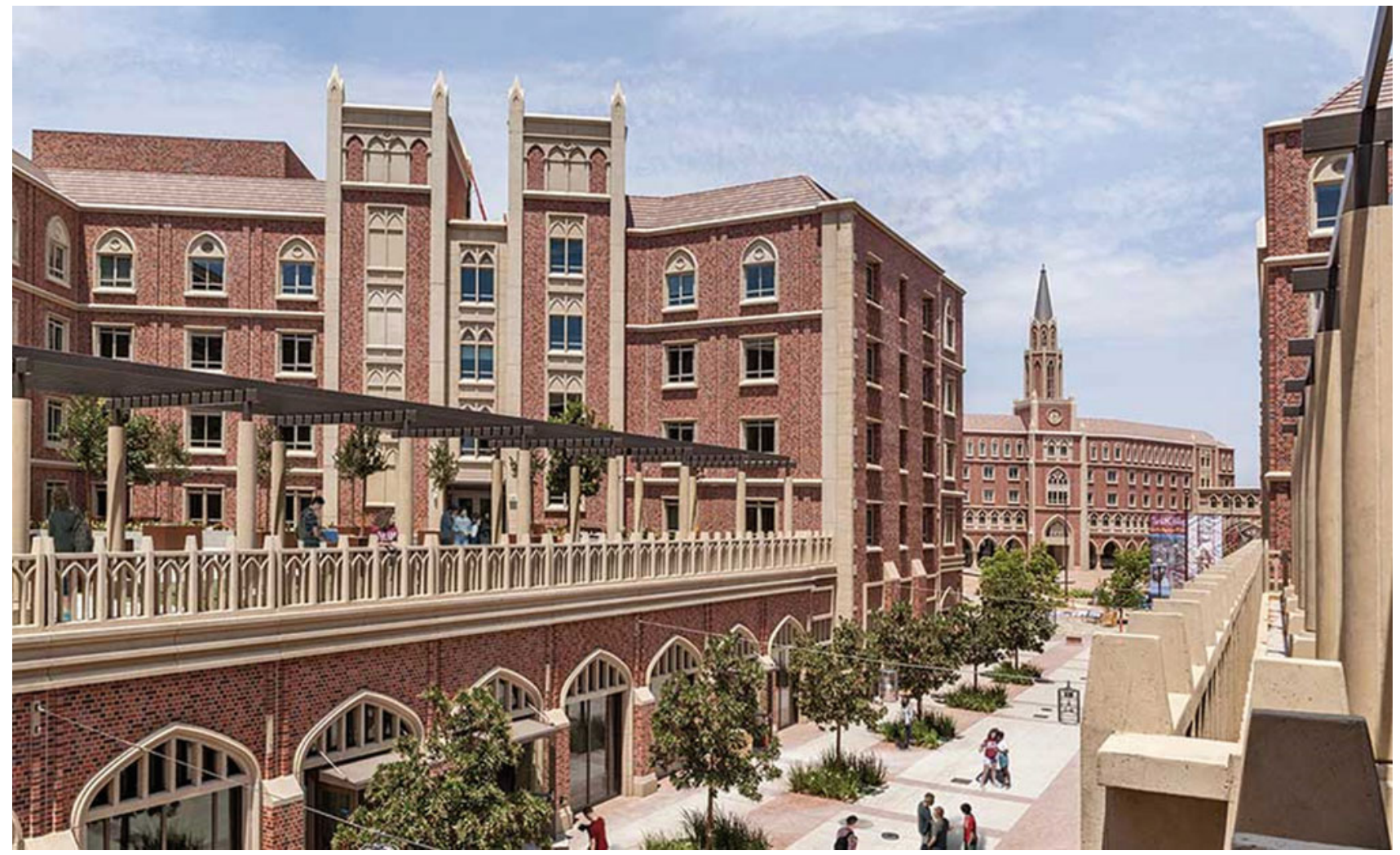

A private research university located in Los Angeles, University of Southern California, maintains strong relations with Hollywood and boasts great experience in digital entertainment. It also has the largest research program in computer science compared to all American universities, as well as the largest engineering and health programs compared to private universities. The University Institute of Innovative Technologies teaches how people interact with technology through virtual characters and simulations. The university also includes the Digital Arts Center, the only center in the USA specializing in digital filmmaking. The student- academic staff ratio is 10:1 and the percentage of accepted compared to applicant students in 2017 is 16\% [72].

In a study of lifestyle and health history of more than 185,000 people, researchers from Keck School of Medicine of the University of Southern California have found that coffee drinkers live longer, finding that drinking coffee is associated with a lower risk of dying from heart disease, cancer, stroke, and diabetes, respiratory and kidney diseases.

Stevens Center for Innovation, the University's Technology Transfer Center, has initiated a number of start-ups in
Table 6.15 Some key statistical figures of the University of Southern California

\begin{tabular}{l|l}
\hline Endowments (2017) & $\$ 5.1$ billion \\
\hline University budget (2017) & $\$ 4.9$ billion \\
\hline $\begin{array}{l}\text { Research support budget (2017) } \\
\text { Returns of university activities }\end{array}$ & $\$ 0.76$ billion \\
\hline Campus area & $\$ 8.0$ billion \\
\hline Number of students (2017) & 308 acres $\left(1.25 \mathrm{~km}^{2}\right)$ \\
\hline Percentage of students admitted to the university (2017) & 45,871 \\
\hline $\begin{array}{l}\text { Number of undergraduate students (2016) } \\
\text { Number of postgraduate students (2016) }\end{array}$ & $16 \%$ of applicants \\
\hline Members of the academic council & $19,371(42 \%$ of total students) \\
\hline & $26,500(58 \%$ of total students) \\
\hline
\end{tabular}


the entertainment industry. The university budget for 2017/2018 increased around $\$ 4.9$ billion, including $\$ 764$ million for research support. Endowment funds reached $\$ 5.1$ billion at the end of June 2017, while the returns of university activities amounted to $\$ 8$ billion.
Table 6.15 displays some key statistical figures that illustrate the quality of research and innovation [72-74].

Figure 6.30 shows the patent applications submitted by the University of Southern California in different fields, while Fig. 6.31 shows the percentage of accepted patent applications.
Fig. 6.30 Patent applications submitted by the University of Southern California

\section{University of Southern California, USA}

\section{(294)}

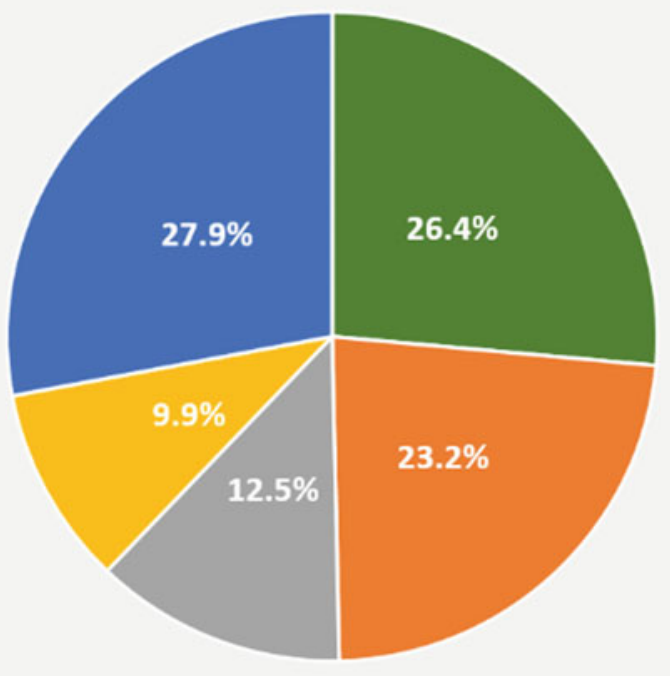

- Pharmaceuticals \& Biotech

- Agriculture, Forestry \& Food

- Chemicals

- Medical Devices \& Healthcare

n Other
Fig. 6.31 Percentage of accepted patent applications submitted by the University of Southern California

\section{University of Southern California, USA}

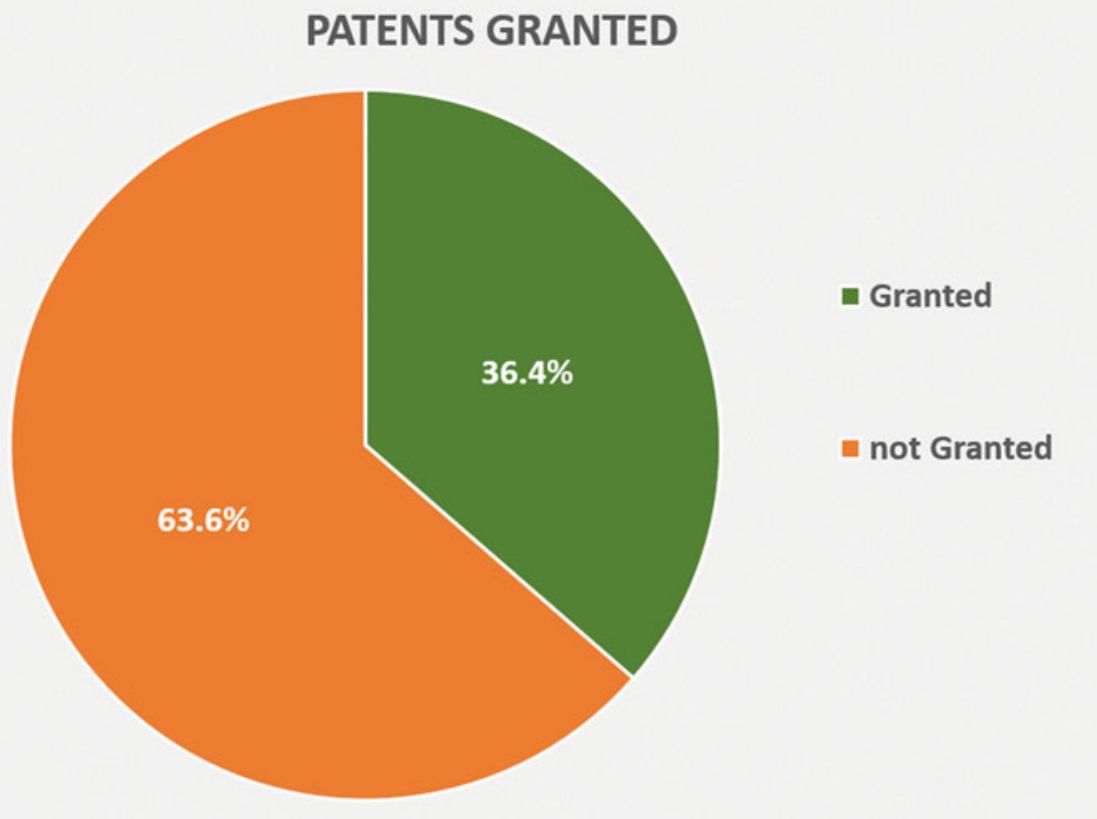




\subsection{Cornell University-USA}

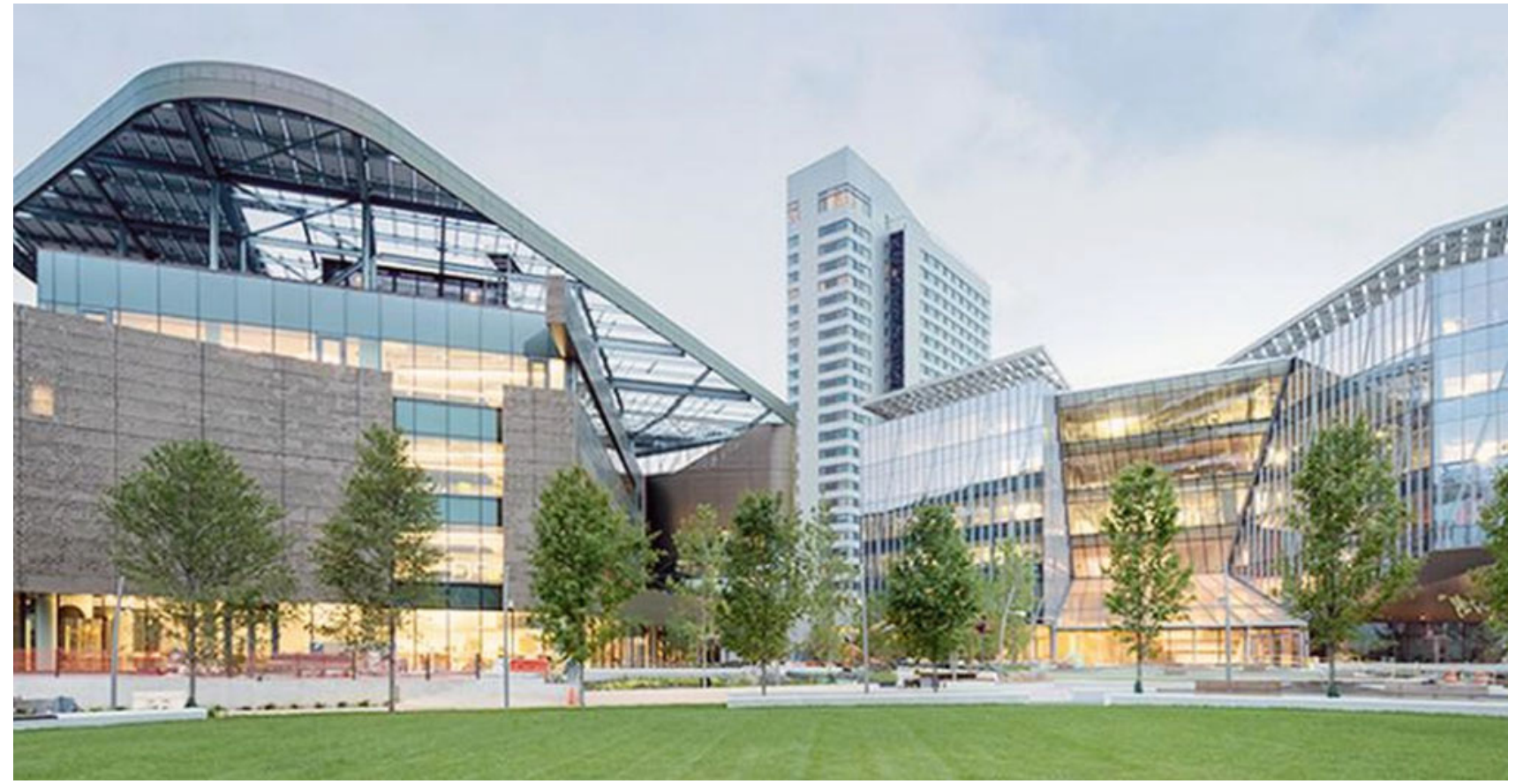

Cornell University was founded in 1865 , a private university with three university locations (Ithaca, New York and Doha, Qatar). The Ithaca campus has seven undergraduate colleges and four postgraduate specialized colleges, and the New York campus has two postgraduate medical schools. The number of students in the university is 22,319, of whom 5605 are in postgraduate studies. The academic staffto-student ratio is estimated to be a member to about eight students (at the postgraduate and undergraduate levels), which helps the university to excel in scientific research and thus innovation [75].

In 2017, Cornell researchers used a high-energy X-ray scanner (called Cornell High Energy Synchrotron Source,
CHESS) to study and improve welding techniques for construction and engineering for Caterpillar Inc., in order to reduce harmful stresses on the materials resulting from the welding process. Researchers at the university have created a new cost-competitive process that uses polymer-coated nanofibers to clean contaminants from wastewater. Nanofibers form a surface for holding and spreading beneficial bacteria, eliminating contaminants.

Table 6.16 displays some key statistical figures that illustrate the quality of research and innovation [75-77].

Figure 6.32 shows patent applications submitted by Cornell University in different fields, while Fig. 6.33 shows the percentage of accepted patent applications.
Table 6.16 Some key statistical figures for Cornell University

\begin{tabular}{l|l}
\hline $\begin{array}{l}\text { Number of Nobel laureates among professors and graduates } \\
\text { Number of Crafoord Prize laureates (Crafoord Prize) among professors or } \\
\text { alumni }\end{array}$ & 3 \\
\hline Number of professors or graduates who are Fields Medal winners & 1 \\
\hline Endowments (2017) & $\$ 6.8$ billion \\
\hline Number of university campuses & 3 \\
\hline Average number of students admitted to the university annually & $14.1 \%$ of applicants \\
\hline Number of undergraduate students (2016) & $\begin{array}{l}16,714 \text { (77\% of total } \\
\text { students) }\end{array}$ \\
\hline Number of postgraduate students (2016) & $\begin{array}{l}5605(23 \% \text { of total } \\
\text { students) }\end{array}$ \\
\hline Number of teaching staff members & 2908 \\
\hline Number of academic staff & 2504 \\
\hline Number of administrative staff & 8253 \\
\hline
\end{tabular}


Fig. 6.32 Patents submitted by Cornell University

Fig. 6.33 Percentage of patents accepted for Cornell University

\section{Cornell University, USA}

TOTAL PATENTS FILED

(294)

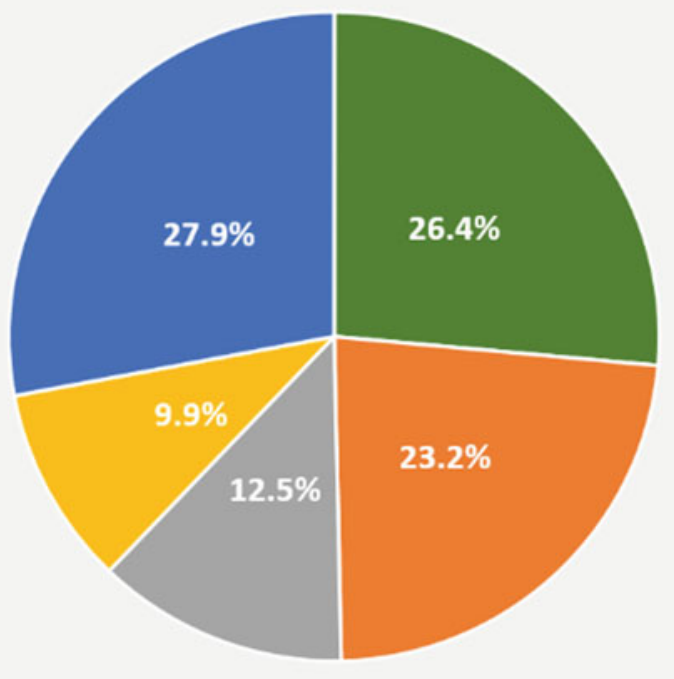

- Pharmaceuticals \& Biotech

n Agriculture, Forestry \& Food

n Chemicals

- Medical Devices \& Healthcare

- Other

\section{Cornell University, USA}

\section{PATENTS GRANTED}

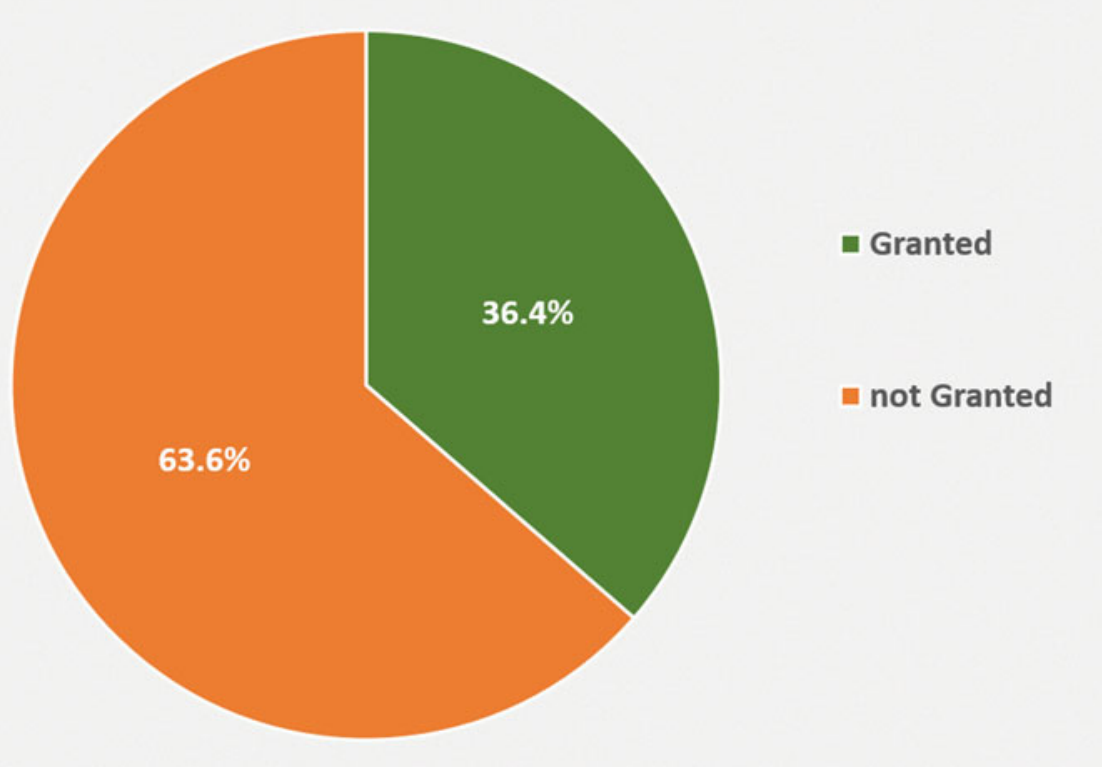




\subsection{Duke University-USA}

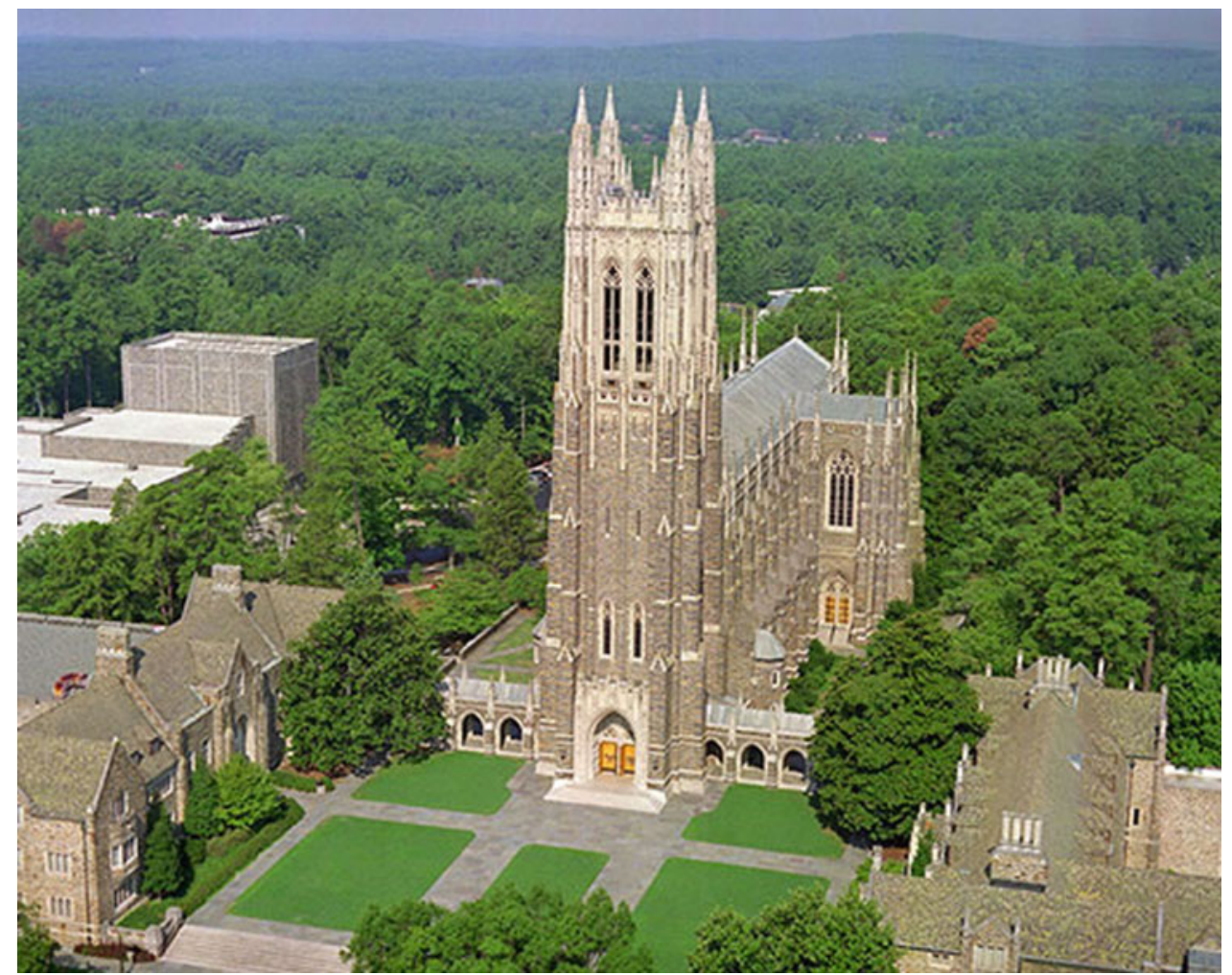

Duke University, the oldest American university, is located in the city of Durham in the state of North Carolina. It was founded by John Harvard in 1838 to be a counterpart to the British Universities of Cambridge and Oxford. It is a private research university that seeks, through the Innovation and Entrepreneurship Initiative, to conduct university research that results in actual, tangible products [78].

The University has many important centers and institutes, such as the marine science laboratory (Duke Marine), the cancer institute (Duke Cancer), and human vaccine institute (Duke Human Vaccine). Duke University played an important role in the creation of the most important social innovation of the twenty-first century. Its graduate, Soleio Cuervo, who graduated in 2003, created the famous "Like" feature, when he worked as a designer on social media site, Facebook.

The number of students at the university is 15,192 , and the number of academic staff is 5022, which means that the student-to-teaching staff ratio is $3: 1$, making the interaction between students and the teaching staff very significant, and this is one of the important factors in the development of the spirit of innovation among students. In addition to that, the student admission rate did not exceed $9 \%$ of applicants in 2016, which means choosing the most outstanding students among those who have met the university's application requirements.

Researchers at Duke University have recently received a $\$ 7$ million grant from The Bill and Melinda Gates Foundation, based on two previous grants totaling $\$ 10.7$ million, to finance the "Reinvent the Toilet" project, which aims at developing a neutral, non-networked sewer system, as nearly $40 \%$ of the world's population suffer from the lack of proper sanitation facilities. As a result, approximately 525.000 children under the age of five die each year from diarrhea diseases, according to the World Health Organization. The university researchers will use the new financial support to test models of their system in India and South Africa.

Table 6.17 displays some key statistical figures that illustrate the quality of research and innovation [78-80].

Figure 6.34 shows patent applications submitted by Duke University in different fields, while Fig. 6.35 shows the percentage of accepted patent applications. 
Table 6.17 Some key statistical figures for Duke University

\begin{tabular}{l|l}
\hline Number of Nobel laureates among professors and graduates & 11 \\
\hline Number of professors or graduates who are Turing Prize winners & 3 \\
\hline Endowments (2017) & $\$ 7.9$ billion \\
\hline University budget (2017) & $\$ 2.3$ billion \\
\hline Number of applicants for university (2017) & 33,110 \\
\hline Number of students admitted to university (2017) & $1744(5.3 \%$ of applicants) \\
\hline Number of undergraduate students (2016) & 6532 (43\% of total students) \\
\hline Number of postgraduate students (2016) & 8660 (57\% of total students) \\
\hline Number of professors & $988(59 \%$ of all) \\
\hline Number of participating professors & $454(27 \%$ of all) \\
\hline Number of assistant professors & $288(14 \%$ of all) \\
\hline Members of the academic council & 5022 \\
\hline Number of administrative staff & 8435 \\
\hline
\end{tabular}

\section{Duke University, USA}

\section{Duke University}

Fig. 6.34 Patents submitted by

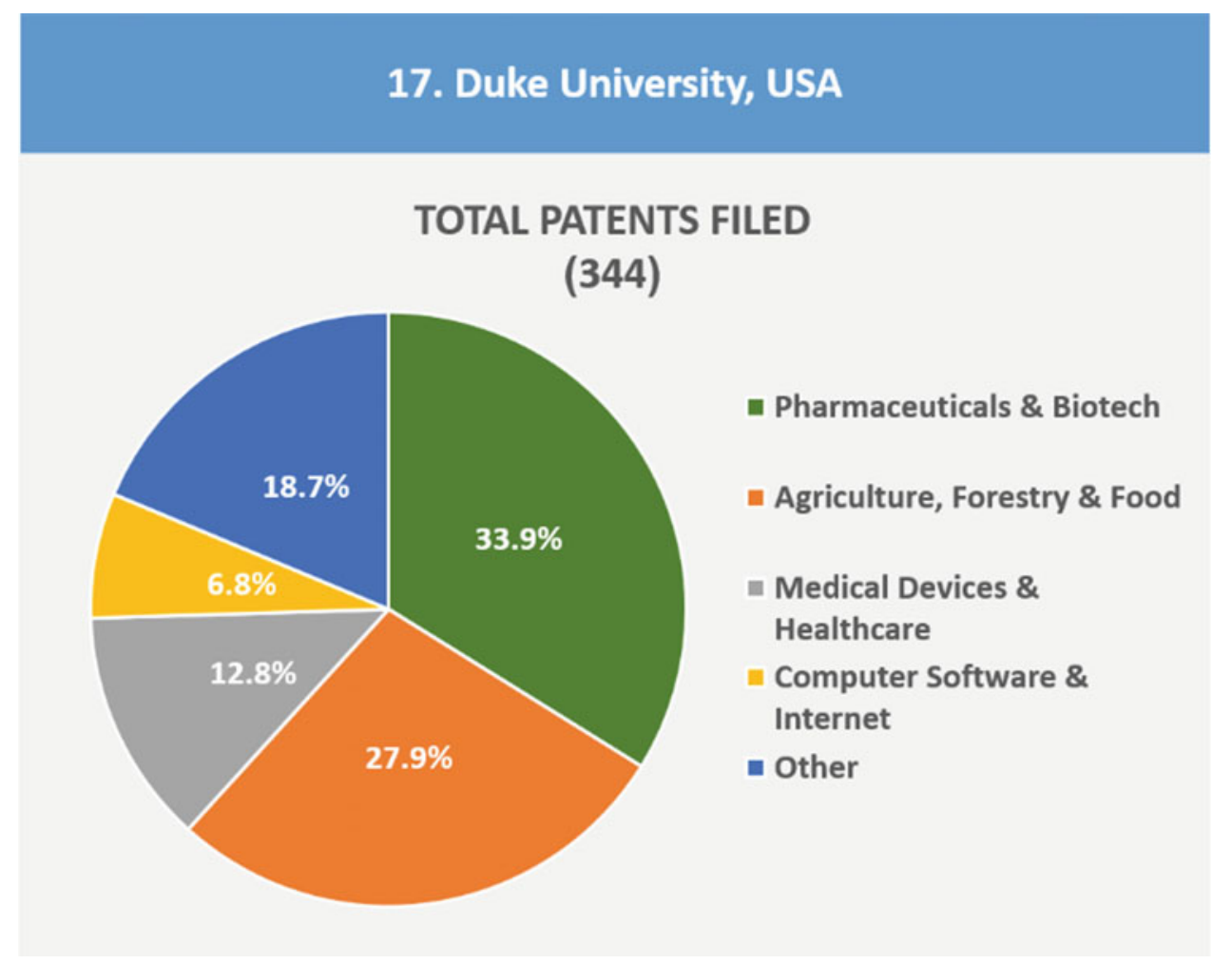


Fig. 6.35 Percentage of patents accepted for Duke University

\section{Duke University, USA}

PATENTS GRANTED

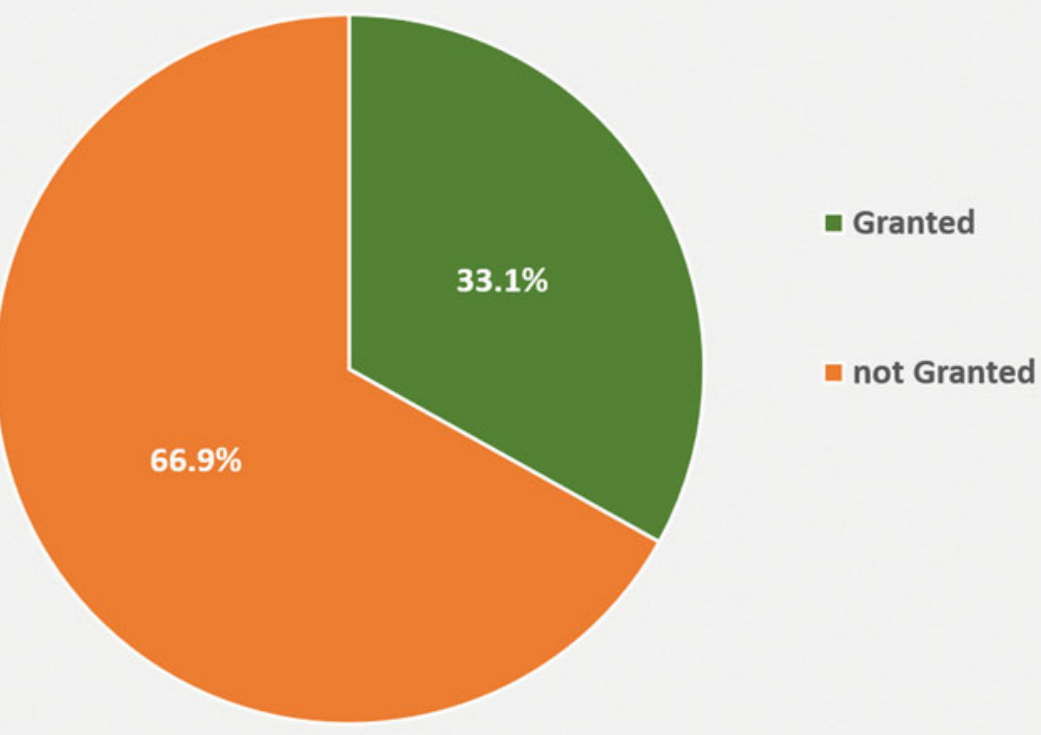

\subsection{University of Cambridge_-United Kingdom}

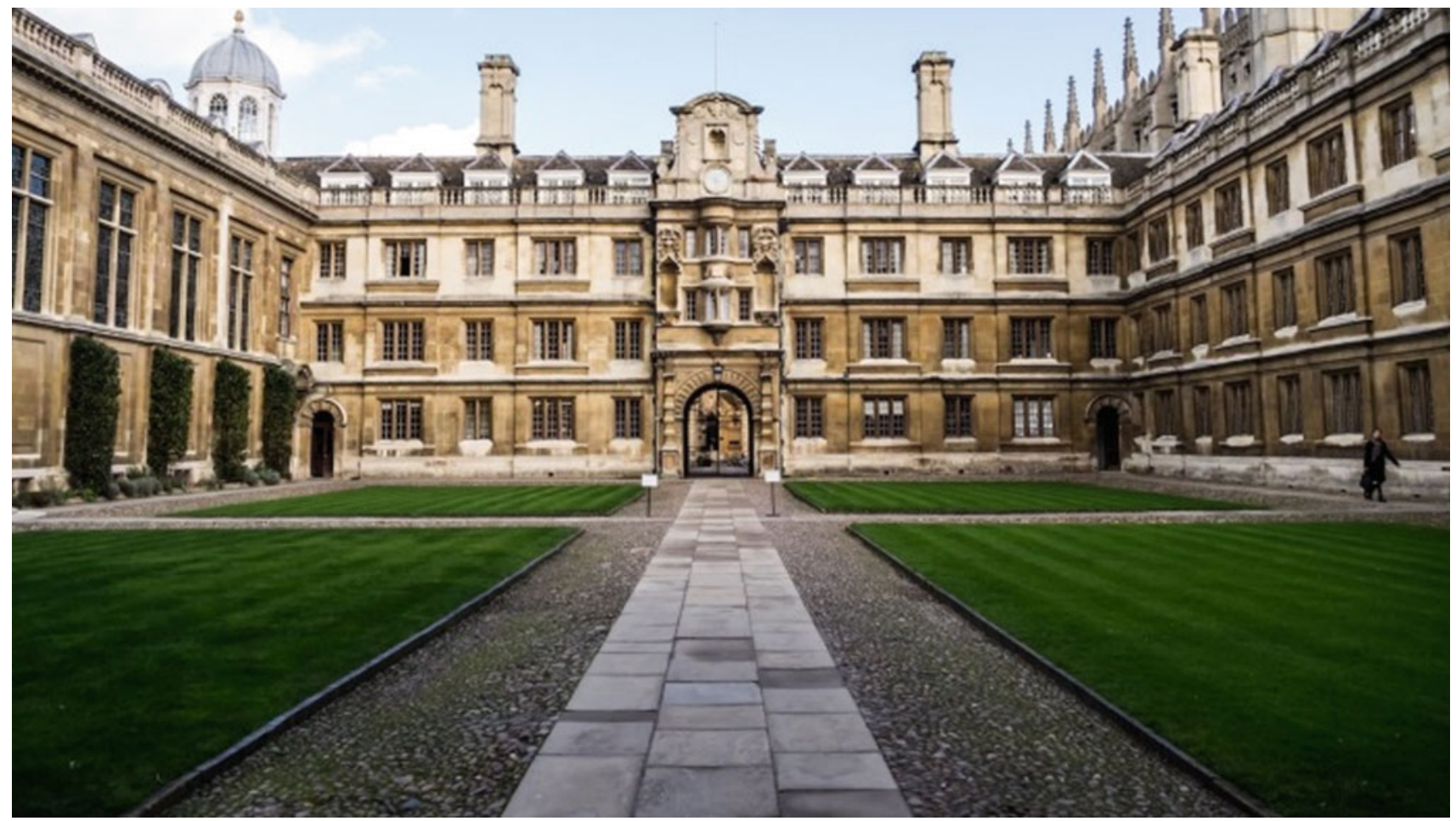


University of Cambridge was founded in 1209 , and it is the second oldest university in the English-speaking world after University of Oxford. The university is located in the city of Cambridge, UK. It ranked first in the World University Rankings according to the QS ranking in 2010, surpassing Harvard University in the USA that year. It is a member of the Russell Group and a member of the League of European Research Universities. Its ranking is always between the first and second places alternating with the prestigious University of Oxford. It is considered the oldest university in the world in the fields of natural sciences, mathematics, and physics [81].

The university scientists received 89 Nobel Prizes, making it surpass any other university in the world. Among its graduates are the electron discoverer, as well as the discoverer of the structure of DNA, and one of its most famous scientists is Isaac Newton. In February 2019, researchers at the university designed an automated learning device to discover drug, which proved to be doubly efficient compared to the device currently used in the industry. This could speed up the development of new treatments for diseases [82].

Cambridge researchers are working on solving one of the biggest mysteries of technology, that is, how to build next-generation batteries that can ignite a green revolution [83].

The university received research grants at the end of 2016 worth $£ 462$ million. The university has strategic relationships with giant companies around the world, such as Boeing Company, which has supported many research projects in aviation and manufacturing technology fields.

Table 6.18 displays some key statistical figures that illustrate the quality of research and innovation [81-84].

Figure 6.36 shows patent applications submitted by the University of Cambridge in different fields, while Fig. 6.37 shows the percentage of accepted patent applications.
Table 6.18 Some key statistical figures for the University of Cambridge

Fig. 6.36 Patents submitted by the University of Cambridge

\begin{tabular}{|l|l|}
\hline Number of Nobel laureates among professors and graduates & 89 \\
\hline University budget & $£ 1.7$ billion \\
\hline Endowments in 2017 & $£ 4.9$ billion \\
\hline Campus area & 288 ha \\
\hline Number of undergraduate students (2016) & 12,340 \\
\hline Number of postgraduate students (2016) & 7615 \\
\hline Teaching staff & 1646 \\
\hline Number of administrative staff & 3615 \\
\hline
\end{tabular}

\section{University of Cambridge, UK}

TOTAL PATENTS FILED

(224)

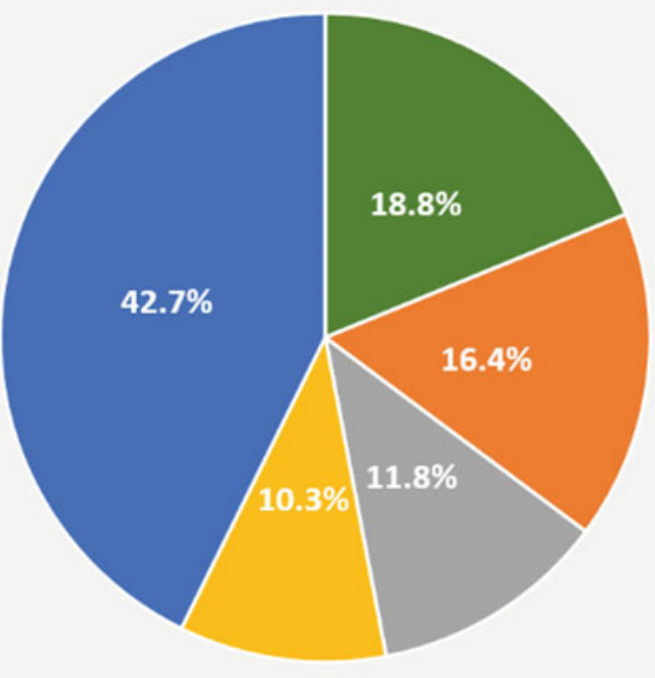

Pharmaceuticals \& Biotech

- Agriculture, Forestry \& Food

n Chemicals

Engineering, Manufacturing \& Mining

- Other 
Fig. 6.37 Percentage of patents accepted for the University of Cambridge
18. University of Cambridge, UK

\section{PATENTS GRANTED}

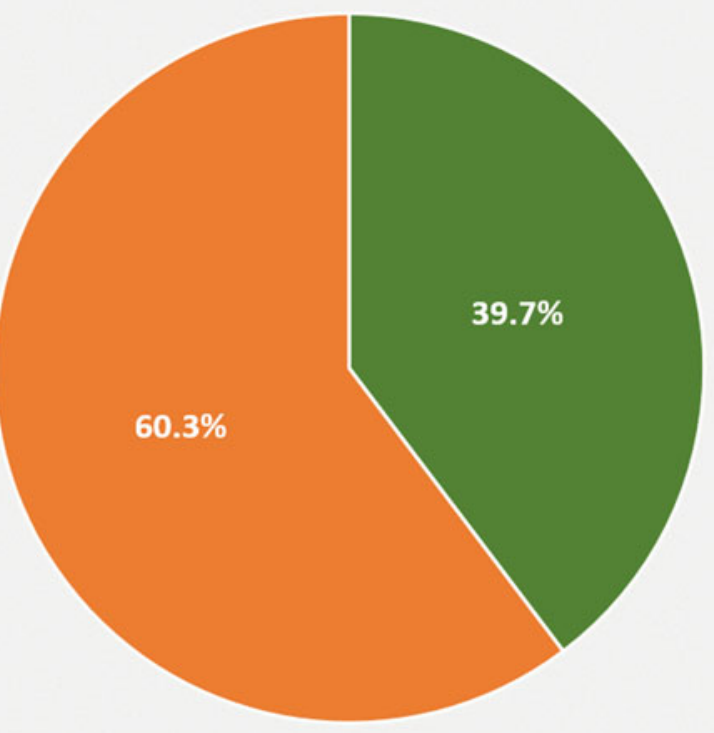

- Granted

not Granted

\subsection{Johns Hopkins University_USA}

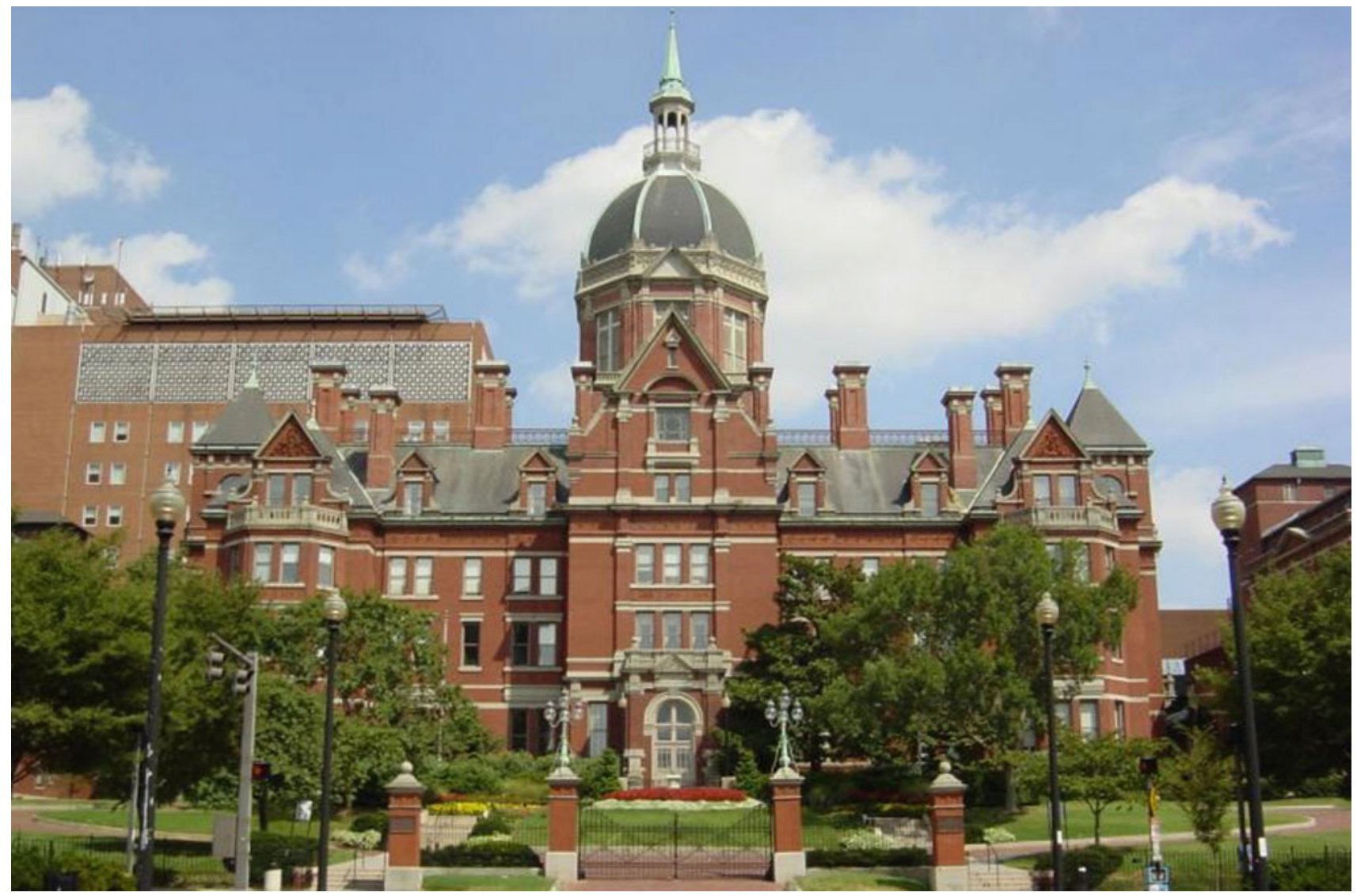


Johns Hopkins University was founded in 1876 ; it is a private research university, named after the man who donated $\$ 7$ million at the time (which is worth about $\$ 145$ million today) [85].

Revenue from patents used in 2018 amounted to US $\$ 17$ million. The university focuses on discoveries and patents in medical fields. In 2018 alone, 150 patents were registered and 8 start-ups were established; the start-ups raised the total venture capital by more than $\$ 451$ million.

The university has achieved great success in bringing corporate finance to its laboratories to benefit these companies from their areas of excellence and provide avenues for research that can have a significant impact on society, especially on human health. Examples of cooperation between the university and giant companies include as follows: A collaboration agreement was signed with AbbVie Company in oncology research in 2016, resulting in six successful projects regarding tumors, with continued cooperation in neuroscience the following year. There is also the collaboration with Bayer Company in four joint research projects at the Wilmer Eye Institute, as well as work in pharmaceutical explorations at JHDD to develop treatments for retinal diseases.

Table 6.19 displays some key statistical figures that illustrate the quality of research and innovation [85-87].

Figure 6.38 shows patent applications submitted by Johns Hopkins University in different fields, while Fig. 6.39 shows the percentage of accepted patents.
Table 6.19 Some key statistical figures for Johns Hopkins University

Fig. 6.38 Patents submitted by Johns Hopkins University

\begin{tabular}{l|l}
\hline Number of Nobel laureates among professors and graduates & 27 \\
\hline Endowments value & Endowments value \\
\hline Number of students (2016) & 26,402 \\
\hline Number of undergraduates (2016) & 5615 \\
\hline Number of postgraduate students & 20,787 \\
\hline Student-to-teaching staff ratio & $7: 1$ \\
\hline
\end{tabular}

\section{Johns Hopkins University, USA}

TOTAL PATENTS FILED (906)

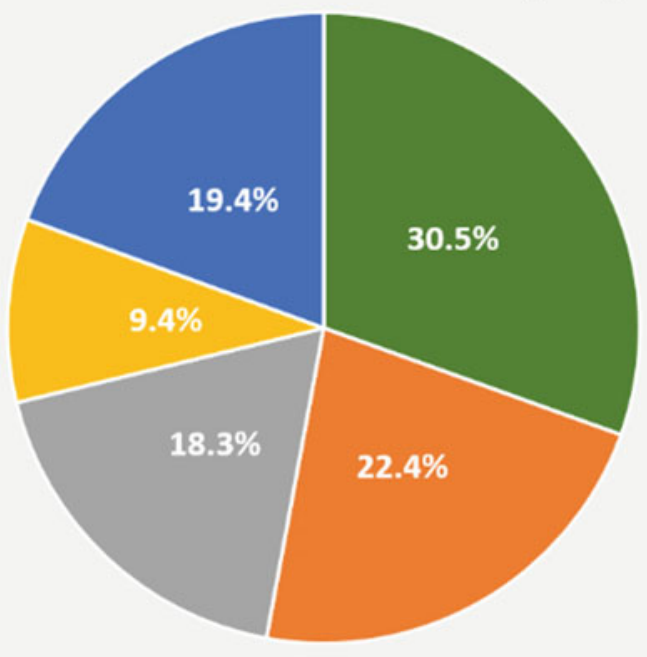

- Pharmaceuticals \& Biotech

- Agriculture, Forestry \& Food

nedical Devices \& Healthcare

= Computer Software \& Internet

a Other 
Fig. 6.39 Percentage of patents accepted for Johns Hopkins University

\section{Johns Hopkins University, USA}

\subsection{University of Tokyo-Japan}

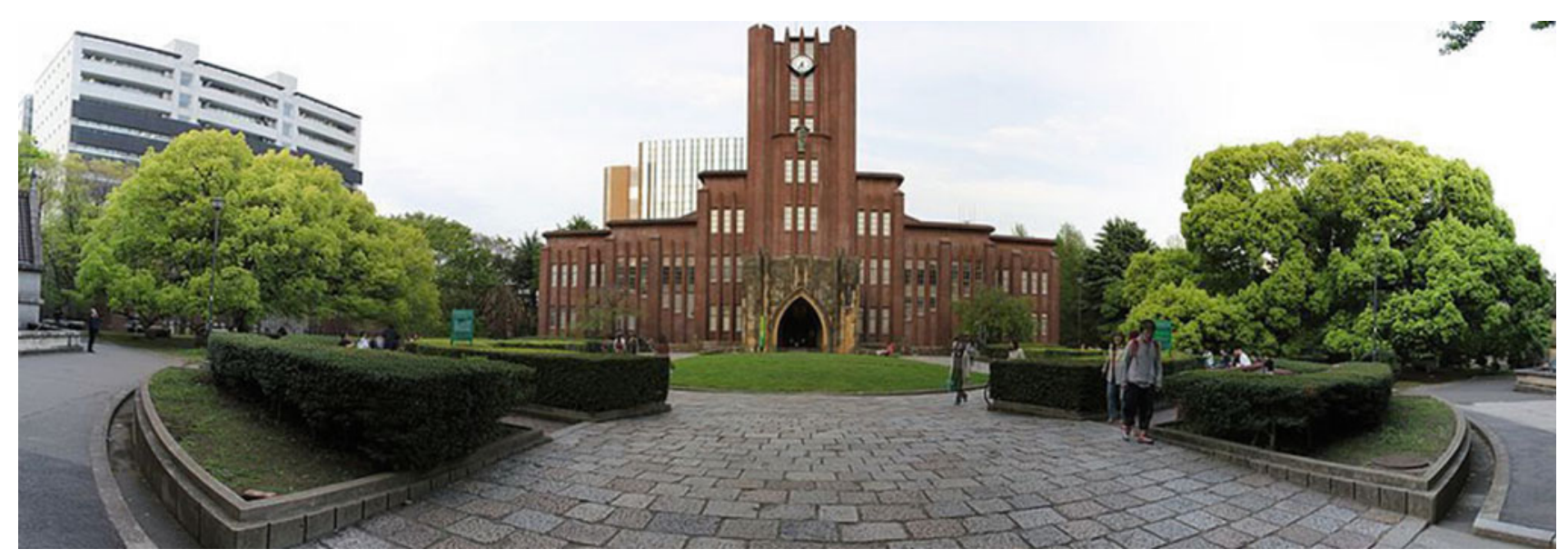

University of Tokyo was founded in 1877 as the first national university in Japan. It consists of three main campuses, as well as 14 university centers and 11 affiliated research institutes, including the Institute for Cosmic Ray Research and the Earthquake Research Institute; in addition to the University of Tokyo Institutes for Advanced Studies for the Physics and Mathematics of the Universe and the Integrated Research System for Sustainability Science.

\section{PATENTS GRANTED}

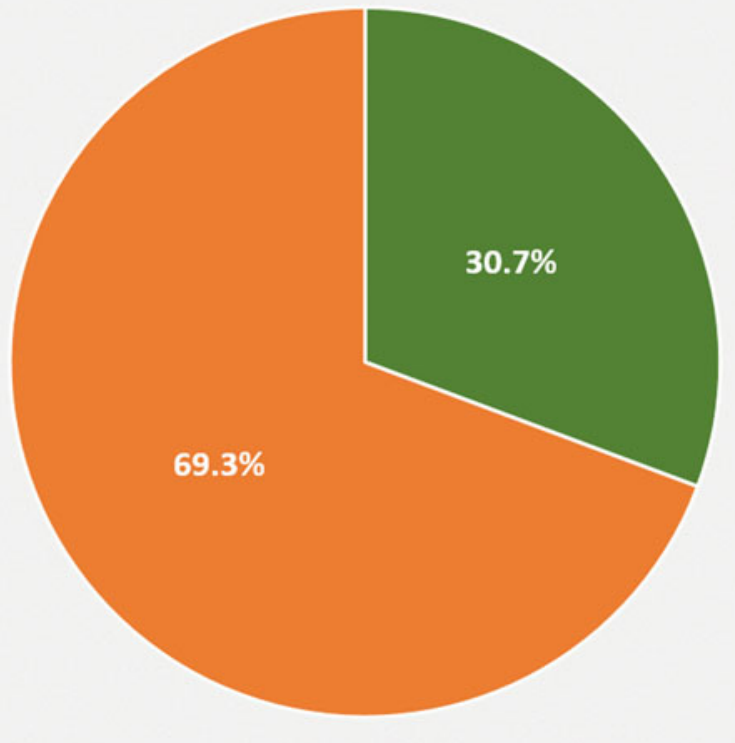

- Granted

not Granted 
Interactive Innovation Awards in Houston and Texas for the development of a robotic artificial leg, a device with a motor mechanism developed to allow the artificial limb to perform functions such as kicking the ground with its toes, helping the user experience a more natural and smooth way of walking [88].

It should be noted that 15 Japanese prime ministers were graduates of this university. Compared with the total number of 62 prime ministers, $24 \%$ of Japanese prime ministers are graduates of the University of Tokyo.

Table 6.20 displays some key statistical figures that illustrate the quality of research and innovation [88-90].

Figure 6.40 shows patent applications submitted by the University of Tokyo in different fields, while Fig. 6.41 shows the percentage of accepted patent applications.
Table 6.20 Some key statistical figures for the University of Tokyo

Fig. 6.40 Patents submitted by the University of Tokyo

\begin{tabular}{l|l}
\hline $\begin{array}{l}\text { Number of Nobel laureates among professors and graduates } \\
\begin{array}{l}\text { Number of professors or graduates who are Pritzker Architecture Prize } \\
\text { winners }\end{array}\end{array}$ & 3 \\
\hline Number of professors or graduates who are Fields Medal winners & 1 \\
\hline University budget (2017) & $\$ 2425$ billion \\
\hline Number of university locations (campuses) & 3 \\
\hline Number of students & 28,693 \\
\hline Number of undergraduate students (2017) & $\begin{array}{l}14,273(49.7 \% \text { of total } \\
\text { students) }\end{array}$ \\
\hline Number of postgraduate students (2017) & $\begin{array}{l}14,420(50.3 \% \text { of total } \\
\text { students) }\end{array}$ \\
\hline Number of teaching staff members & 2609 \\
\hline Members of the academic council & 6022 \\
\hline Number of administrative staff & 5779 \\
\hline
\end{tabular}

\section{University of Tokyo, Japan}

TOTAL PATENTS FILED

(985)

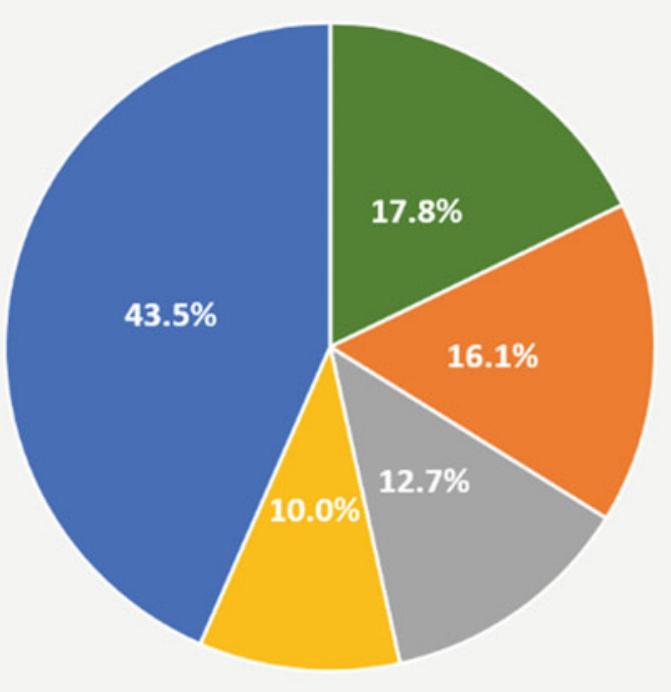

- Pharmaceuticals \& Biotech

agriculture, Forestry \& Food

- Chemicals

- Medical Devices \& Healthcare

- Other 
Fig. 6.41 Percentage of patents accepted for the University of Tokyo

\section{University of Tokyo, Japan}

\section{PATENTS GRANTED}

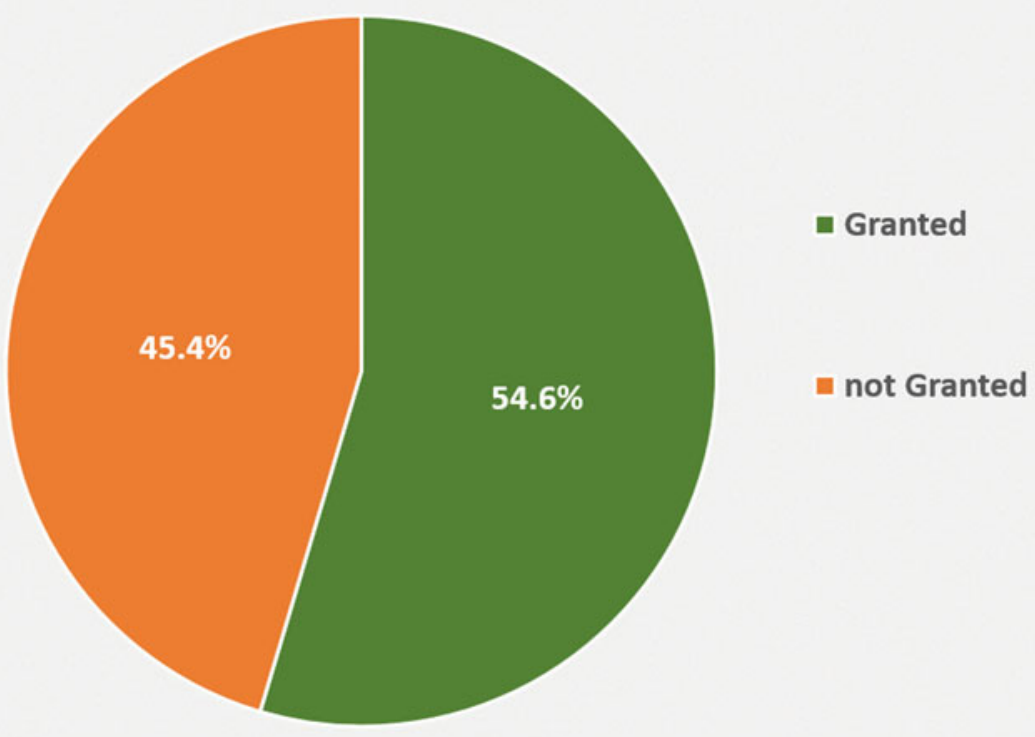

\subsection{University of Erlangen Nuremberg-Germany}

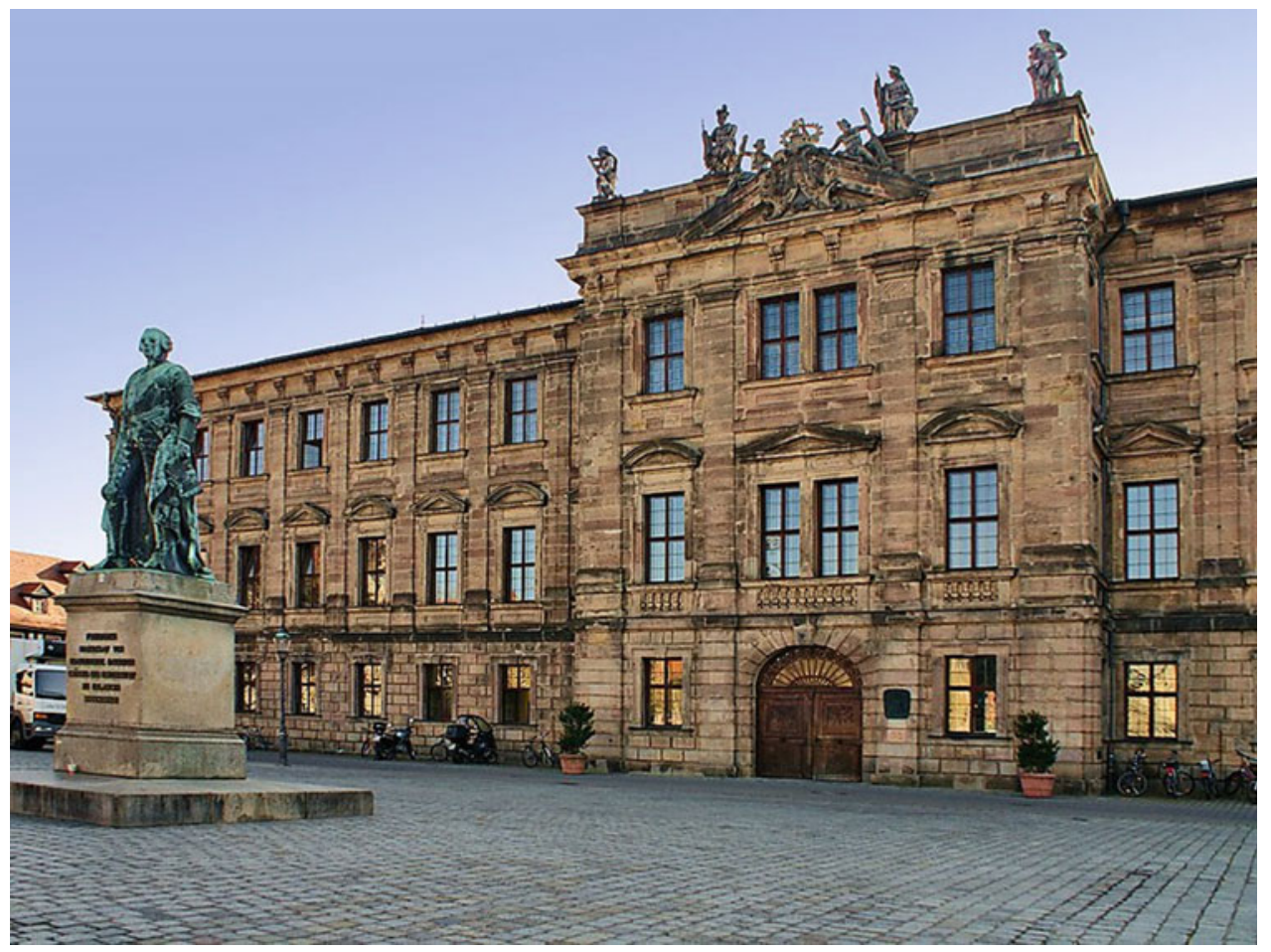


University of Erlangen Nuremberg was founded in 1743 as a public research university and is also known as FriedrichAlexander University, the second biggest university in the area of Bavaria. The university research depends upon the support it receives from around 70 institutions, funds and Leagues for education, in addition to its own budget, and it offers scholarships, especially for talented students. More than 40 teachers are being funded either fully or partially by companies and research associations.

Researchers in the university have recently found that treatment with Neurofeedback can achieve long-term benefits for children who suffer from attention deficit hyperactivity disorder, providing positive effects that last for at least 6 months after treatment. In this method of treatment, children use a computer software connected to electroencephalography (EEG) to monitor the brain activity and practice the way of organizing their behavior and improving it. In addition, other researchers, in collaboration with researchers in the universities of Mainz and Kassel, have recently constructed the smallest engine in the world, consisting of just a single atom that can effectively turn heat into Kinetic energy. The development of such nanomotors allows researchers to know more about thermodynamics of individual particles and could help lead to new approaches for building larger engines.

Table 6.21 displays some key statistical figures that illustrate the quality of research and innovation [91-92].

Figure 6.42 shows patents submitted by the University of Erlangen Nuremberg in different fields, while Fig. 6.43 shows the percentage of accepted patents.
Table 6.21 Some key statistical figures of the University of Erlangen Nuremberg

\begin{tabular}{l|l}
\hline Number of Nobel laureates among professors and graduates & 4 \\
\hline Number of Leibniz prize laureates from professors or alumni & 6 \\
\hline University budget & $€ 543.1$ million \\
\hline Number of students (2015) & 40,174 \\
\hline Teaching staff & 4040 \\
\hline Number of administrative staff (2015) & 2290 \\
\hline
\end{tabular}

Fig. 6.42 Patents submitted by the University of Erlangen Nuremberg

\section{University of Erlangen Nuremberg, Germany}

TOTAL PATENTS FILED

(211)

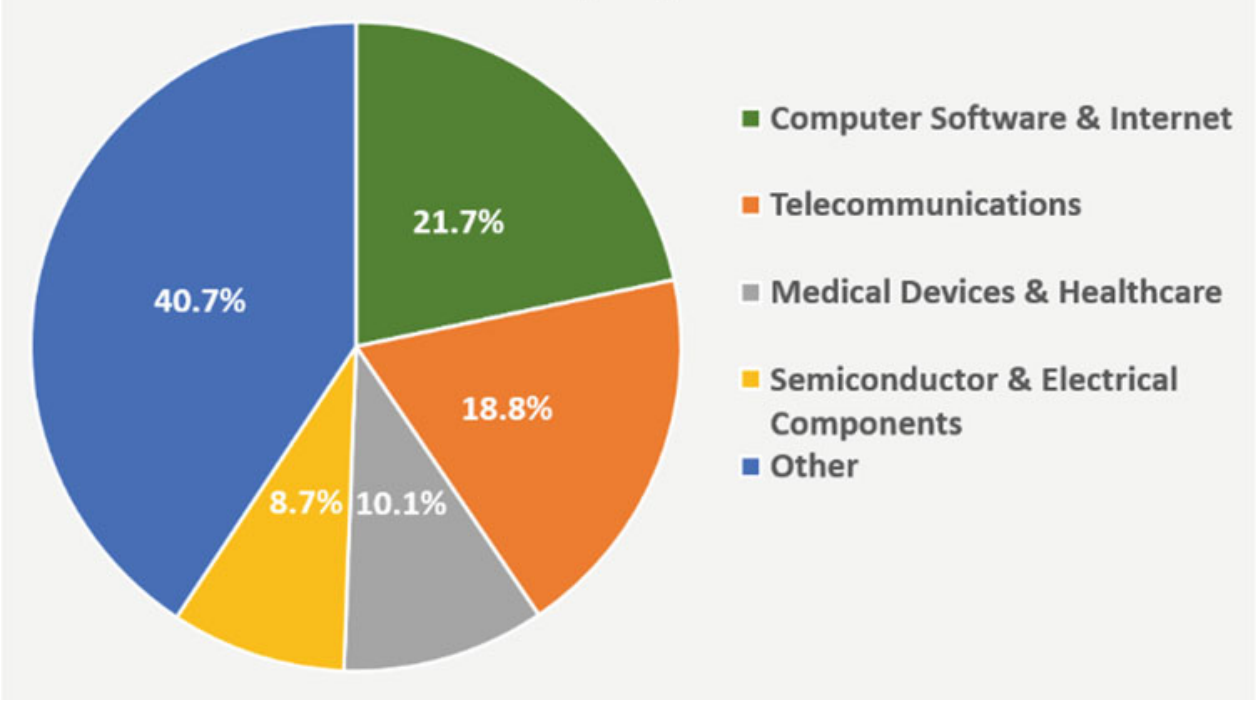


Fig. 6.43 Percentage of accepted patents of the University of Erlangen Nuremberg

\section{University of Erlangen Nuremberg, Germany}

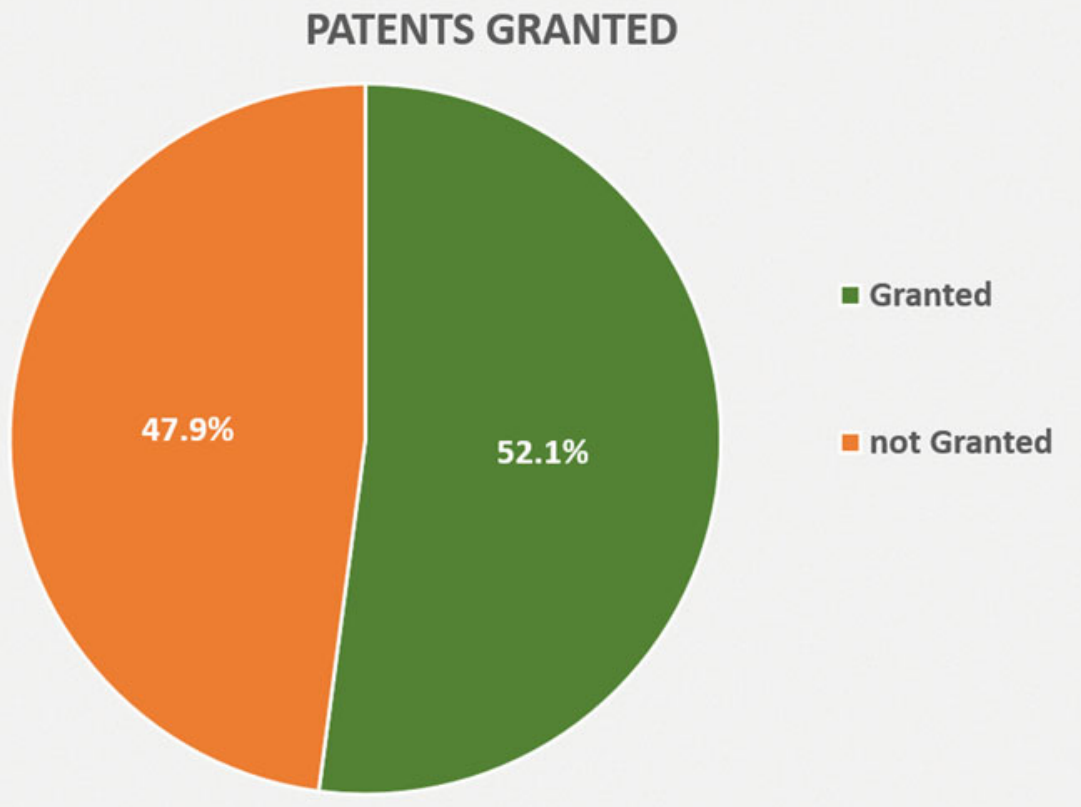

\subsection{University of Toronto-Canada}

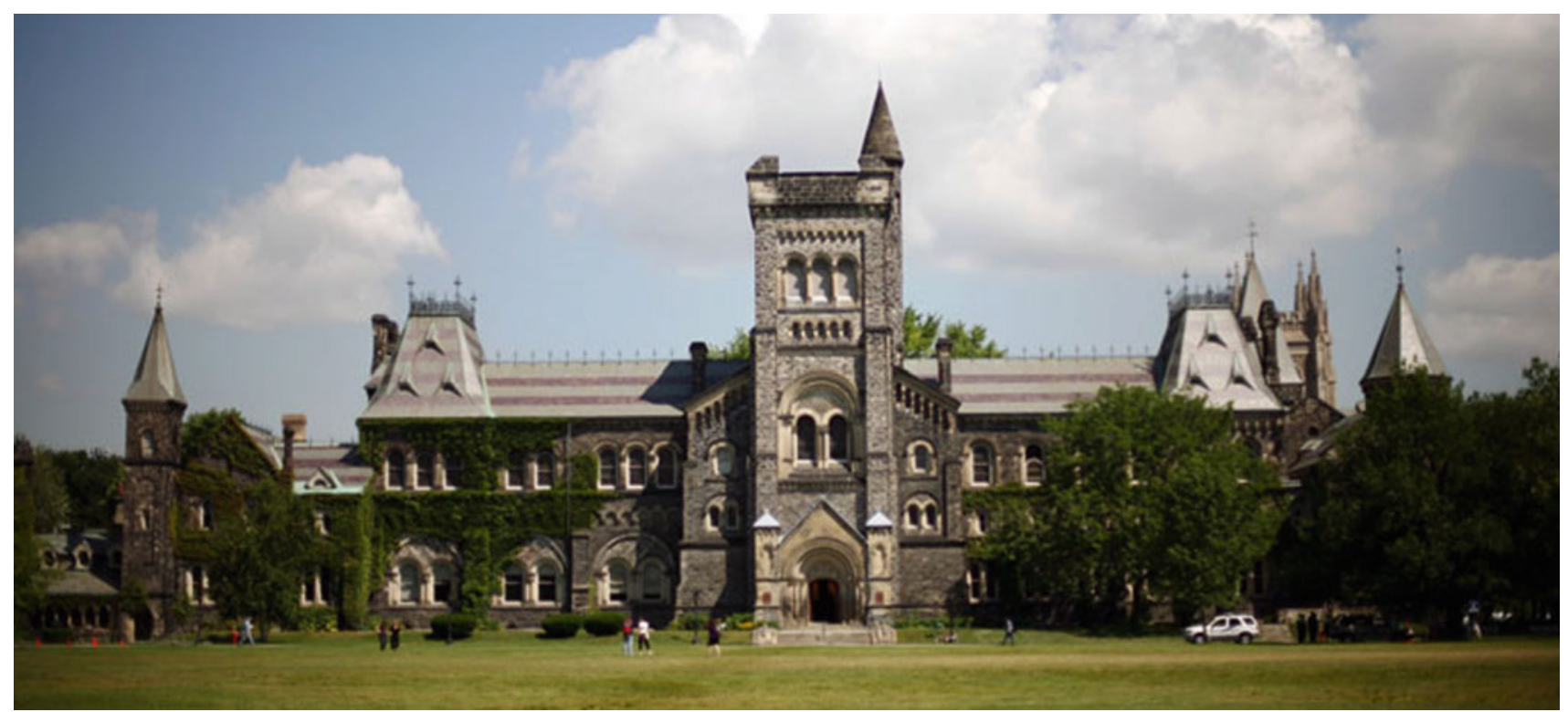

The university was founded by the royal charter in 1827 as a royal university, and now it has three campuses in the area of Toronto.

In March 2017, University of Toronto launched an institute for artificial intelligence (Vector Institute of Artificial Intelligence), an independent non-profit research institute that conducts research and works on adopting these techniques and marketing them. The institute cooperates with companies, such as Google and Uber. University of Toronto is a founding member of MaRS Discovery District, a non-profit organization that helps entrepreneurs in both public and private sectors to grow their companies. Recently, the university has also allocated a new $14,000-\mathrm{ft}^{2}$ area in the campus to cooperate with entrepreneurs. The total value of research funds granted to the university's researchers was $\$ 391$ million in the academic year 
2015/2016. When added to the fund granted to the university through partner hospitals, the total was $\$ 1.2$ billion.

Postgraduate students come from 168 countries, but most of them come from China; there are more than ten thousand Chinese students. The university contributes to the Canadian economy with about CAD 15.7 billion a year, and it has more than 150 start-ups in the last five years (2012-2017).
James Till, a biophysicist in the university and an expert in brain diseases, discovered stem cells in the early 1960s, and medicine research is still a main area of focus [93].

Table 6.22 displays some key statistical figures that illustrate the quality of research and innovation [93-96].

Figure 6.44 shows patents submitted by University of the Toronto in different fields, while Fig. 6.45 shows the percentage of accepted patents.
Table 6.22 Some key statistical figures of the University of Toronto

Fig. 6.44 Patents submitted by the University of Toronto

\begin{tabular}{l|l}
\hline $\begin{array}{l}\text { Number of Nobel laureates among professors and graduates } \\
\begin{array}{l}\text { Number of Gairdner Foundation International Award laureates among } \\
\text { professors or alumni }\end{array}\end{array}$ & 10 \\
\hline $\begin{array}{l}\text { The establisher of Fields Medal is one of the university's professors } \\
\text { Endowments (2017) }\end{array}$ & $\begin{array}{l}\text { CAD } 2.8 \text { billion } \$ 2.22 \\
\text { billion) }\end{array}$ \\
\hline University budget (2017) & $\$ 1$ billion \\
\hline Total value of research grants (2015/2016) & CAD 1.2 billion \\
\hline University's annual contribution to the Canadian economy & CAD 15.7 billion \\
\hline Number of university campuses & 3 \\
\hline Number of university students (2017) & 88,066 \\
\hline Number of undergraduate students (2017) & $\begin{array}{l}70,028 \text { (80\% of total } \\
\text { students) }\end{array}$ \\
\hline Number of postgraduate students (2017) & $\begin{array}{l}18,038 \text { (20\% of total } \\
\text { students) }\end{array}$ \\
\hline Number of teaching staff members & 2547 \\
\hline Number of assistant professors & $(14 \%)$ \\
\hline Members of the academic council & 5274 \\
\hline Number of administrative staff & 4590 \\
\hline
\end{tabular}

\section{University of Toronto, Canada}

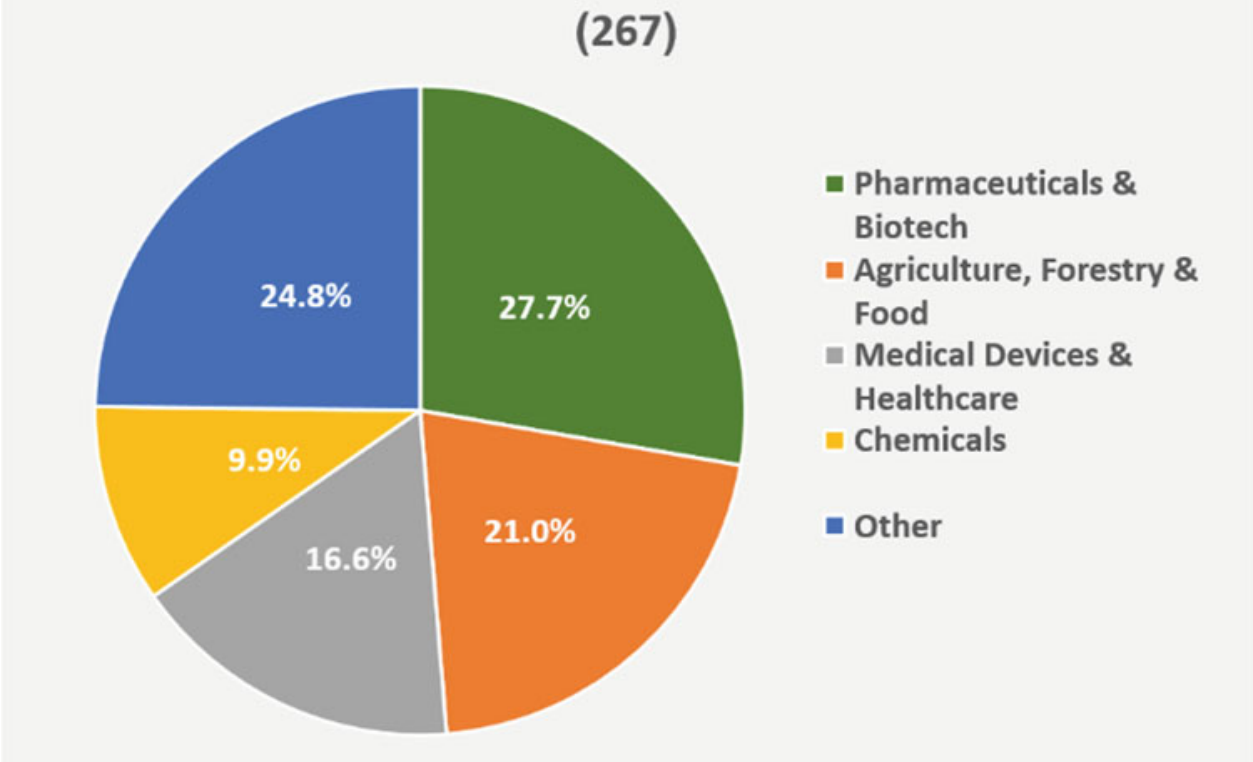


Fig. 6.45 Percentage of accepted patents of the University of Toronto

\section{University of Toronto, Canada}

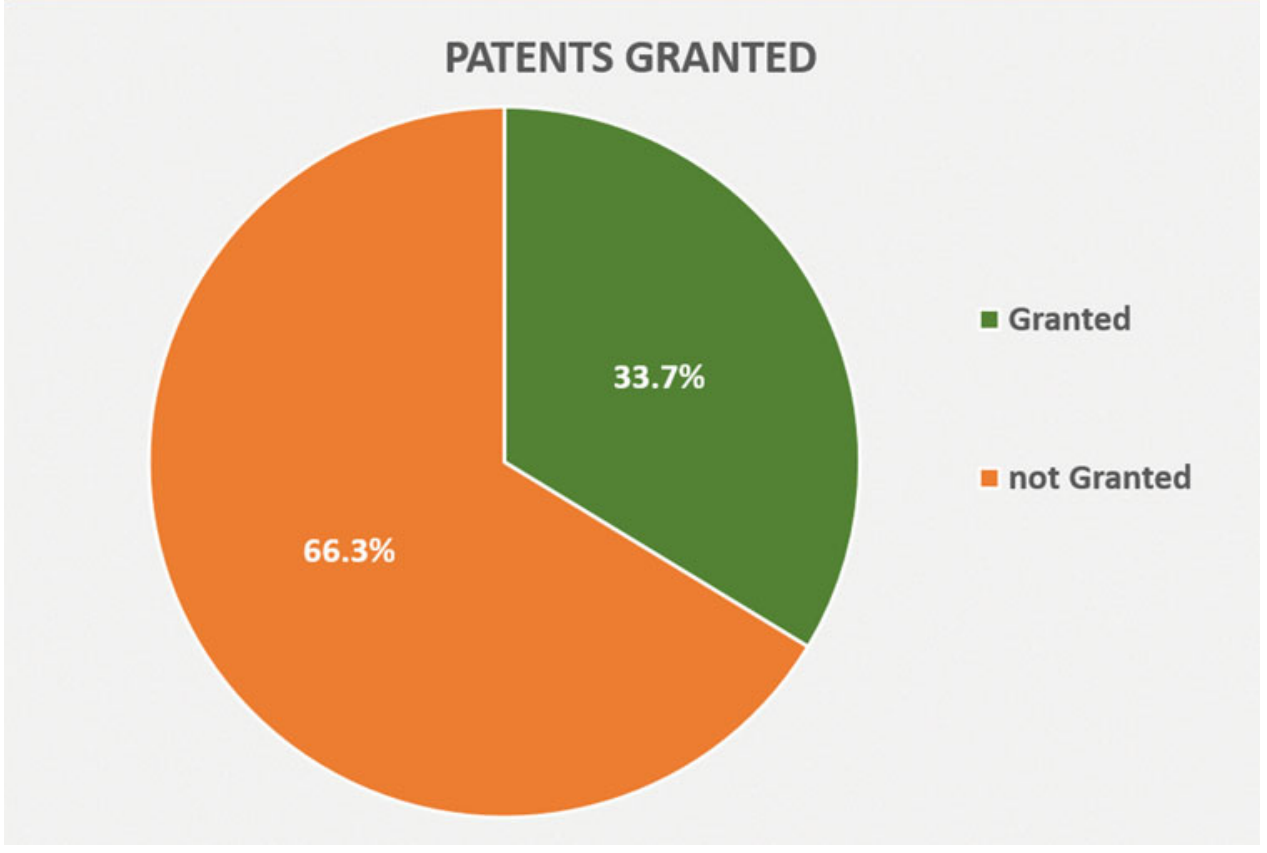

\subsection{Tsinghua University-China}

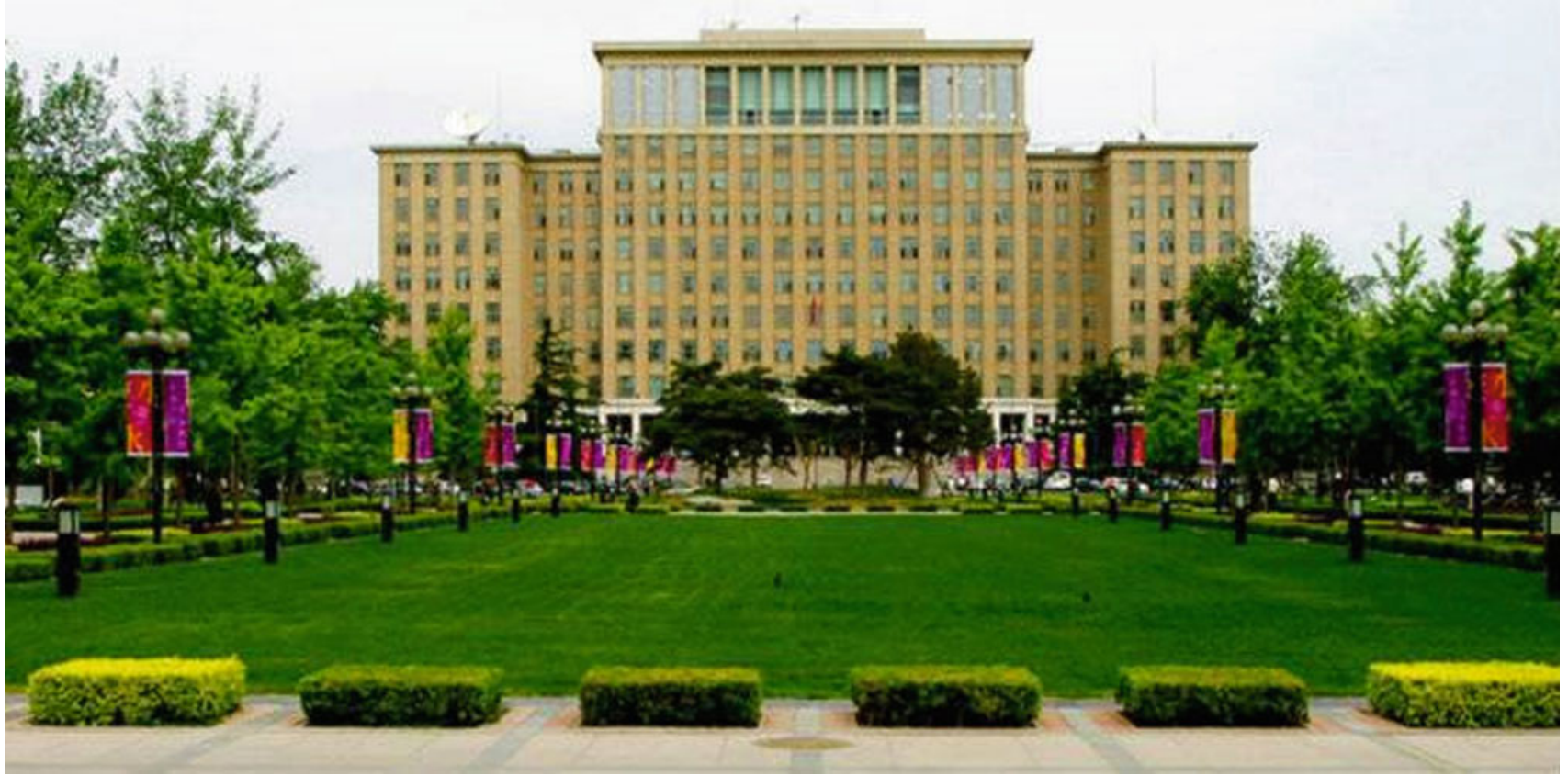


Tsinghua University or THU was founded in 1911, as a school to prepare students to be sent by the government to study in the USA. In 1952, it became a cross-disciplinary public research university. THU's researchers are intensifying their efforts to cooperate with global partners. THU has a high ranking both globally and locally. Globally, it is ranked (17) in the QS ranking, (22) in the Times ranking, and (45) in Shanghai ranking, which indicates its prestigious position in the fields of research and innovation.

THU made a strategic partnership agreement with University of California, Berkeley, to establish a postgraduate school in China, which is scheduled to be opened in
2021. Also, it collaborated with Bill and Melinda Gates Foundation in 2017 to establish the World Health Institute for drugs, a center for research and development that focuses on finding new therapies for some of the world's most urgent health crises. The university's investment arms keenly pursued investments in American semiconductor companies.

Table 6.23 displays some key statistical figures that illustrate the quality of research and innovation [97-98].

Figure 6.46 shows patents submitted by Tsinghua University in different fields, while Fig. 6.47 shows the percentage of accepted patents.
Table 6.23 Some key statistical figures of Tsinghua University

Fig. 6.46 Patents submitted by Tsinghua University

\begin{tabular}{l|l}
\hline Campus area & 395 ha \\
\hline Number of students (2018) & 47,762 \\
\hline Number of undergraduate students (2015) & 15,570 \\
\hline Number of postgraduate students (2015) & 19,311 \\
\hline Teaching staff & 3416 \\
\hline Number of administrative staff (2015) & 4101
\end{tabular}

\section{Tsinghua University, China}

\section{TOTAL PATENTS FILED}

(742)

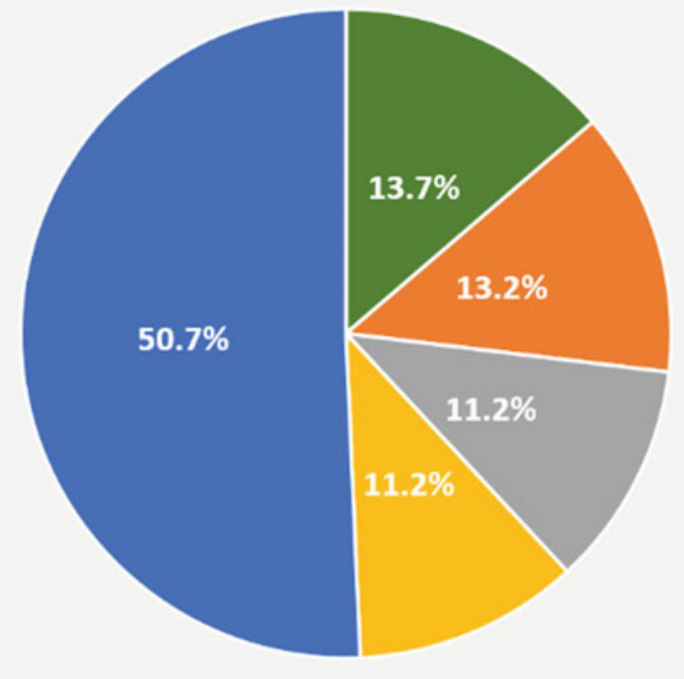

Computer Software \& Internet

Energy / Petroleum

- Semiconductor \& Electrical Components

- Medical Devices \& Healthcare

- Other 
Fig. 6.47 Percentage of accepted patents of Tsinghua University

\section{Tsinghua University, China}

\section{PATENTS GRANTED}

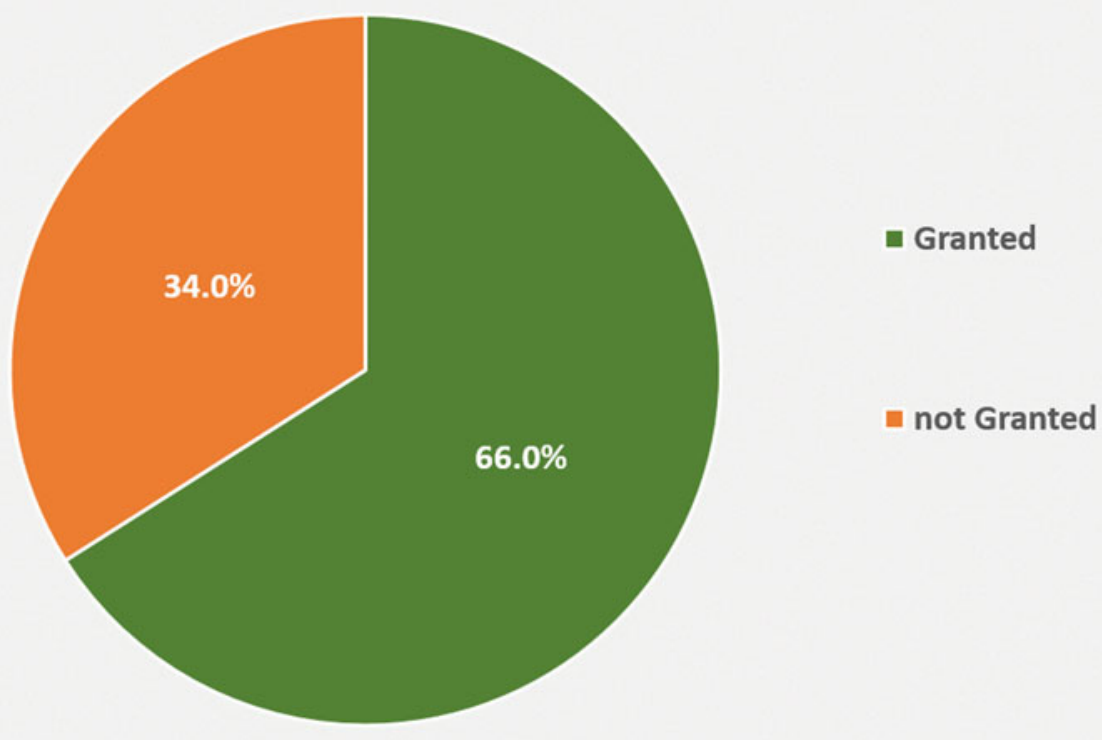

\subsection{Montpellier University-France}

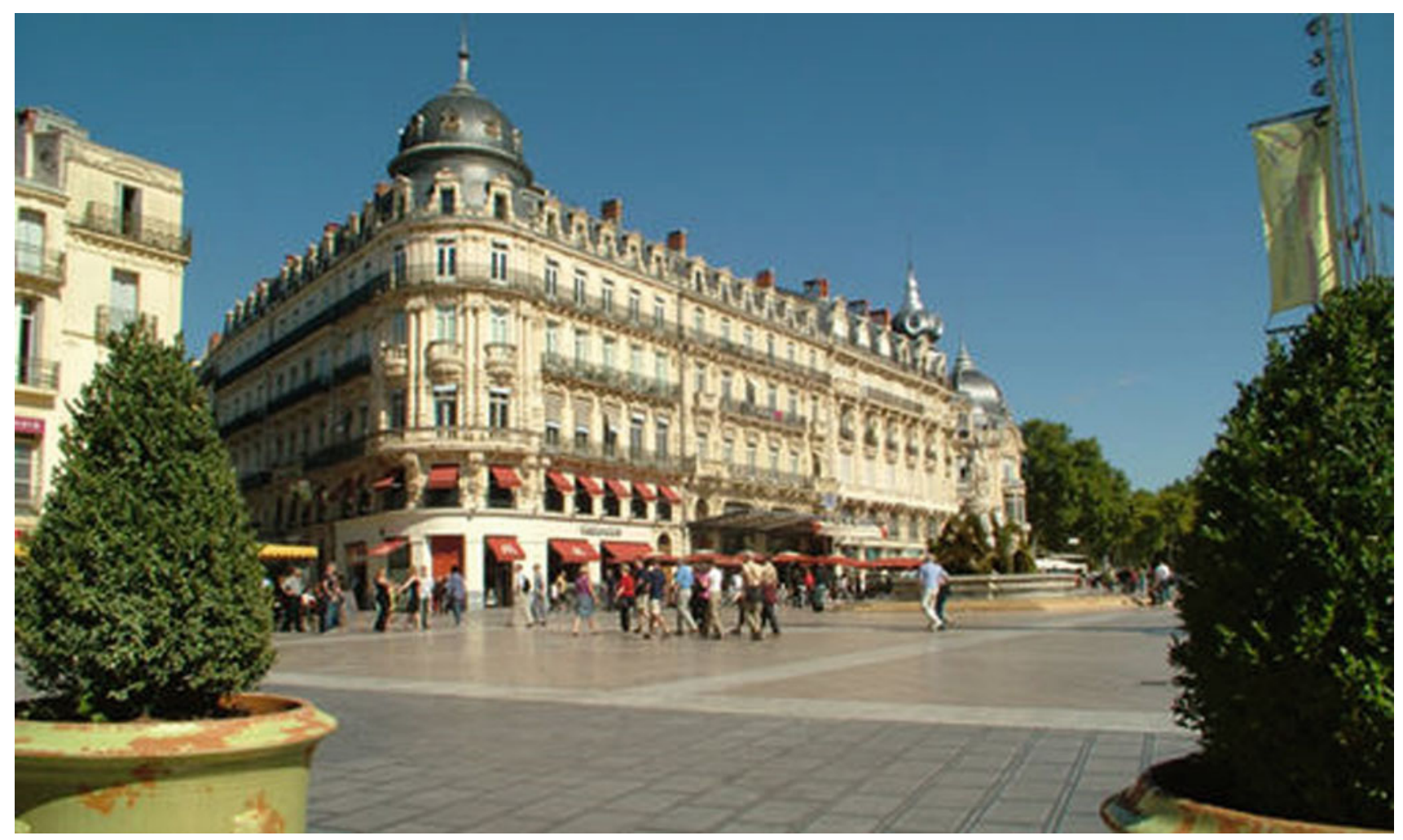


The origins of Montpellier University can be traced back to 1289 when a school was founded to teach medicine, law, and literature. However, the university took its recent shape only in 2012 following the merger of three local institutions: Montpellier University 1, Montpellier University 2, and the Paul Valery Montpellier University 3. In this university, which is based in southeastern France, approximately $50 \%$ of the $1800 \mathrm{Ph} . \mathrm{D}$. students come from other countries.

Montpellier University has close ties with industry in the area of southeastern France, especially in the biomedical and new technologies sector. The university includes nine academic faculties, six institutes, and two schools. The 76 research institutes focus on topics including agricultural sciences, health, biology, chemistry, physics, and information technology. The number of students in the university reached 47,000 in 2017 , and the number of teaching staff reached 2300 [99-102].
Montpellier University has 586 patent families, and the Montpellier University of Excellence project (MUSE) was chosen on February 21, 2017, by an international jury to fund Initiatives for Science, Innovation, Territories and Economy (I-SITE). MUSE will provide a tremendous boost for postgraduate research on both national and international levels. University of Montpellier is one of the pioneer universities in France (the sixth French university). It is very well placed in the main world ranking, as it is the first in ecology in Shanghai ranking in 2018, the first innovative university in Reuters' ranking, and is ranked the fifth in France in Leiden ranking for quality of scientific publications. Every year, hundreds of international students choose to come to it.

Figure 6.48 shows patents submitted by Montpellier University in different fields, while Fig. 6.49 shows the percentage of accepted patents.
Fig. 6.48 Patents submitted by Montpellier University

\section{University of Montpellier, France}

TOTAL PATENTS FILED

(205)

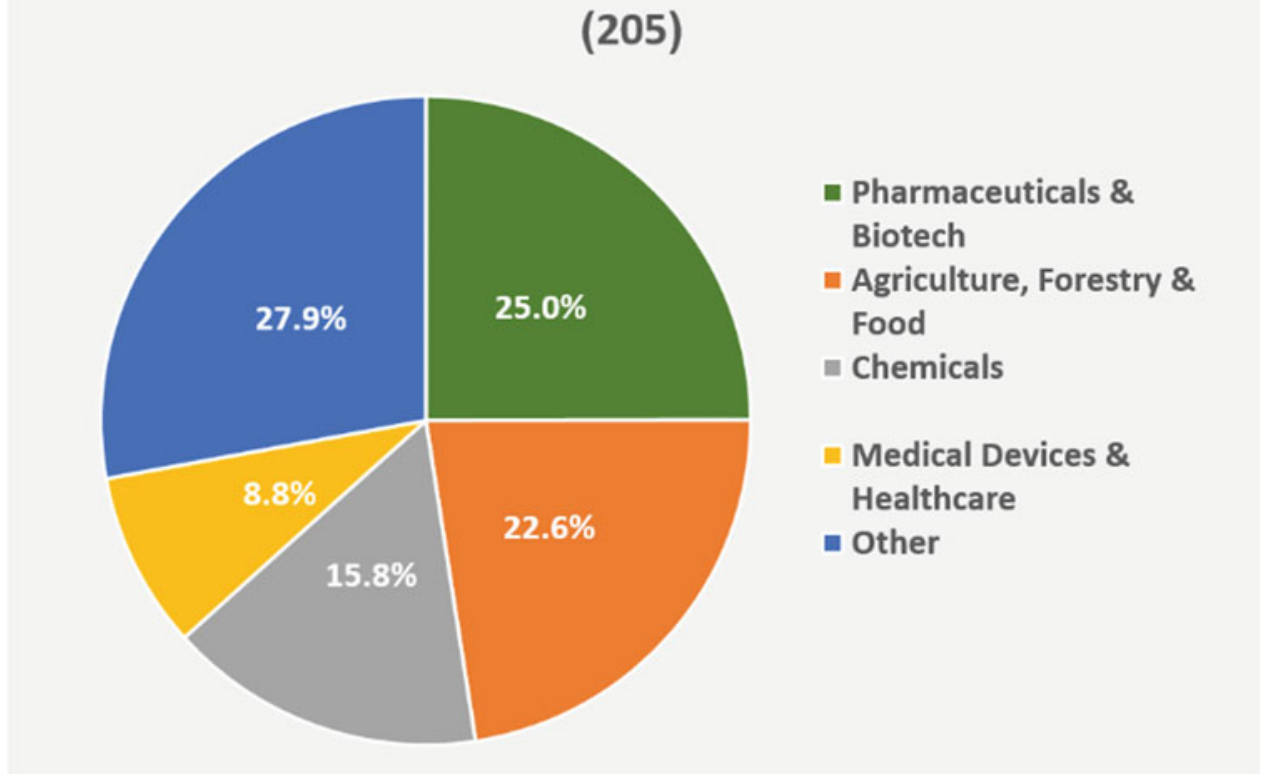


Fig. 6.49 Percentage of accepted patents of Montpellier University

\section{University of Montpellier, France}

\section{PATENTS GRANTED}

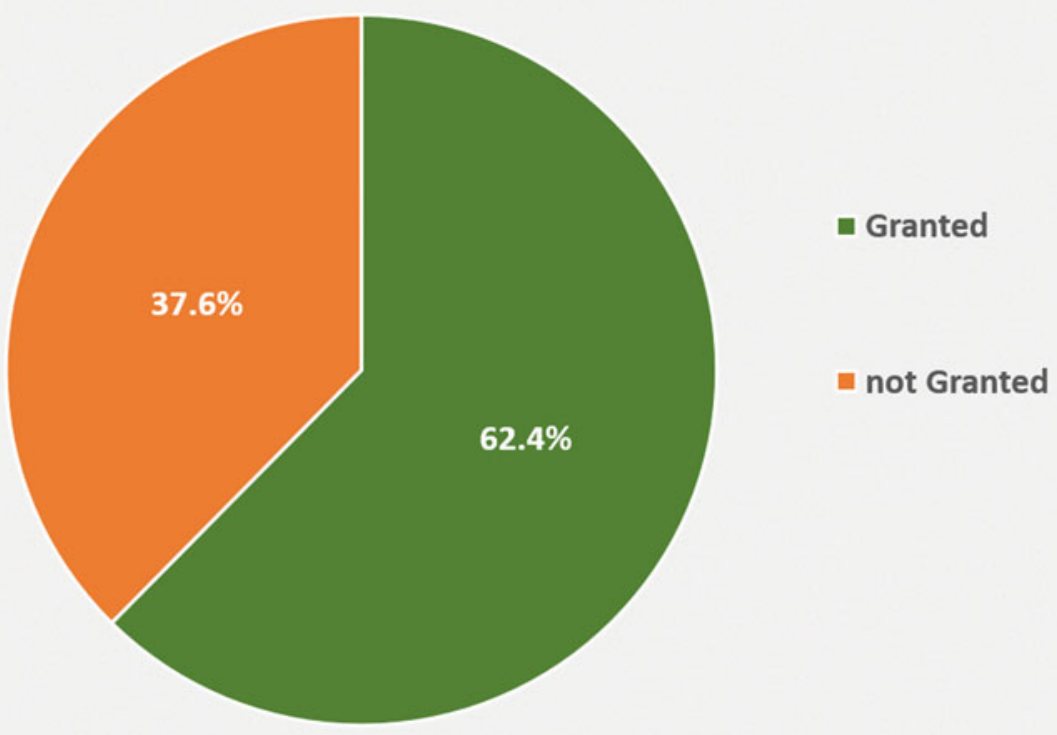

\subsection{Technical University of Denmark-Denmark}

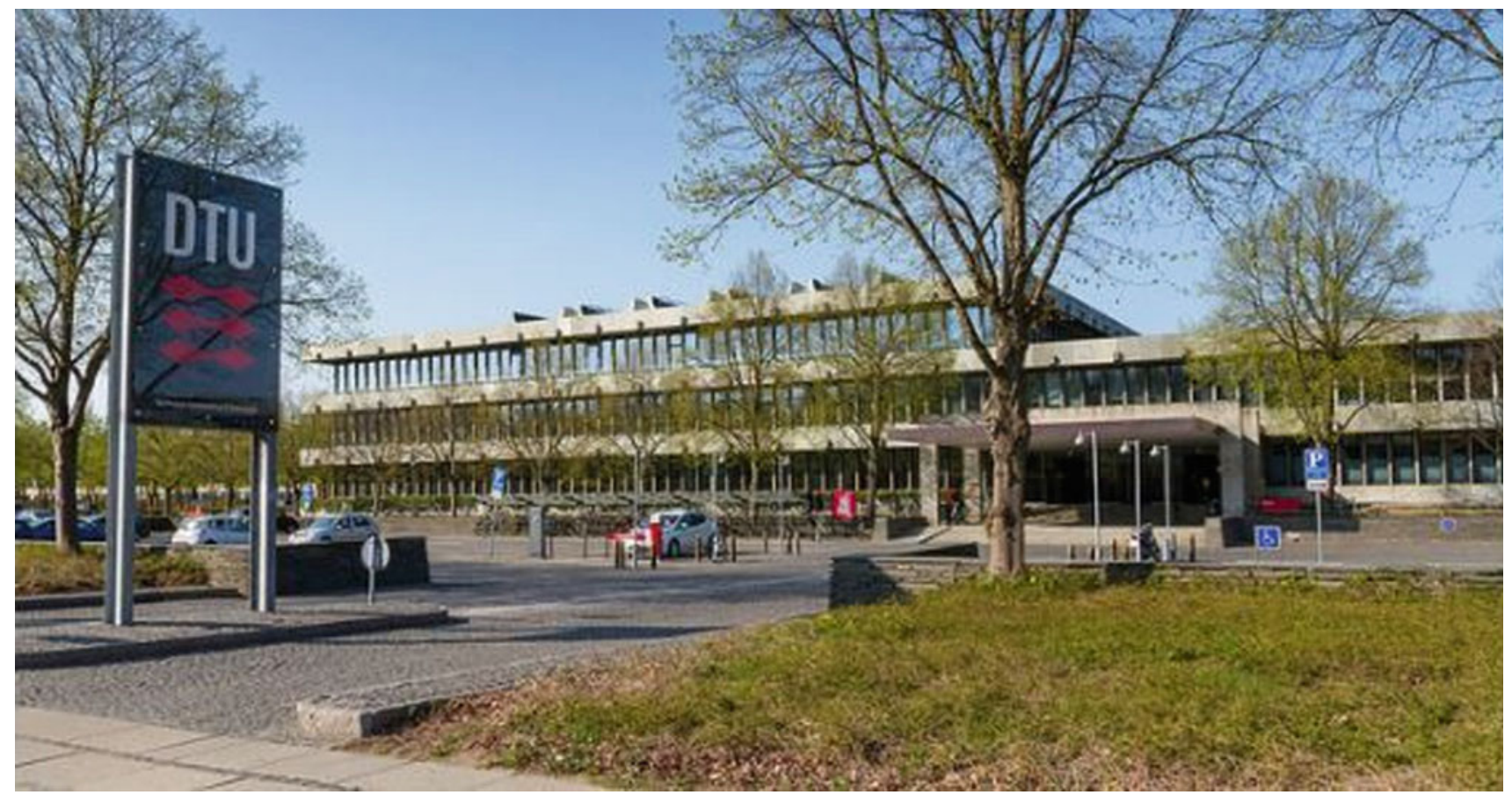


Technical University of Denmark or DTU was founded by the well-known Danish physicist known as the father of electromagnetism (Hans Christian Ørsted) in 1829. In 2016, DTU completed three massive building projects, including a $43,000-\mathrm{m}^{2}$ life science and bioengineering complex that brings together an important part of life science research labs. In its main campus, a new building was constructed that incorporates the Department of Photonic Engineering for research, teaching, and investigating photons and laser, and other light applications [103].

DTU's researchers registered 152 inventions in 2014 and spun off 51 projects and cooperated with industry in 1249 projects. One of these projects is collaboration with the Danish company DuPont Lightstone, and involves a method to embed optical fibers directly into LED displays to become robust and durable. The student-to-teaching staff ratio is $6: 1$. It should be noted that the number of projects with industry reached 1324 in 2017, and the number of start-ups reached 67. These figures show that the success this university is achieving in the field of inventing and establishing start-ups is largely based on the collaboration with industry, which, in turn, brings progress and prosperity to the university and society. It is noted that the numbers of $\mathrm{PhD}$ degree holders in the years: 2014, 2015, and 2016 were 323, 358, and 359, respectively.

Table 6.24 displays some key statistical figures that illustrate the quality of research and innovation [103-105].

Figure 6.50 shows patents submitted by the Technical University of Denmark in different fields, while Fig. 6.51 shows the percentage of accepted patents.
Table 6.24 Some key statistical figures of Technical University of Denmark

Fig. 6.50 Patents submitted by Technical University of Denmark

\begin{tabular}{|l|l|}
\hline Number of Nobel laureates among professors and graduates & 2 \\
\hline Number of undergraduates (2016) & 7197 (65\% of total students) \\
\hline Number of postgraduate students (2016) & $3834(35 \%$ of total students) \\
\hline Number of teaching staff members & 2003 \\
\hline Members of the academic council & 1330 \\
\hline Number of administrative staff & 1540 \\
\hline Number of projects carried out with industry (2015) & 1249 \\
\hline Number of projects carried out with industry (2016) & 1324 \\
\hline Number of start-ups (2016) & 67 \\
\hline
\end{tabular}

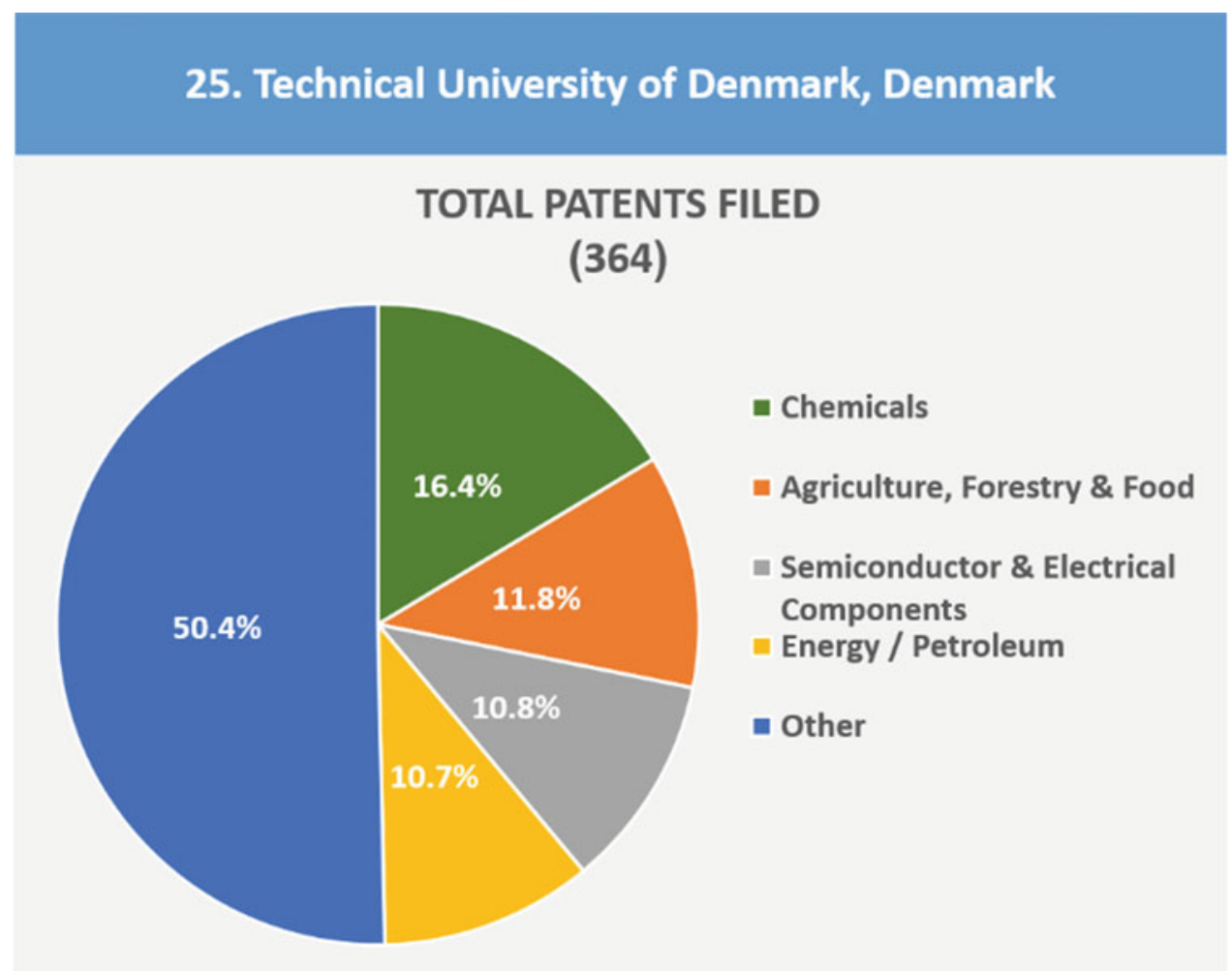


Fig. 6.51 Percentage of accepted patents of Technical University of Denmark

\section{Technical University of Denmark, Denmark}

\section{PATENTS GRANTED}

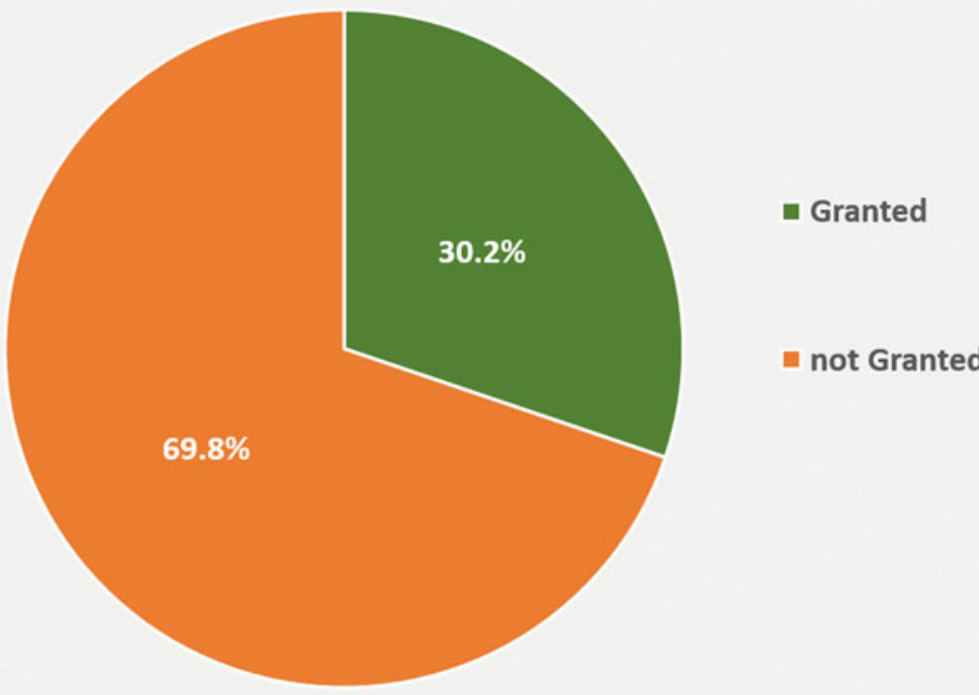

\subsection{Delft University of Technology—Netherlands}

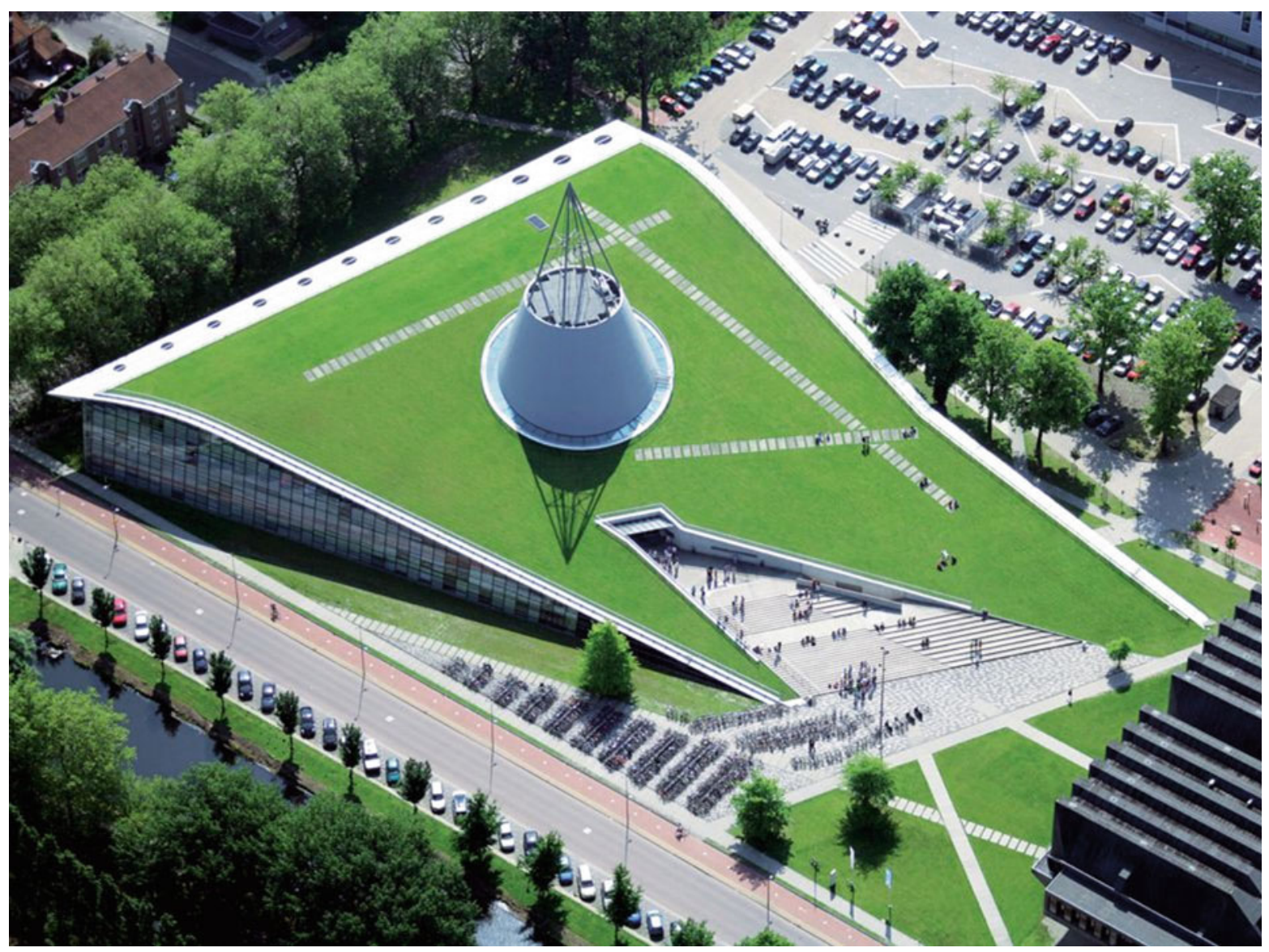


Delft University of Technology or (TU Delft) is the oldest and biggest technical university in Netherlands, for it was founded in 1842 by King William II in order to train civil engineers. It specializes in science, engineering, and design research. TU Delft conducts a lot of its research in cross-disciplinary institutes, such as Wind Energy Institute, that covers all aspects of modern wind turbines technology, and Climate Institute, where researchers are producing advanced climate sensors and developing better models to describe climate change. Among the significant work done at the university is the help of high-tech entrepreneurs center in launching 160 start-ups since it was founded in 2005. The student-to-teaching staff ratio is approximately $4.4: 1$, a ratio that allows the students to have good interaction with the academic staff. The value of revenues from projects contracted outside the university is $€ 184.6$ million [106].

Some of TU Delft's expertise has also extended to the world of arts. In 2008, its scientists used X-ray spectroscope to reveal a hidden portrait under a painting for artist "Van Gogh." TU Delft's students have recently beat 26 other universities at the first Hyperloop Pod competition, organized by Elon Musk's SpaceX in Los Angeles, a test of vehicles that travel at high speed through a $1.2-\mathrm{km}$ low-pressure tube.

Table 6.25 displays some key statistical figures that illustrate the quality of research and innovation [106-108].

Figure 6.52 shows patents submitted by the Delft University of Technology in different fields, while Fig. 6.53 shows the percentage of accepted patents.
Table 6.25 Some key statistical figures of Delft University of Technology

Fig. 6.52 Patents submitted by Delft University of Technology

\begin{tabular}{l|l}
\hline Number of Nobel laureates among professors and graduates & 2 \\
\hline University's budget (2016) & $€ 1246$ billion (\$1.47 billion) \\
\hline Revenues from research contracted outside the university & $€ 184.6$ million \\
\hline Number of undergraduate students (2016) & 11,363 (54\% of total students) \\
\hline Number of postgraduate students (2016) & 9860 (46\% of total students) \\
\hline Number of PhD students (postgraduate students) & 1093 \\
\hline Number of teaching staff members & 3375 \\
\hline Members of the academic council & 2280 \\
\hline Number of administrative staff & 2935 \\
\hline Number of start-ups from 2005 to 2017 & 160 \\
\hline
\end{tabular}

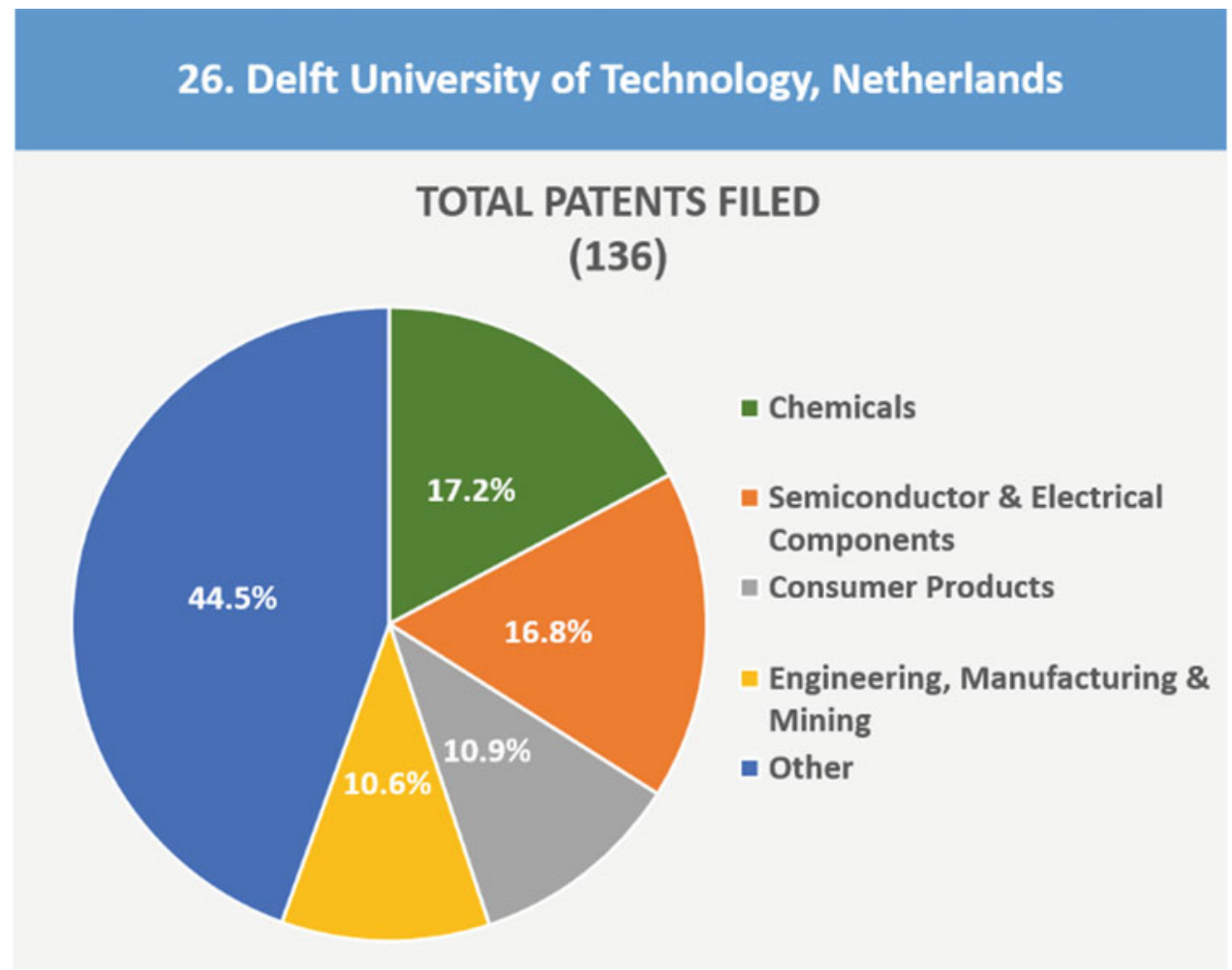


Fig. 6.53 Percentage of accepted patents of Delft University of Technology

\section{Delft University of Technology, Netherlands}

\section{PATENTS GRANTED}

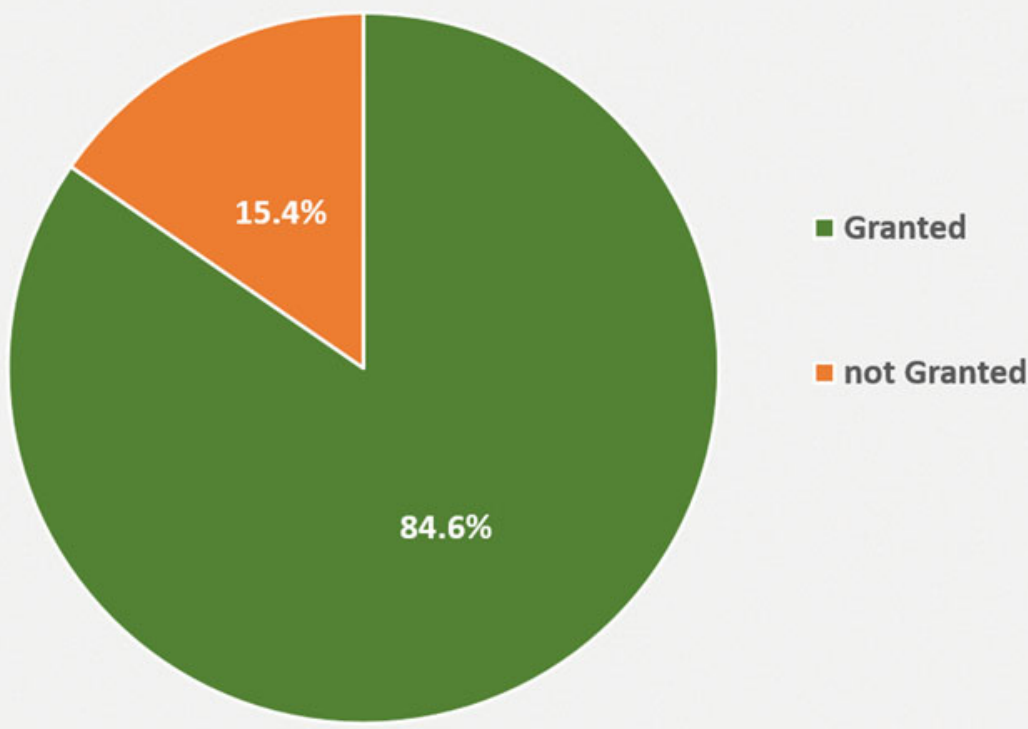

\subsection{National University of Singapore-Singapore}

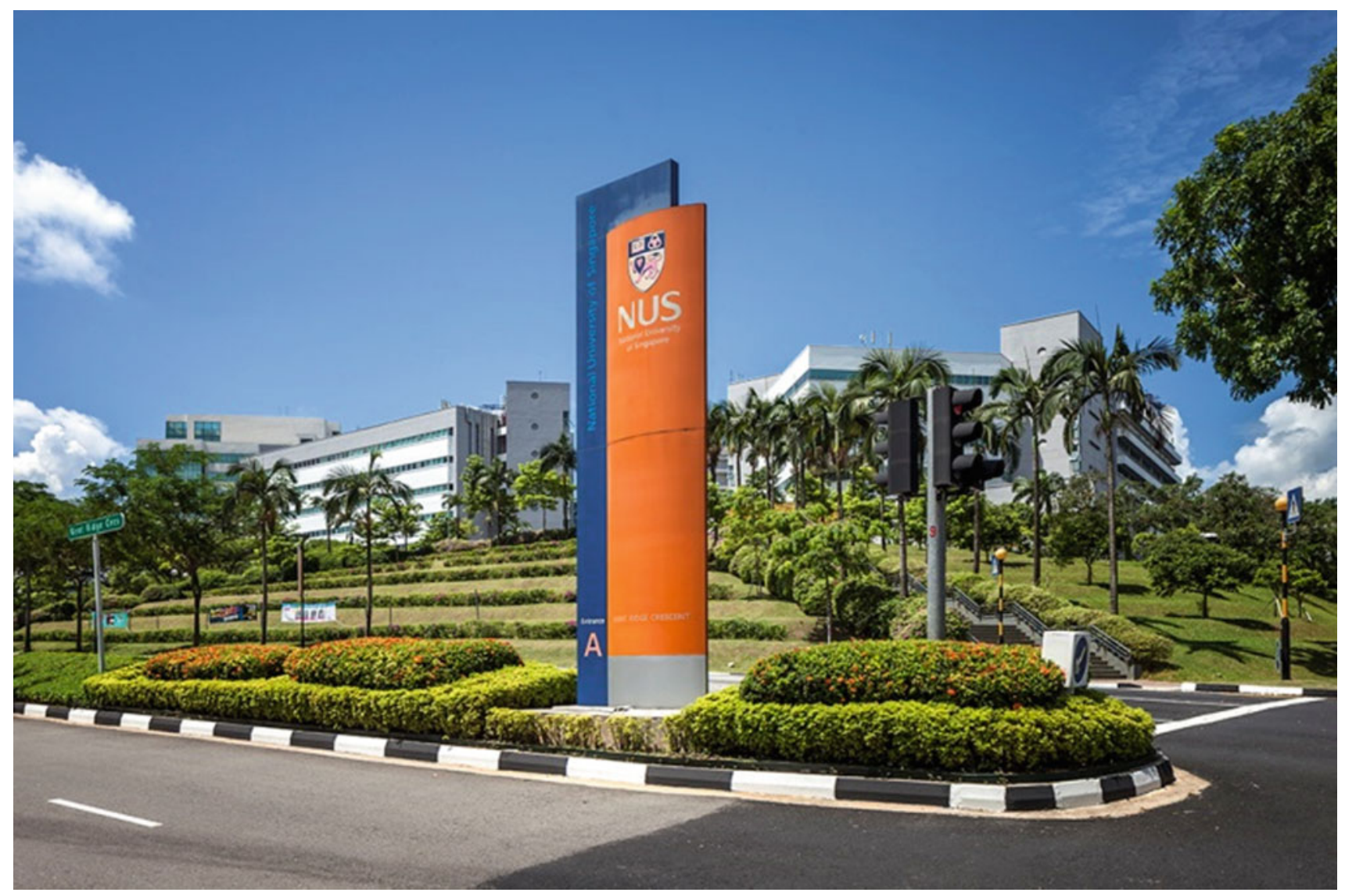


It is the oldest institution of higher education in Singapore. National University of Singapore (NUS) was founded in 1905 as a government medical school under Federated Malay States, with just 23 students back then. The university became what it is today after a merger with Nanyang University in 1980, and currently has three campuses. National University of Singapore launched a cooperation initiative with the cloud computing company and the largest issuer of smart cards in Singapore in order to develop technologies necessary to reach a Cashless Singapore. Modern innovations in the university include innovating a "dye" that works on improving medical imaging techniques, developing nanofilm that uses tiny moving magnetic material to store massive amounts of data; and creating simple, affordable nanofiber air filters that not only clean the air, but also provide ultra violet protection. The university incorporates a number of specialized research centers, including the Centre for Quantum Technologies, Cancer Science Institute of Singapore and the Mechanobiology Institute of Singapore. Among its alumni are Mahathir Mohamad, Prime Minister of Malaysia and the pioneer of its renaissance, also one of the presidents of Singapore and two of its prime ministers.

Table 6.26 displays some key statistical figures that illustrate the quality of research and innovation [109-111].

Figure 6.54 shows patents submitted by National University of Singapore in different fields, while Fig. 6.55 shows the percentage of accepted patents.
Table 6.26 Some key statistical figures National University of Singapore

Fig. 6.54 Patents submitted by National University of Singapore

\begin{tabular}{|l|l|}
\hline Endowments (2017) & S\$3.73 billion (\$2.76 million) \\
\hline Campuses & 3 \\
\hline Number of university's students (2017) & 39,536 \\
\hline Number of undergraduate students (2017) & 29,130 (74\% of total students) \\
\hline Number of postgraduate students (2017) & 10,406 (26\% of total students) \\
\hline Number of teaching staff members & 2196 \\
\hline Members of the academic council & 2820 \\
\hline
\end{tabular}

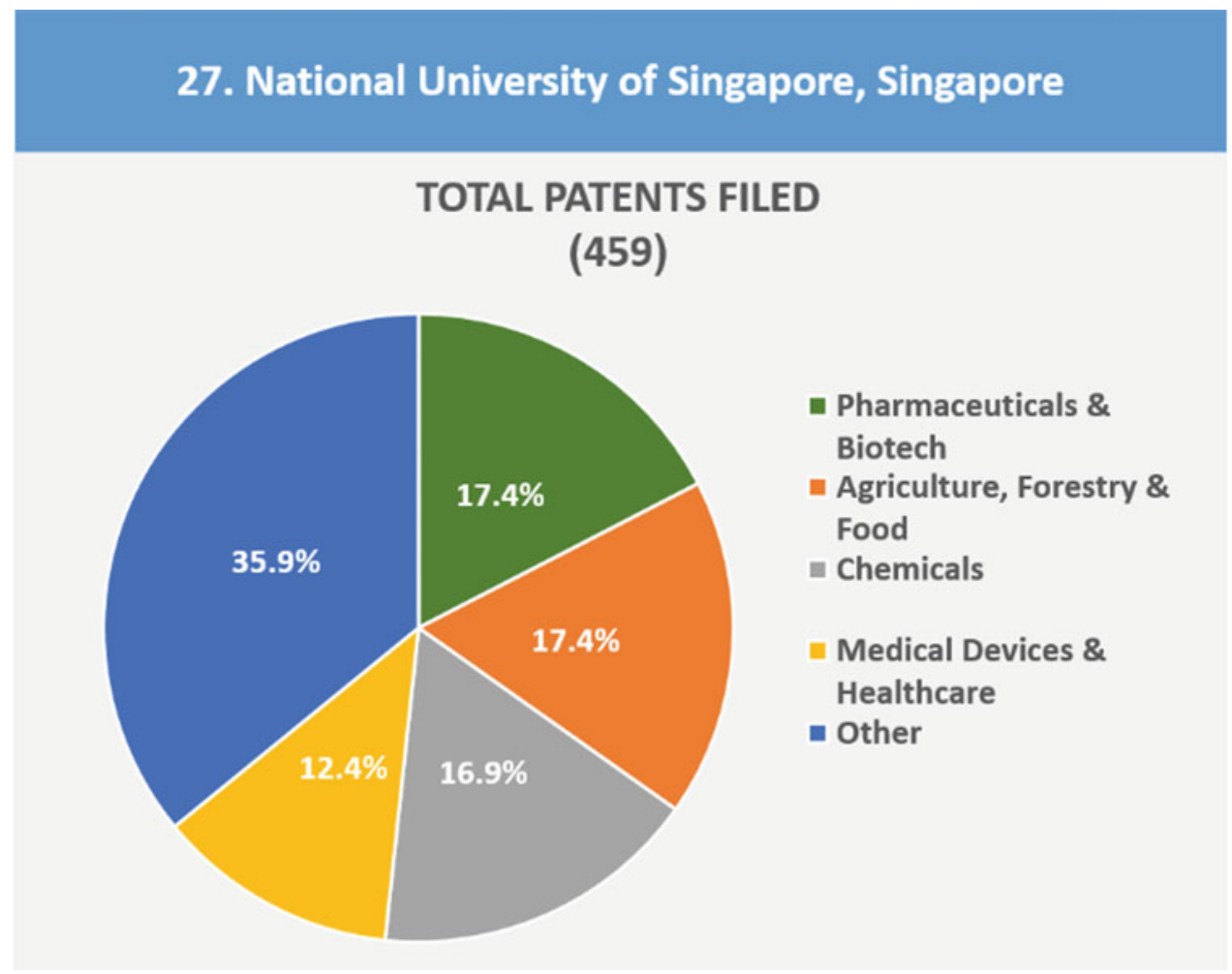


Fig. 6.55 Percentage of accepted patents of National University of Singapore

\section{National University of Singapore, Singapore}

\section{PATENTS GRANTED}

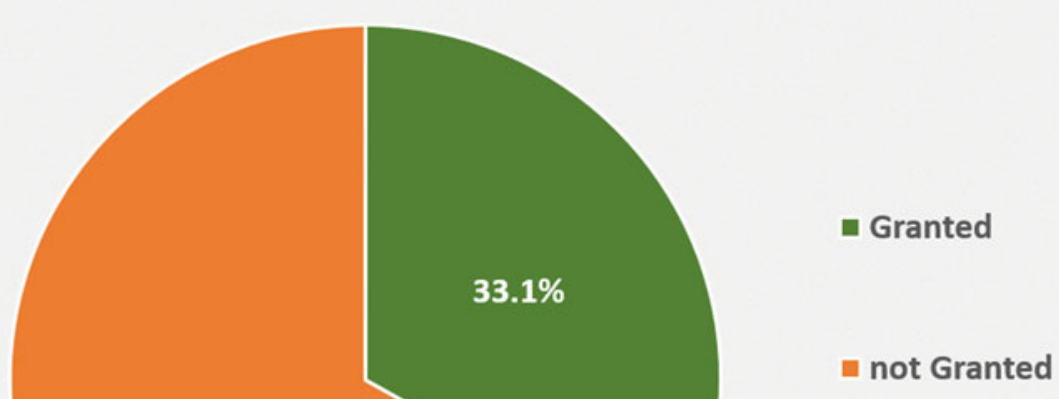

Open Access This chapter is licensed under the terms of the Creative Commons Attribution 4.0 International License (http://creative commons.org/licenses/by/4.0/), which permits use, sharing, adaptation, distribution and reproduction in any medium or format, as long as you give appropriate credit to the original author(s) and the source, provide a link to the Creative Commons license and indicate if changes were made.
The images or other third party material in this chapter are included in the chapter's Creative Commons license, unless indicated otherwise in a credit line to the material. If material is not included in the chapter's Creative Commons license and your intended use is not permitted by statutory regulation or exceeds the permitted use, you will need to obtain permission directly from the copyright holder. 